\title{
Natural Berberine Hybridized Benzimidazoles as Novel Unique Bactericides against Staphylococcus aureus
}

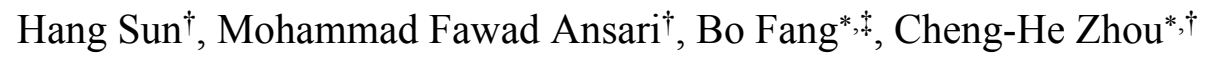

${ }^{\dagger}$ Institute of Bioorganic \& Medicinal Chemistry, Key Laboratory of Luminescence Analysis and Molecular Sensing (Southwest University), Ministry of Education, School of Chemistry and Chemical Engineering, Southwest University, Chongqing, 400715,

China

${ }_{\ddagger}$ College of Pharmacy, National \& Local Joint Engineering Research Center of Targeted and Innovative Therapeutics, Chongqing Key Laboratory of Kinase Modulators as Innovative Medicine, Chongqing University of Arts and Sciences, Chongqing, 402160, China

* Corresponding Address:

*Tel.: +86-23-68254967; E-mail: zhouch@swu.edu.cn (Cheng-He Zhou); fangbo2100@163.com (Bo Fang) 


\section{Table of contents}

1. Results.

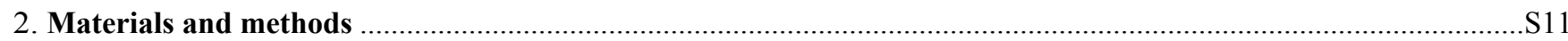

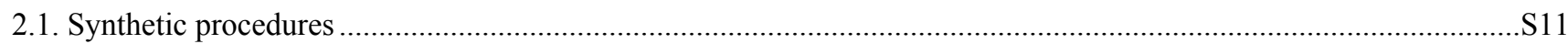

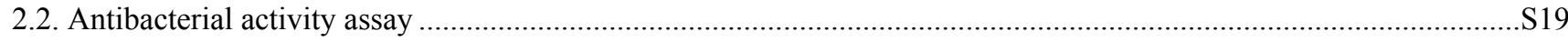

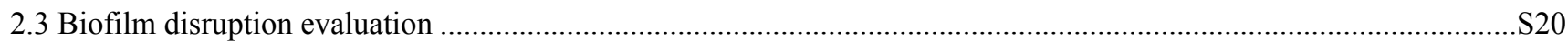

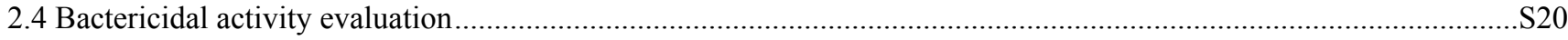

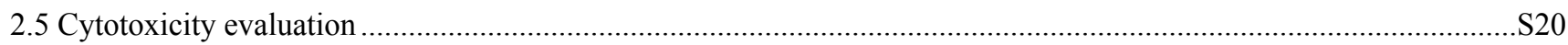

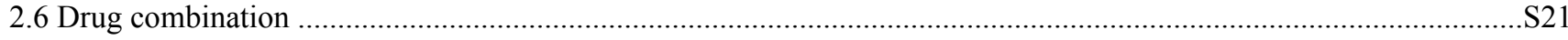

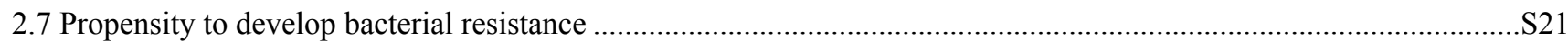

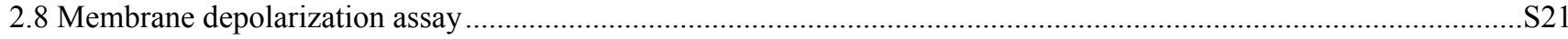

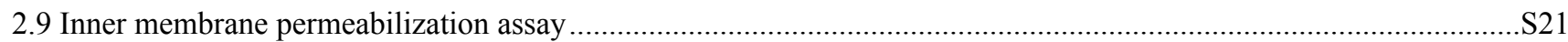

2.10 Supramolecular interactions between active molecule 7d and Calf Thymus DNA..............................................S22

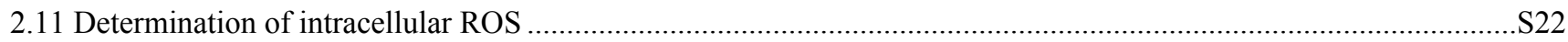

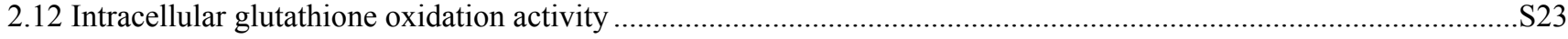

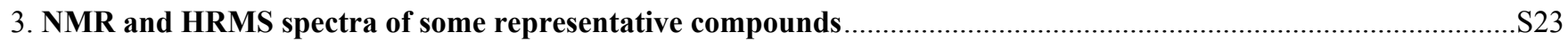

3.1 Spectra of compound 4a

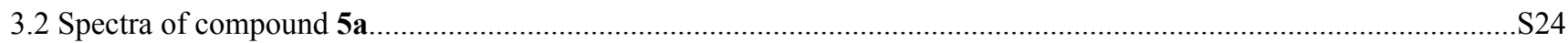

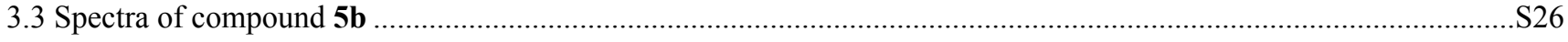

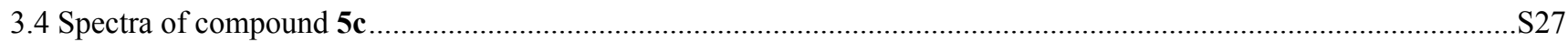

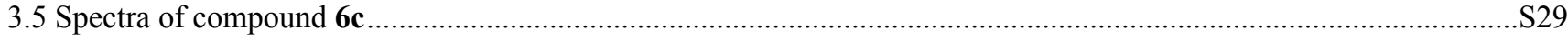

3.6 Spectra of compound 7e

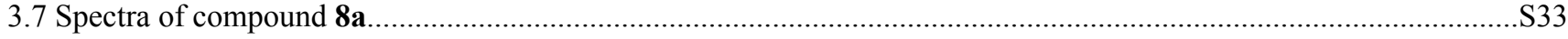

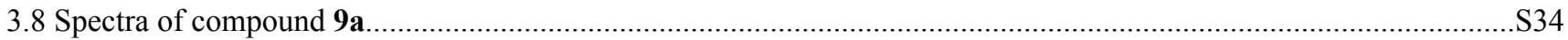




\section{Results}

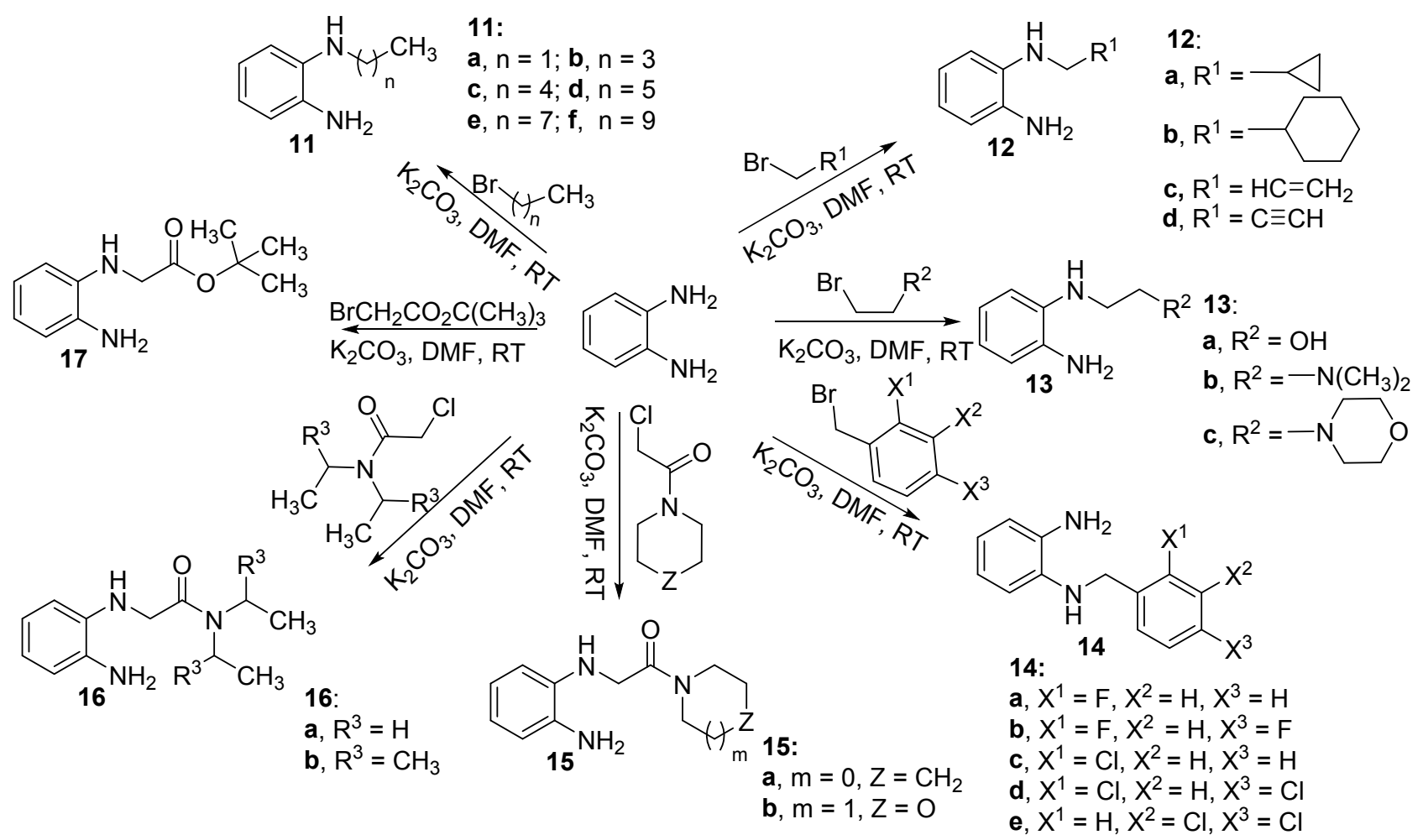

Scheme S1 Synthetic route for monosubstituted $o$-phenylenediamines 11-17. 
Table S1. Drug combination of target compound 7d with norfloxacin (MIC, mM).

\begin{tabular}{|c|c|c|c|c|c|c|}
\hline \multirow{3}{*}{ Bacteria } & \multicolumn{4}{|c|}{$\mathrm{MIC}(\mathrm{mM})$} & \multirow{3}{*}{$\begin{array}{c}\text { FIC } \\
\text { Index }^{\mathrm{a}}\end{array}$} & \multirow{3}{*}{ Effect } \\
\hline & \multicolumn{2}{|c|}{ Alone } & \multicolumn{2}{|c|}{ Combination } & & \\
\hline & $7 d$ & Norfloxacin & $7 d$ & Norfloxacin & & \\
\hline MRSA & 0.006 & 0.025 & 0.0004 & 0.0002 & 0.0745 & synergism \\
\hline S. aureus & 0.013 & 0.025 & 0.0004 & 0.0008 & 0.0621 & synergism \\
\hline $\begin{array}{c}\text { S. aureus } \\
\text { ATCC } 29213\end{array}$ & 0.006 & 0.006 & 0.0004 & 0.0002 & 0.0993 & synergism \\
\hline P. aeruginosa & 0.051 & 0.006 & 0.0126 & 0.0008 & 0.3775 & synergism \\
\hline A. baumannii & 0.013 & 0.025 & 0.0016 & 0.0031 & 0.2483 & synergism \\
\hline K. pneumoniae & 0.101 & 0.013 & 0.0126 & 0.0016 & 0.2452 & synergism \\
\hline E. coli & 0.202 & 0.050 & 0.0016 & 0.0004 & 0.0157 & synergism \\
\hline
\end{tabular}

${ }^{\text {a }}$ FIC (fractional inhibitory concentration) = MIC (A combination)/MIC (A alone) + MIC (B combination)//MIC (B alone); FIC $\leq 0.5$ represents synergism, FIC $>0.5$ and $\leq 1.0$ represents additivism, FIC $>1$ and $\leq 2$ represents an indifferent effect, and FIC $>2$ represents antagonism. 


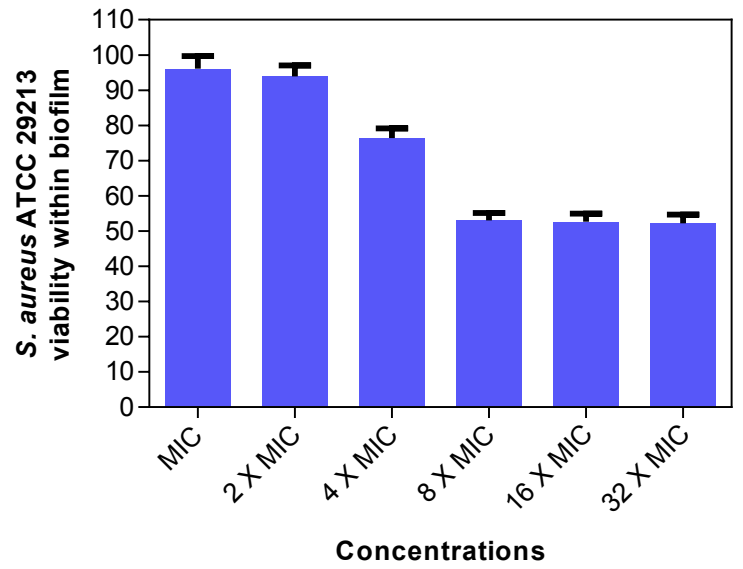

Figure S1. Inhibitory activity of compound 7d on S. aureus ATCC 29213 viability by alamar blue assay. 

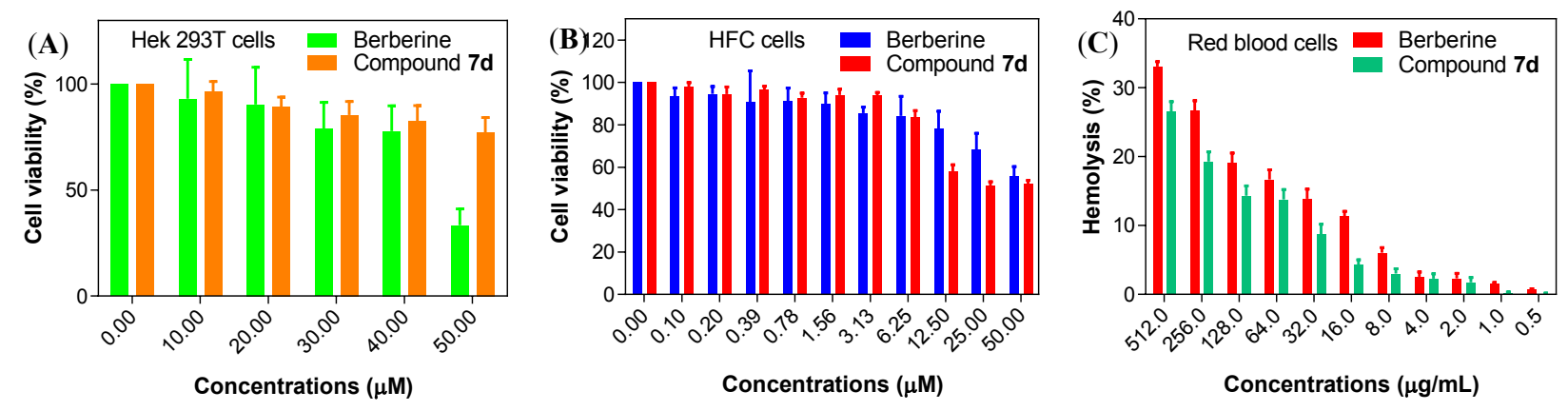

Figure S2. Cytotoxicity of compound 7d and berberine against Hek 293T, HCF and red blood cells. 

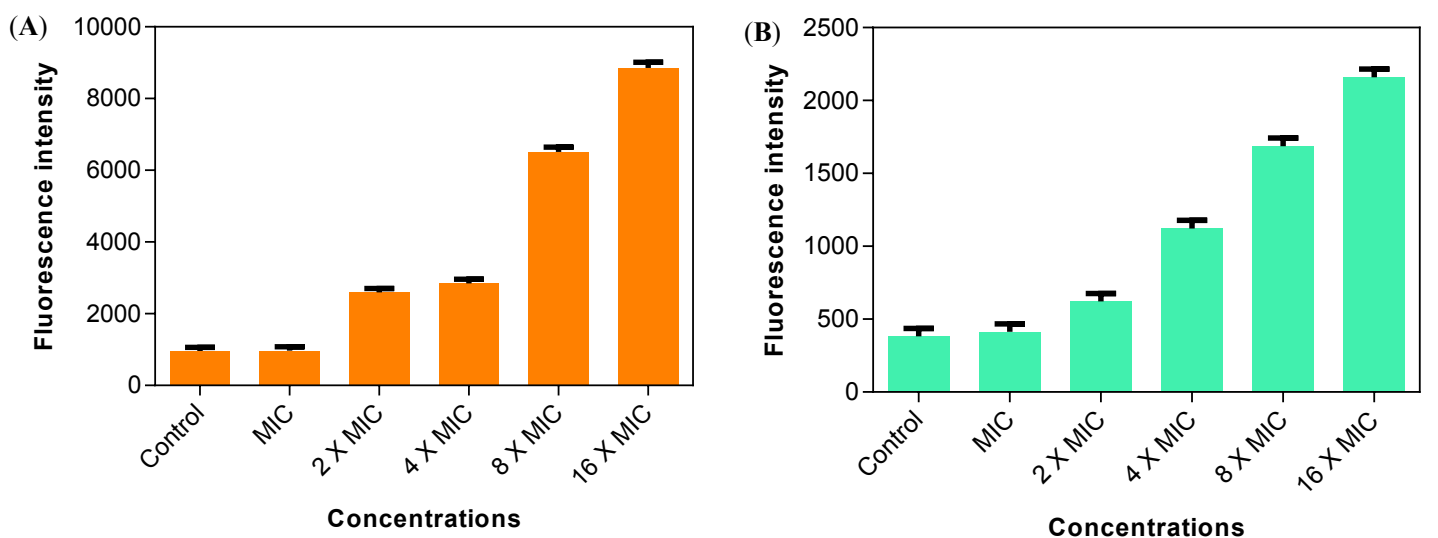

Figure S3. (A) Membrane depolarization in S. aureus ATCC 29213 cells treated by compound 7d. (B) Membrane permeabilization of S. aureus ATCC 29213 treated by compound 7d. 

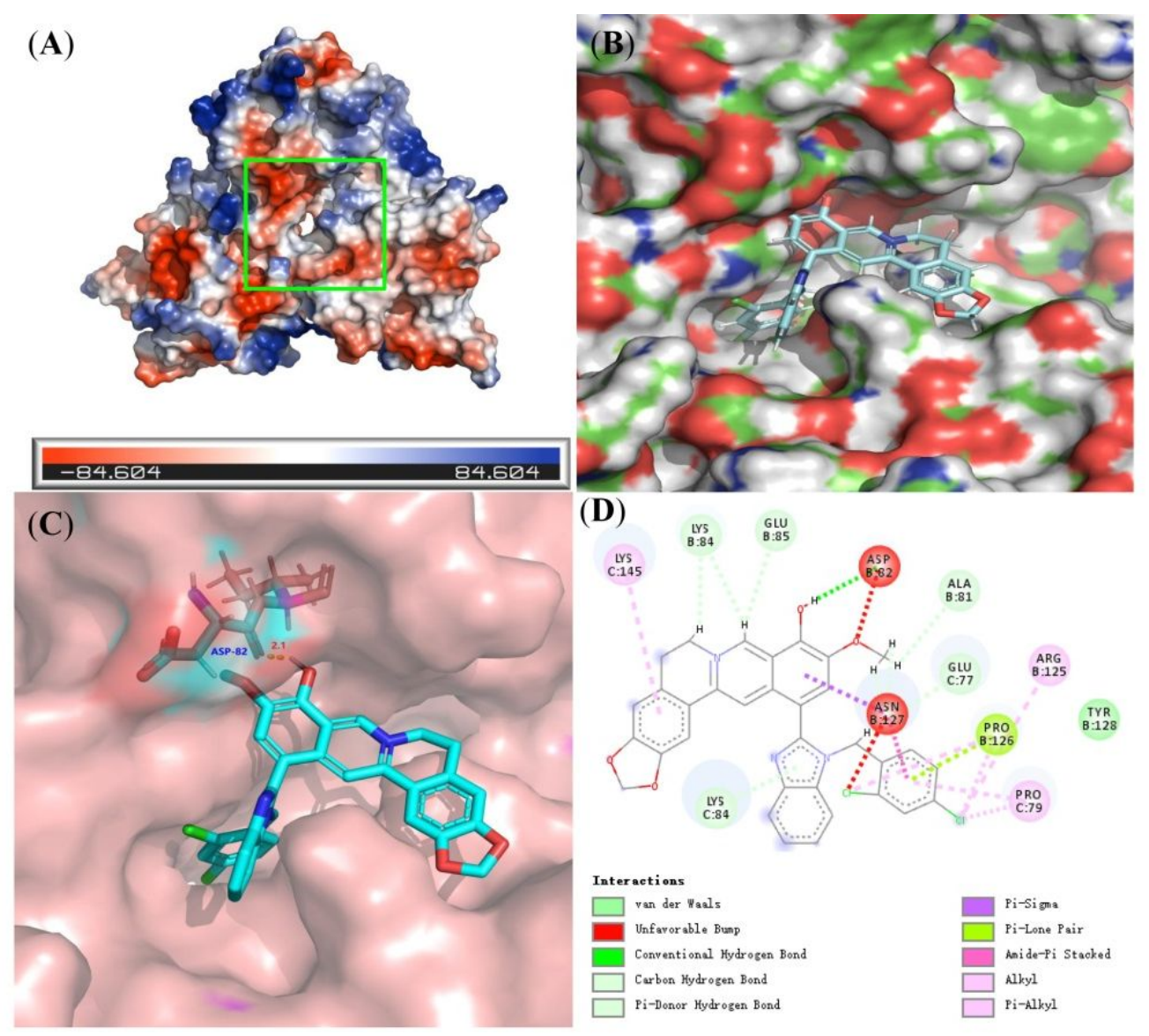

(D)
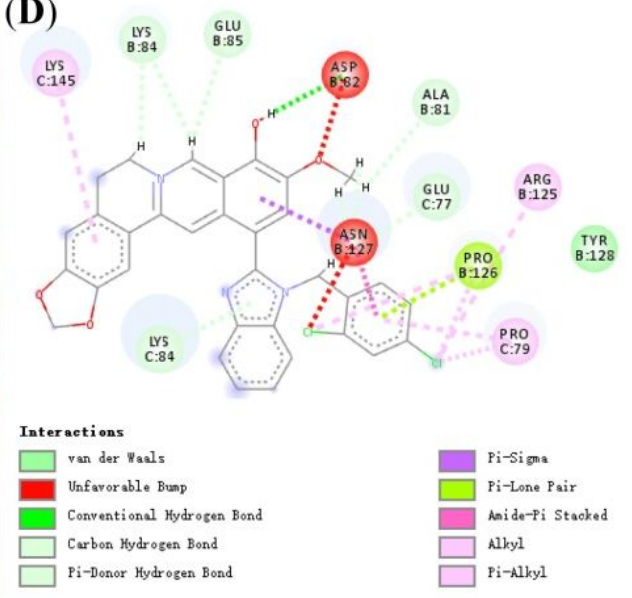

Figure S4. (A-C) Three-dimensional supramolecular conformation of highly active molecule 7d docked in S. aureus sortase A (PDB ID: 1T2W). (D) Two-dimensional supramolecular conformation of highly active molecule 7d docked in $S$. aureus sortase 

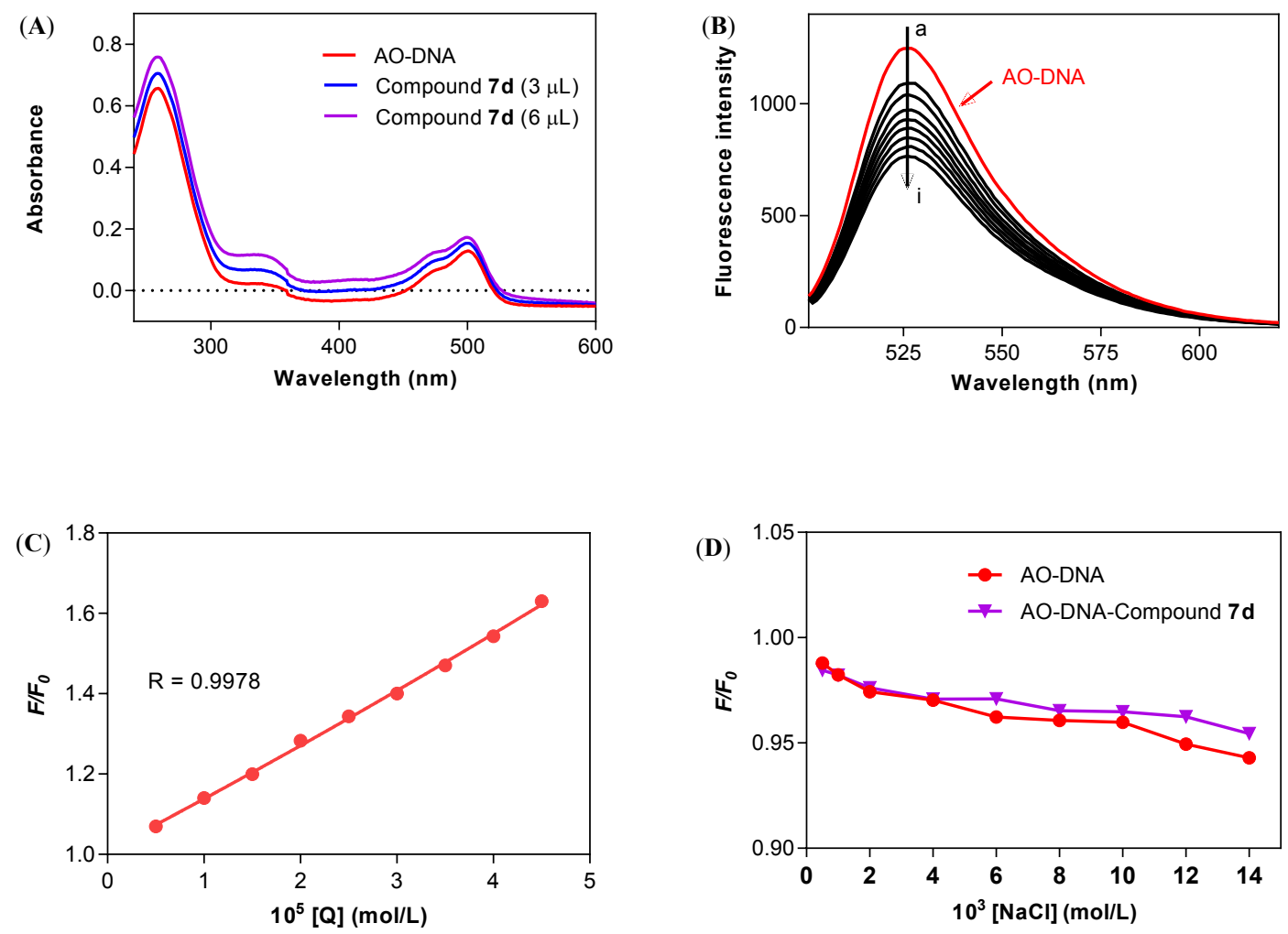

Figure S5. Interaction of active compound 7d with DNA. (A) The absorption spectral curves of AO-DNA complex in the presence of compound $7 \mathbf{d}\left(0,0.25\right.$ and $\left.0.5 \times 10^{-2} \mathrm{mM}\right)$. (B) Fluorescence change of AO-DNA complex in the presence of different concentrations of compound 7d $\left(0-2 \times 10^{-2} \mathrm{mM}\right)$. (C) The Stern-Volmer quenching of AO-DNA complex by compound 7d; (D) Effect of $\mathrm{NaCl}$ for the fluorescence change of AO-DNA and AO-DNA-7d $\left(\mathrm{c}(\mathrm{AO})=5.60 \times 10^{-3} \mathrm{mM}\right.$, $\mathrm{c}($ DNA $\left.)=5.68 \times 10^{-2} \mathrm{mM}, \mathrm{c}(\mathbf{7 d})=2.5 \times 10^{-3} \mathrm{mM}\right)$. 

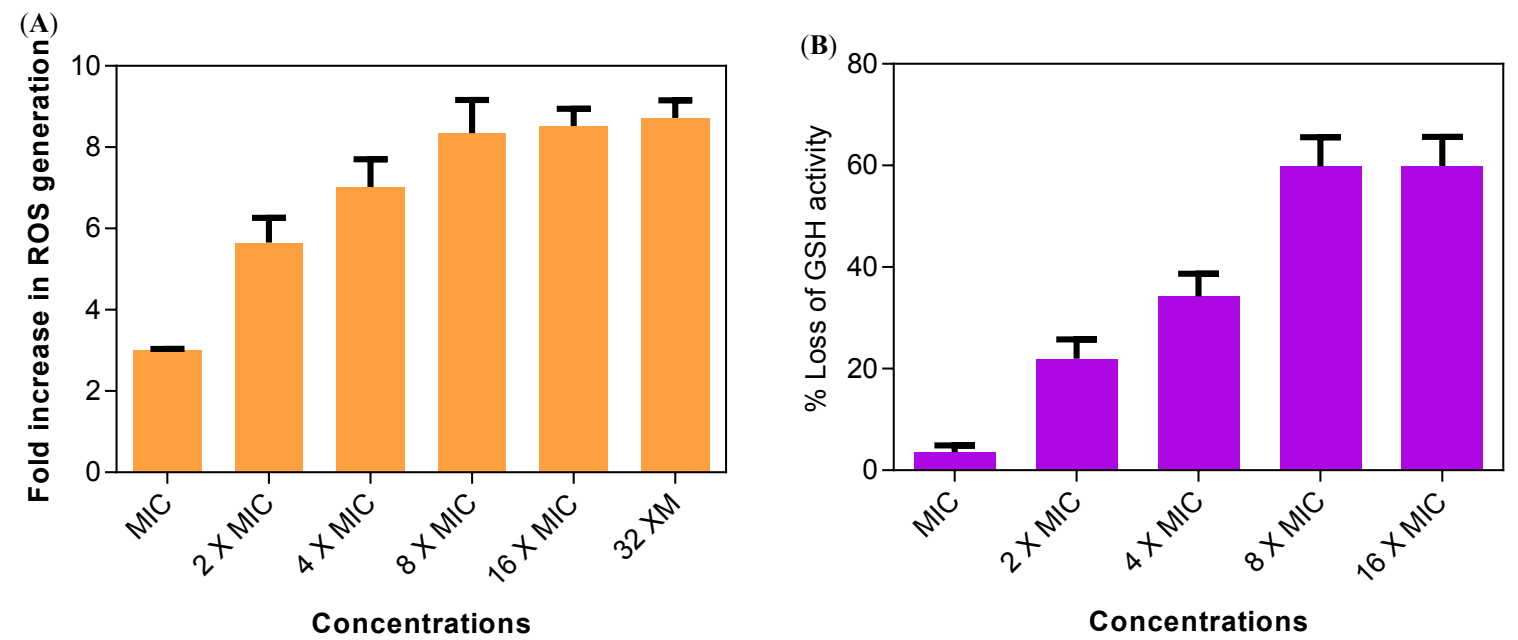

Figure S6. (A) Fold change in ROS generation of S. aureus ATCC 29213 by treated with increasing concentration of compound 7d. (B) Loss of GSH activity in S. aureus ATCC 29213 cells treated by compound 7d. 


\section{Materials and methods}

\subsection{Synthetic procedures}

The abbreviations of BBR, Bim and $\mathrm{Ph}$ are designated as the berberine backbone, benzimidazole skeleton and benzene ring, respectively.

12-Formyl-9-hydroxy-10-methoxy-5,6-dihydro-[1,3]dioxolo[4,5-g]isoquinolino[3,2-a] isoquinolin-7-ium chloride (2). Berberine was demethylated at $190{ }^{\circ} \mathrm{C}$ under vacuum, and then hydrochloric acid/ethanol (95/5) was added to generate berberrubine hydrochloride $\mathbf{1}$. The mixture of hexamethelenetetramine ( $706 \mathrm{mg}, 5.50 \mathrm{mmol})$ and compound $\mathbf{1}$ in trifluoroacetic acid $(10 \mathrm{~mL})$ was refluxed for $8 \mathrm{~h}$. The reaction system was cooled to room temperature, and then the diluted hydrochloric acid $(10 \%, 5 \mathrm{~mL})$ was added with stirring for $20 \mathrm{~min}$. A saturated solution of sodium hydrogen carbonate was added to neutralize the mixture and the solid emerged. The obtained solid was purified by column chromatography on silica gel using dichloromethane/methanol $(\mathrm{V} / \mathrm{V}, 15 / 1, \mathrm{Rf}=0.5)$ as eluent to produce target compound 2 as yellow solid with the yield of 55.4\%. Mp: $241-243{ }^{\circ} \mathrm{C} ;{ }^{1} \mathrm{H}$ NMR $\left(600 \mathrm{MHz}, \mathrm{CD}_{3} \mathrm{OD}-d_{4}\right) \delta 9.82(\mathrm{~s}, 1 \mathrm{H}$, BBR-8-H), $8.76(\mathrm{~s}, 1 \mathrm{H}, \mathrm{CHO}), 8.15(\mathrm{~s}, 1 \mathrm{H}, \mathrm{BBR}-13-H), 7.56(\mathrm{~s}, 1 \mathrm{H}, \mathrm{BBR}-11-H), 6.97(\mathrm{~s}, 1 \mathrm{H}, \mathrm{BBR}-1-H), 6.13(\mathrm{~s}, 2 \mathrm{H}$, $\mathrm{OCH}_{2} \mathrm{O}$ ), 6.04 (s, 1H, BBR-4-H), 4.91 (bs, 2H, BBR-6-2H), 4.10 (s, 3H, OCH $), 3.27-3.23$ (m, 2H, BBR-5-2H) ppm; ${ }^{13} \mathrm{C}$ NMR $\left(150 \mathrm{MHz}, \mathrm{CD}_{3} \mathrm{OD}-d_{4}\right) \delta 150.73,148.54,145.45,144.59,144.52,137.22,130.49,130.20,125.62,124.03,120.67$, 118.34, 116.92, 108.02, 104.93, 102.29, 101.25, 56.29, 55.52, 26.88 ppm; HRMS (ESI) calcd. for $\mathrm{C}_{20} \mathrm{H}_{16} \mathrm{ClNO}_{5}[\mathrm{M}-\mathrm{Cl}]^{+}$, 350.1023, found, 350.1018 .

\section{2-(1H-Benzoimidazol-2-yl)-9-hydroxy-10-methoxy-5,6-dihydro-[1,3]dioxolo[4,5-g]isoquinolino[3,2-a]}

isoquinolin-7-ium chloride (3a). The mixture of intermediate 2 (250 mg, $0.65 \mathrm{mmol})$, o-phenylenediamine (141 mg, 1.30 mmol) and sodium pyrosulfite $(247 \mathrm{mg}, 1.30 \mathrm{mmol})$ in $N, N$-dimethyl formamide $(10 \mathrm{~mL})$ was heated at $110{ }^{\circ} \mathrm{C}$ for $6 \mathrm{~h}$. After the reaction was completed, water $(20 \mathrm{~mL})$ added and the solid was precipitated. The residue was dissolved in chloroform and extracted with brine water. The combined organic phase was dried over anhydrous sodium sulfate and evaporated. Crude product was purified by silica gel column chromatography using dichloromethane/methanol $(\mathrm{V} / \mathrm{V}, 15 / 1, \mathrm{Rf}=0.2-0.4)$ as eluent to give pure target compound 3a as yellow solid (247 mg, 80.2\%). Mp: $>250{ }^{\circ} \mathrm{C} ;{ }^{1} \mathrm{H}$ NMR $\left(600 \mathrm{MHz}\right.$, DMSO- $\left.d_{6}\right) \delta$ 10.03 (s, 1H, BBR-8-H), 9.25 (s, 1H, BBR-13-H), 8.66 (s, 1H, BBR-11-H), 7.89 (bs, 3H, BBR-1-H, Bim-4-H, Bim-7- $H$ ), 7.53 (bs, 2H, Bim-5-H, Bim-6-H), 7.09 (s, 1H, BBR-4-H), 6.16 (s, 2H, OCH $\mathrm{O}_{2} \mathrm{O}$ ), 4.93 (bs, 2H, BBR-6-2H), 4.17 (s, 3H, $\mathrm{OCH}_{3}$ ), 3.21 (bs, 2H, BBR-5-2H) ppm; ${ }^{13} \mathrm{C}$ NMR (150 MHz, DMSO- $\left.d_{6}\right) \delta 162.79,150.38,148.05,147.08,145.43,138.28$, 131.51, 130.56, 125.21, 121.08, 118.44, 118.38, 114.97, 108.83, 106.64, 102.54, 57.84, 49.05, 26.96 ppm; HRMS (ESI): calculated for $\mathrm{C}_{26} \mathrm{H}_{20} \mathrm{ClN}_{3} \mathrm{O}_{4}[\mathrm{M}-\mathrm{Cl}]^{+}, 438.1448$, found, 438.1434 .

12-(5-Chloro-1H-benzoimidazol-2-yl)-9-hydroxy-10-methoxy-5,6-dihydro-[1,3]dioxolo[4,5-g]isoquinolino[3,2-a]is oquinolin-7-ium chloride (3b). Compound 3b was prepared by cyclization reaction of intermediate 2 (250 $\mathrm{mg}, 0.65 \mathrm{mmol}$ ) and 4-chloro-1,2-benzenediamine $(185 \mathrm{mg}, 1.30 \mathrm{mmol})$ in the presence of sodium pyrosulfite $(247 \mathrm{mg}, 1.30 \mathrm{mmol})$ according to the same procedure described for 3a. A pure yellow solid was obtained (158 mg, 46.9\%). Mp: $>250{ }^{\circ} \mathrm{C} ;{ }^{1} \mathrm{H}$ NMR (600 MHz, DMSO- $\left.d_{6}\right) \delta 10.01$ (s, 1H, BBR-8-H), 9.57 (s, 1H BBR-13-H)), 8.69 (s, 1H, BBR-11-H), 7.85 (s, 1H, Bim-4-H), 7.81 (d, $J=8.5 \mathrm{~Hz}, 1 \mathrm{H}$, Bim-6-H), 7.71 (s, 1H, BBR-1-H), 7.44 (d, $J=8.3 \mathrm{~Hz}, 1 \mathrm{H}$, Bim-7-H), 7.07 (s, 1H, 
BBR-4-H), 6.17 (s, 2H, OCH $\left.\mathrm{O}_{2} \mathrm{O}\right), 4.96-4.90$ (m, 2H, BBR-6-2H), 4.17 (s, 3H, OCH $H_{3}, 3.26-3.18$ (m, 2H, BBR-5-2H) ppm; ${ }^{13} \mathrm{C}$ NMR $\left(150 \mathrm{MHz}, \mathrm{DMSO}-d_{6}\right) \delta 150.09,148.42,148.04,146.76,138.88,131.31,121.41,119.84,113.58,108.87,105.94$, 102.45, 99.99, 56.21, 53.84, 27.32 ppm; HRMS (ESI): calculated. for $\mathrm{C}_{26} \mathrm{H}_{19} \mathrm{Cl}_{2} \mathrm{~N}_{3} \mathrm{O}_{4}[\mathrm{M}-\mathrm{Cl}]^{+}, 471.1059$, found, 471.1073 .

12-(5-Bromo-1H-benzoimidazol-2-yl)-9-hydroxy-10-methoxy-5,6-dihydro-[1,3]dioxolo[4,5-g]isoquinolino[3,2-a]is oquinolin-7-ium chloride (3c). Compound 3c was prepared by cyclization reaction of intermediate 2 (250 mg, $0.65 \mathrm{mmol})$ and 4-bromo-1,2-benzenediamine $(243 \mathrm{mg}, 1.30 \mathrm{mmol})$ in the presence of sodium pyrosulfite $(247 \mathrm{mg}$, $1.30 \mathrm{mmol})$ according to the same procedure described for 3a. A pure brown solid was obtained $(219 \mathrm{mg}, 61.1 \%)$. $\mathrm{Mp}:>250{ }^{\circ} \mathrm{C} ;{ }^{1} \mathrm{H} \mathrm{NMR}$ $\left(600 \mathrm{MHz}, \mathrm{DMSO}-d_{6}\right) \delta 10.00$ (s, 1H, BBR-8-H), 9.56 (s, 1H, BBR-13-H), 8.69 (s, 1H, BBR-11-H), $7.96(\mathrm{~d}, J=8.3 \mathrm{~Hz}, 1 \mathrm{H}$, Bim-4H), 7.75 (d, $J=8.5 \mathrm{~Hz}, 1 \mathrm{H}, \mathrm{Bim}-6 H), 7.71$ (s, 1H, BBR-1-H), 7.54 (d, $J=8.2 \mathrm{~Hz}, 1 \mathrm{H}, \mathrm{Bim}-7-H), 7.06$ (s, $1 \mathrm{H}$, BBR-4-H), 6.17 (s, 2H, OCH $\left.\mathrm{O}_{2} \mathrm{O}\right), 4.96$ - 4.89 (m, 2H, BBR-6-2H), 4.17 (s, 3H, OCH $), 3.24-3.18$ (m, 2H, BBR-5-2H) ppm; ${ }^{13} \mathrm{C}$ NMR (150 MHz, DMSO-d $) \delta 162.79,150.37,148.07,146.86,145.17,138.11,131.38,130.34,127.24,120.98,118.60$, 118.31, 108.82, 106.20, 102.55, 57.97, 55.37, 49.05 ppm; HRMS (ESI): calculated for $\mathrm{C}_{26} \mathrm{H}_{19} \mathrm{BrClN}_{3} \mathrm{O}_{4}\left[\mathrm{M}-\mathrm{Cl}^{+}, 516.0553\right.$, found, 516.0567.

\section{9-Hydroxy-10-methoxy-12-(5-methyl-1H-benzoimidazol-2-yl)-5,6-dihydro-[1,3]dioxolo[4,5-g]isoquinolino}

[3,2-a]isoquinolin-7-ium chloride (3d). Compound 3d was prepared by cyclization reaction of intermediate 2 (250 mg, 0.65 $\mathrm{mmol})$ and 4-methyl-1,2-benzenediamine $(159 \mathrm{mg}, 1.30 \mathrm{mmol})$ in the presence sodium pyrosulfite $(247 \mathrm{mg}, 1.30 \mathrm{mmol}) \mathrm{of}$ according to the same procedure described for 3a. A pure brown solid was obtained $(220 \mathrm{mg}, 69.5 \%)$. Mp: $>250{ }^{\circ} \mathrm{C} ;{ }^{1} \mathrm{H} \mathrm{NMR}$ $\left(600 \mathrm{MHz}, \mathrm{DMSO}-d_{6}\right) \delta 10.07$ (s, 1H, BBR-8-H), 8.95 (s, 1H, BBR-13-H), 8.68 (s, 1H, BBR-11-H), 8.03 (s, 1H, Bim-4-H), $7.81(\mathrm{~d}, J=8.3 \mathrm{~Hz}, 1 \mathrm{H}, \mathrm{Bim}-6-H), 7.72$ (s, 1H, BBR-1-H), 7.43 (d, $J=8.3 \mathrm{~Hz}, 1 \mathrm{H}, \mathrm{Bim}-7-H), 7.08$ (s, 1H, BBR-4-H), 6.16 $\left(\mathrm{s}, 2 \mathrm{H}, \mathrm{OCH}_{2} \mathrm{O}\right), 4.98-4.92(\mathrm{~m}, 2 \mathrm{H}, \mathrm{BBR}-6-2 \mathrm{H}), 4.17\left(\mathrm{~s}, 3 \mathrm{H}, \mathrm{OCH}_{3}\right), 3.24-3.18(\mathrm{~m}, 2 \mathrm{H}, \mathrm{BBR}-5-2 \mathrm{H}), 2.55(\mathrm{~s}, 3 \mathrm{H}, \mathrm{CH})$ ppm; ${ }^{13} \mathrm{C}$ NMR $\left(150 \mathrm{MHz}, \mathrm{CD}_{3} \mathrm{OD}-d_{4}\right) \delta 151.49,150.24,148.23,146.76,136.67,130.19,123.98,123.11,122.74,120.89$, $118.25,115.45,111.17,107.98,104.32,102.07,55.93,54.43,50.53,27.32$ ppm; HRMS (ESI): calculated for $\mathrm{C}_{27} \mathrm{H}_{22} \mathrm{ClN}_{3} \mathrm{O}_{4}$ $[\mathrm{M}-\mathrm{Cl}]^{+}, 451.1605$, found, 451.1612 .

\section{9-Hydroxy-10-methoxy-12-(5-methoxy-1H-benzoimidazol-2-yl)-5,6-dihydro-[1,3]dioxolo[4,5-g]isoquinolino}

[3,2-a]isoquinolin-7-ium chloride (3e). Compound 3e was prepared by cyclization reaction of intermediate 2 (250 mg, 0.65 $\mathrm{mmol})$ and 4-methoxyl-1,2-benzenediamine $(180 \mathrm{mg}, 1.30 \mathrm{mmol})$ in the presence of sodium pyrosulfite $(247 \mathrm{mg}, 1.30 \mathrm{mmol})$ according to the same procedure described for 3a. A pure brown solid was obtained $(123 \mathrm{mg}, 37.6 \%)$. $\mathrm{Mp}$ : $>250{ }^{\circ} \mathrm{C} ;{ }^{1} \mathrm{H} \mathrm{NMR}$ $\left(400 \mathrm{MHz}, \mathrm{DMSO}-d_{6}\right) \delta 9.82$ (s, 1H, BBR-8-H), 9.49 (s, 1H, BBR-13-H), 8.08 (s, 1H, BBR-11-H), $7.53(\mathrm{~d}, J=8.7 \mathrm{~Hz}, 1 \mathrm{H}$, Bim-7-H), 7.44 (s, 1H, BBR-1-H), 7.11 (s, 1H, Bim-4-H), 7.03 (s, 1H, BBR-4-H), 6.86 (d, J = 8.7 Hz, 1H, Bim-6-H), 6.16 (s, $2 \mathrm{H}, \mathrm{OCH}_{2} \mathrm{O}$ ), 4.69 (bs, 2H, BBR-6-2H), 3.97 (s, 3H, Bim-5-OCH $), 3.84$ (s, 3H, OCH $), 3.14$ (bs, $\left.2 \mathrm{H}, \mathrm{BBR}-5-2 H\right)$ ppm; ${ }^{13} \mathrm{C}$ NMR $\left(100 \mathrm{MHz}, \mathrm{DMSO}-d_{6}\right) \delta 156.27,149.70,147.96,146.36,136.57,130.76,121.78,111.82,108.94,105.10,102.38$, 56.89, 56.00, 49.06, 27.39 ppm; HRMS (ESI): calculated for $\mathrm{C}_{27} \mathrm{H}_{22} \mathrm{ClN}_{3} \mathrm{O}_{5}[\mathrm{M}-\mathrm{Cl}]^{+}, 468.1554$, found, 468.1546 .

\section{2-(1-Ethyl-1H-benzoimidazol-2-yl)-9-hydroxy-10-methoxy-5,6-dihydro-[1,3]dioxolo[4,5-g]isoquinolino[3,2-a]iso} quinolin-7-ium chloride (4a). Ethyl derivative 4a was prepared by cyclization reaction of intermediate 2 (250 mg, 0.65 mmol), 11a (177 mg, $1.30 \mathrm{mmol})$ and sodium pyrosulfite $(247 \mathrm{mg}, 1.30 \mathrm{mmol})$ according to the same procedure described for 3a. A pure yellow solid was obtained (163 mg, 49.8\%). Mp: $>250{ }^{\circ} \mathrm{C} ;{ }^{1} \mathrm{H}$ NMR $\left(600 \mathrm{MHz}, \mathrm{CD}_{3} \mathrm{OD}-d_{4}\right) \delta 10.12(\mathrm{~s}, 1 \mathrm{H}$, BBR-8-H), 8.52 (s, 1H, BBR-13-H), 8.36 (s, 1H, BBR-11-H), 8.16 (d, J=6.7 Hz, 1H, Bim-4-H), 8.02 (d, $J=6.2,1 \mathrm{H}$, Bim-7-H), $7.87-7.78$ (m, 2H, Bim-5-H, Bim-6-H), 7.64 (s, 1H, BBR-1-H), 6.98 (s, 1H, BBR-4- $H)$, 6.06 (s, 2H, OCH $H_{2} \mathrm{O}$ ), 
5.00 (bs, 2H, BBR-6-2H), 4.54 (bs, 2H, $\mathrm{CH}_{2} \mathrm{CH}_{3}$ ), 4.19 (s, 3H, $\mathrm{OCH}_{3}$ ), 3.31 (bs, 2H, BBR-5-2H), 1.51 (t, J=6.1 Hz, 3H, $\left.\mathrm{CH}_{2} \mathrm{CH}_{3}\right)$ ppm; ${ }^{13} \mathrm{C}$ NMR $\left(150 \mathrm{MHz}, \mathrm{CD}_{3} \mathrm{OD}-d_{4}\right) \delta 152.57,151.27,149.84,148.52,147.45,146.62,141.27,133.93,133.21$, $132.87,132.59,129.29,128.55,128.11,121.51,119.24,117.45,115.78,114.69,110.02,109.38,107.24,103.71,58.26$, 57.38, 42.98, 28.16, 15.03 ppm. HRMS (ESI): calculated for $\mathrm{C}_{28} \mathrm{H}_{24} \mathrm{ClN}_{3} \mathrm{O}_{4}[\mathrm{M}-\mathrm{Cl}]^{+}, 466.1761$, found, 466.1768 .

12-(1-Butyl-1H-benzoimidazol-2-yl)-9-hydroxy-10-methoxy-5,6-dihydro-[1,3]dioxolo[4,5-g]isoquinolino[3,2-a]iso quinolin-7-ium chloride (4b). Butyl derivative 4b was prepared by cyclization reaction of intermediate 2 (250 $\mathrm{mg}, 0.65$ $\mathrm{mmol}), 11 \mathrm{~b}(214 \mathrm{mg}, 1.30 \mathrm{mmol})$ and sodium pyrosulfite $(247 \mathrm{mg}, 1.30 \mathrm{mmol})$ according to the same procedure described for 3a. A pure yellow solid was obtained (238 mg, 69.0\%). Mp: $>250{ }^{\circ} \mathrm{C} ;{ }^{1} \mathrm{H}$ NMR $\left(600 \mathrm{MHz}, \mathrm{CD}_{3} \mathrm{OD}-d_{4}\right) \delta 10.12(\mathrm{~s}, 1 \mathrm{H}$, BBR-8-H), 8.53 (s, 1H, BBR-13-H), 8.32 (s, 1H, BBR-11-H), 8.14 (d, $J=8.2 \mathrm{~Hz}, 1 \mathrm{H}$, Bim-4- $H$ ), 8.02 (d, $J=8.6 \mathrm{~Hz}, 1 \mathrm{H}$, Bim-7-H), $7.86-7.80$ (m, 2H, Bim-5-H, Bim-6-H), 7.63 (s, 1H, BBR-1-H), 6.98 (s, 1H, BBR-4-H), 6.07 (s, 2H, OCH $H_{2} \mathrm{O}$ ), 5.00 (bs, 2H, BBR-6-2H), 4.48 (bs, 2H, $\mathrm{CH}_{2}\left(\mathrm{CH}_{2}\right)_{2} \mathrm{CH}_{3}$ ), 4.18 (s, 3H, OCH $\mathrm{H}_{3}, 3.31$ (bs, 2H, BBR-5-2H), 1.89 (bs, 2H, $\left.\mathrm{CH}_{2} \mathrm{CH}_{2} \mathrm{CH}_{2} \mathrm{CH}_{3}\right), 1.32-1.26\left(\mathrm{~m}, 2 \mathrm{H},\left(\mathrm{CH}_{2}\right)_{2} \mathrm{CH}_{2} \mathrm{CH}_{3}\right), 0.80\left(\mathrm{t}, J=7.1 \mathrm{~Hz}, 3 \mathrm{H},\left(\mathrm{CH}_{2}\right)_{3} \mathrm{CH}_{3}\right) \mathrm{ppm} ;{ }^{13} \mathrm{C}$ NMR $(150 \mathrm{MHz}$ $\left.\mathrm{CD}_{3} \mathrm{OD}-d_{4}\right) \delta 151.92,149.95,149.27,148.13,146.70,141.17,135.99,134.96,131.72,129.95,122.85,122.80,122.44$, $121.15,120.09$, 118.29, 115.33, 110.58, 107.90, 104.34, 101.16, 101.94, 55.58, 54.03, 41.16, 28.74, 28.38, 27.48, 21.62, 12.65 ppm; HRMS (ESI): calculated for $\mathrm{C}_{30} \mathrm{H}_{28} \mathrm{ClN}_{3} \mathrm{O}_{4}[\mathrm{M}-\mathrm{Cl}]^{+}, 491.1074$, found, 491.1068.

\section{9-Hydroxy-10-methoxy-12-(1-pentyl-1H-benzoimidazol-2-yl)-5,6-dihydro-[1,3]dioxolo[4,5-g]isoquinolino}

[3,2-a]isoquinolin-7-ium chloride (4c). Pentyl derivative $4 \mathbf{c}$ was prepared by cyclization reaction of intermediate 2 ( $250 \mathrm{mg}$, $0.65 \mathrm{mmol}), 11 \mathrm{c}(232 \mathrm{mg}, 1.30 \mathrm{mmol})$ and sodium pyrosulfite $(247 \mathrm{mg}, 1.30 \mathrm{mmol})$ according to the same procedure described for 3a. A pure yellow solid was obtained (238 mg, 71.9\%). Mp: $209-211{ }^{\circ} \mathrm{C} ;{ }^{1} \mathrm{H}$ NMR $\left(600 \mathrm{MHz}, \mathrm{CD}_{3} \mathrm{OD}-d_{4}\right) \delta$ 9.42 (s, 1H, BBR-8-H), 7.88 (s, 1H, BBR-13-H), 7.75 (d, $J=7.7$ Hz, 1H, Bim-4-H), 7.63 (s, 1H, BBR-11-H), $7.61(\mathrm{~s}, 1 \mathrm{H}$, Bim-7-H), 7.37 (m, 2H, Bim-5-H, Bim-6-H), 7.10 (s, 1H, BBR-1-H), 6.83 (s, 1H, BBR-4-H), 5.96 (s, 2H, OCH $H_{2}$ ), 4.65 (t, $J$ $=5.7 \mathrm{~Hz}, 2 \mathrm{H}, \mathrm{BBR}-6-2 H), 4.21\left(\mathrm{t}, J=7.1 \mathrm{~Hz}, 2 \mathrm{H}, \mathrm{CH}_{2}\left(\mathrm{CH}_{2}\right)_{3} \mathrm{CH}_{3}\right), 3.93(\mathrm{~s}, 3 \mathrm{H}, \mathrm{OCH}), 3.17-3.10(\mathrm{t}, J=5.7 \mathrm{~Hz}, 2 \mathrm{H}$, BBR-5-2H), $1.72-1.68\left(\mathrm{~m}, 2 \mathrm{H}, \mathrm{CH}_{2} \mathrm{CH}_{2}\left(\mathrm{CH}_{2}\right)_{2} \mathrm{CH}_{3}\right), 1.09-0.95\left(\mathrm{~m}, 4 \mathrm{H}, \mathrm{CH}_{2} \mathrm{CH}_{2}\left(\mathrm{CH}_{2}\right)_{2} \mathrm{CH}_{3}\right), 0.63$ (t, J= 7.0 Hz, 3H, $\left.\left(\mathrm{CH}_{2}\right)_{4} \mathrm{CH}_{3}\right)$ ppm; ${ }^{13} \mathrm{C}$ NMR $\left(150 \mathrm{MHz}, \mathrm{CD}_{3} \mathrm{OD}-d_{4}\right) \delta 151.92,149.95,149.27,148.13,146.70,141.17,135.99,134.96$, $131.72,129.95,122.85,122.80,122.44,121.15,120.09,118.29,115.33,110.58,107.90,104.34,101.16,101.94,55.58$, 54.03, 41.16, 28.74, 28.38, 27.48, 21.62, 12.65 ppm; HRMS (ESI): calculated for $\mathrm{C}_{31} \mathrm{H}_{30} \mathrm{ClN}_{3} \mathrm{O}_{4}[\mathrm{M}-\mathrm{Cl}]^{+}, 508.2231$, found, 508.2235 .

12-(1-Hexyl-1H-benzoimidazol-2-yl)-9-hydroxy-10-methoxy-5,6-dihydro-[1,3]dioxolo[4,5-g]isoquinolino[3,2-a]iso quinolin-7-ium chloride (4d). Hexyl derivative 4d was prepared by cyclization reaction of intermediate 2 (250 mg, 0.65 $\mathrm{mmol}), 11 \mathrm{~d}(250 \mathrm{mg}, 1.30 \mathrm{mmol})$ and sodium pyrosulfite $(247 \mathrm{mg}, 1.30 \mathrm{mmol})$ according to the same procedure described for 3a. A pure yellow solid was obtained (158 mg, 43.6\%). Mp: $215-217{ }^{\circ} \mathrm{C} ;{ }^{1} \mathrm{H}$ NMR $\left(600 \mathrm{MHz}, \mathrm{CD}_{3} \mathrm{OD}-d_{4}\right) \delta 10.09(\mathrm{~s}$, 1H, BBR-8-H), 8.48 (s, 1H, BBR-13-H), 8.29 (s, 1H, BBR-11-H), 8.08 (d, $J=8.0 \mathrm{~Hz}, 1 \mathrm{H}, \mathrm{Bim}-4-H), 8.00$ (d, $J=7.3 \mathrm{~Hz}, 1 \mathrm{H}$, Bim-7-H), $7.80-7.73$ (m, 2H, Bim-5-H, Bim-6-H), 7.58 (s, 1H, BBR-1-H), 6.98 (s, 1H, BBR-4-H), 6.06 (s, 2H, OCH $H_{2} \mathrm{O}$ ), $5.02-4.96(\mathrm{~m}, 2 \mathrm{H}, \mathrm{BBR}-6-2 \mathrm{H}), 4.45\left(\mathrm{t}, J=7.2 \mathrm{~Hz}, 2 \mathrm{H}, \mathrm{CH}_{2}\left(\mathrm{CH}_{2}\right)_{4} \mathrm{CH}_{3}\right), 4.17\left(\mathrm{~s}, 3 \mathrm{H}, \mathrm{OCH}_{3}\right), 3.32-3.27(\mathrm{~m}, 2 \mathrm{H}$, BBR-5-2H), $1.91-1.84\left(\mathrm{~m}, 2 \mathrm{H}, \mathrm{CH}_{2} \mathrm{CH}_{2}\left(\mathrm{CH}_{2}\right)_{3} \mathrm{CH}_{3}\right), 1.22-1.08\left(\mathrm{~m}, 6 \mathrm{H},\left(\mathrm{CH}_{2}\right)_{2}\left(\mathrm{CH}_{2}\right)_{3} \mathrm{CH}_{3}\right), 0.75(\mathrm{t}, J=6.7 \mathrm{~Hz}, 3 \mathrm{H}$, $\left.\left(\mathrm{CH}_{2}\right)_{5} \mathrm{CH}_{3}\right)$ ppm; ${ }^{13} \mathrm{C}$ NMR $\left(150 \mathrm{MHz}, \mathrm{CD}_{3} \mathrm{OD}-d_{4}\right) \delta 151.14,150.06,148.46,147.09,146.77,145.37,139.58,133.17$, $131.79,131.15,127.67,126.45,126.20,120.11,117.89,116.09,115.18,113.00,109.73,108.01,105.65,102.32,56.89$, 55.90, 45.96, 30.80, 28.82, 26.81, 25.83, 21.98, 12.76 ppm. HRMS (ESI): calculated for $\mathrm{C}_{32} \mathrm{H}_{32} \mathrm{ClN}_{3} \mathrm{O}_{4}[\mathrm{M}-\mathrm{Cl}]^{+}, 522.2387$; 
found, 522.2379 .

\section{9-Hydroxy-10-methoxy-12-(1-octyl-1H-benzoimidazol-2-yl)-5,6-dihydro-[1,3]dioxolo[4,5-g]isoquinolino[3,2-a]}

isoquinolin-7-ium chloride (4e). Octyl derivative 4e was prepared by cyclization reaction of intermediate 2 (250 $\mathrm{mg}, 0.65$ $\mathrm{mmol}), 11 \mathrm{e}(286 \mathrm{mg}, 1.30 \mathrm{mmol})$ and sodium pyrosulfite $(247 \mathrm{mg}, 1.30 \mathrm{mmol})$ according to the same procedure described for 3a. A pure yellow solid was obtained $(262 \mathrm{mg}, 86.8 \%)$. Mp: $229-231{ }^{\circ} \mathrm{C} ;{ }^{1} \mathrm{H}$ NMR $\left(600 \mathrm{MHz}, \mathrm{CD}_{3} \mathrm{OD}-d_{4}\right) \delta 9.57(\mathrm{~s}, 1 \mathrm{H}$, BBR-8-H), 7.99 (d, $J=7.0 \mathrm{~Hz}, 1 \mathrm{H}, \mathrm{BBR}-13-H), 7.80$ (d, $J=7.9 \mathrm{~Hz}, 1 \mathrm{H}$ Bim-4- $H$ ), 7.79 (s, 1H, BBR-11-H), 7.68 (d, $J=7.9$ Hz, 1H, Bim-7-H), 7.44 (t, $J=7.5$ Hz, 1H, Bim-6-H), 7.41 (t, $J=7.5$ Hz, 1H, Bim-5-H), 7.16 (s, 1H, BBR-1-H), 6.87 (s, $1 \mathrm{H}$, BBR-4-H), 5.99 (s, 2H, OCH $\left.\mathrm{O}_{2} \mathrm{O}\right), 4.74$ (t, $\left.J=5.9 \mathrm{~Hz}, 2 \mathrm{H}, \mathrm{BBR}-6-2 \mathrm{H}\right), 4.28\left(\mathrm{t}, J=6.9 \mathrm{~Hz}, 2 \mathrm{H}, \mathrm{CH}_{2}\left(\mathrm{CH}_{2}\right)_{6} \mathrm{CH}_{3}\right), 3.99(\mathrm{~s}, 3 \mathrm{H}$, $\left.\mathrm{OCH}_{3}\right), 3.22-3.15(\mathrm{~m}, 2 \mathrm{H}, \quad \mathrm{BBR}-5-2 \mathrm{H}), 1.37-1.27\left(\mathrm{~m}, 2 \mathrm{H}, \mathrm{CH}_{2} \mathrm{CH}_{2}\left(\mathrm{CH}_{2}\right)_{5} \mathrm{CH}_{3}\right), 1.11-1.07(\mathrm{~m}, 2 \mathrm{H}$, $\left.\left(\mathrm{CH}_{2}\right)_{2} \mathrm{CH}_{2}\left(\mathrm{CH}_{2}\right)_{4} \mathrm{CH}_{3}\right), 1.00$ (bs, $\left.8 \mathrm{H},\left(\mathrm{CH}_{2}\right)_{3}\left(\mathrm{CH}_{2}\right)_{4} \mathrm{CH}_{3}\right), 0.77$ (t, $\left.J=7.3 \mathrm{~Hz}, 3 \mathrm{H},\left(\mathrm{CH}_{2}\right)_{7} \mathrm{CH}_{3}\right) \mathrm{ppm} ;{ }^{13} \mathrm{C} \mathrm{NMR}(150 \mathrm{MHz}$, $\left.\mathrm{CD}_{3} \mathrm{OD}-d_{4}\right) \delta 151.36,150.07,148.47,148.12,146.63,141.77,136.31,134.91,131.64,130.04,123.14,122.95$ - 122.91, $122.69,120.89,119.59,118.24,115.51,110.79,107.95,106.13,104.32,102.02,55.73,51.18,44.37,31.28,28.90,28.72$, 28.55, 27.36, 26.15, 21.11, 12.91 ppm; HRMS (ESI): calculated for $\mathrm{C}_{34} \mathrm{H}_{36} \mathrm{ClN}_{3} \mathrm{O}_{4}[\mathrm{M}-\mathrm{Cl}]^{+}, 550.2700$, found, 550.2718.

\section{2-(1-Decyl-1H-benzoimidazol-2-yl)-9-hydroxy-10-methoxy-5,6-dihydro-[1,3]dioxolo[4,5-g]isoquinolino[3,2-a]iso}

quinolin-7-ium chloride (4f). Dectyl derivative $\mathbf{4 f}$ was prepared by cyclization reaction of intermediate $2(250 \mathrm{mg}, 0.65$ $\mathrm{mmol}), 11 \mathrm{f}(323 \mathrm{mg}, 1.30 \mathrm{mmol})$ and sodium pyrosulfite $(247 \mathrm{mg}, 1.30 \mathrm{mmol})$ according to the same procedure described for 3a. A pure yellow solid was obtained $(245 \mathrm{mg}, 65.2 \%)$. Mp: $217-219{ }^{\circ} \mathrm{C} ;{ }^{1} \mathrm{H}$ NMR $\left(600 \mathrm{MHz}, \mathrm{CD}_{3} \mathrm{OD}-d_{4}\right) \delta 9.88(\mathrm{~s}, 1 \mathrm{H}$, BBR-8-H), 8.13 (bs, 2H, BBR-13-H, BBR-11-H), 7.84 (d, $J=7.8 \mathrm{~Hz}, 1 \mathrm{H}, \mathrm{Bim}-4-H), 7.76$ (d, $J=7.9 \mathrm{~Hz}, 1 \mathrm{H}, \mathrm{Bim}-7-H)$, 7.48 (dt, $J=21.8,7.3 \mathrm{~Hz}, 2 \mathrm{H}, \mathrm{Bim}-5-H$, Bim-6-H), 7.25 (s, 1H, BBR-1-H), 6.91 (s, 1H, BBR-4-H), 6.01 (s, 2H, OCH $H_{2} \mathrm{O}$ ), 4.89 (bs, 2H, BBR-6-2H), 4.31 (t, $J=6.9 \mathrm{~Hz}, 2 \mathrm{H}, \mathrm{CH}_{2}\left(\mathrm{CH}_{2}\right)_{8} \mathrm{CH}_{3}$ ), 4.09 (s, 3H, OCH $), 3.25-3.18$ (m, 2H, BBR-5-2H), 1.73 (bs, 2H, $\left.\mathrm{CH}_{2} \mathrm{CH}_{2}\left(\mathrm{CH}_{2}\right)_{7} \mathrm{CH}_{3}\right), 1.24-1.18\left(\mathrm{~m}, 2 \mathrm{H},\left(\mathrm{CH}_{2}\right)_{2} \mathrm{CH}_{2}\left(\mathrm{CH}_{2}\right)_{6} \mathrm{CH}_{3}\right), 1.14-1.09$ (m, 2H, $\left.\left(\mathrm{CH}_{2}\right)_{3} \mathrm{CH}_{2}\left(\mathrm{CH}_{2}\right)_{5} \mathrm{CH}_{3}\right)$, $1.09-1.04\left(\mathrm{~m}, 2 \mathrm{H},\left(\mathrm{CH}_{2}\right)_{4} \mathrm{CH}_{2}\left(\mathrm{CH}_{2}\right)_{4} \mathrm{CH}_{3}\right), 0.99$ (bs, 8H, $\left.\left(\mathrm{CH}_{2}\right)_{5}\left(\mathrm{CH}_{2}\right)_{4} \mathrm{CH}_{3}\right), 0.84\left(\mathrm{t}, J=7.3 \mathrm{~Hz}, 3 \mathrm{H},\left(\mathrm{CH}_{2}\right)_{9} \mathrm{CH}_{3}\right)$ ppm; ${ }^{13} \mathrm{C}$ NMR $\left(150 \mathrm{MHz}, \mathrm{CD}_{3} \mathrm{OD}-d_{4}\right) \delta 150.83,149.40,148.44,146.57,145.96,140.55,138.15,134.72,131.92,130.66,125.83$, $123.90,123.48,120.32,118.05,116.53,111.29,108.05,104.78,102.25,56.49,55.39,44.67,31.49,29.03,29.01,28.90$, 28.84, 28.58, 26.96, 26.16, 22.22, 12.96 ppm; HRMS (ESI): calculated for $\mathrm{C}_{36} \mathrm{H}_{40} \mathrm{ClN}_{3} \mathrm{O}_{4}[\mathrm{M}-\mathrm{Cl}]^{+}, 578.3013$, found, 578.3029

\section{2-(1-(Cyclopropylmethyl)-1H-benzoimidazol-2-yl)-9-hydroxy-10-methoxy-5,6-dihydro[1,3]dioxolo[4,5-g]isoquin} olino[3,2-a] isoquinolin-7-ium chloride (5a). Cyclopropyl derivative 5a was prepared by cyclization reaction of intermediate $2(250 \mathrm{mg}, 0.65 \mathrm{mmol}), 12 \mathrm{a}(211 \mathrm{mg}, 1.30 \mathrm{mmol})$ and sodium pyrosulfite $(247 \mathrm{mg}, 1.30 \mathrm{mmol})$ according to the same procedure described for 3a. A pure yellow solid was obtained (78 mg, 24.4\%). Mp: $223-225{ }^{\circ} \mathrm{C}$; ${ }^{1} \mathrm{H} \mathrm{NMR}(600 \mathrm{MHz}$, $\left.\mathrm{CD}_{3} \mathrm{OD}-d_{4}\right) \delta 9.46(\mathrm{~s}, 1 \mathrm{H}, \mathrm{BBR}-8-H), 7.87$ (s, 1H, BBR-13-H), 7.77 (d, $\left.J=7.9 \mathrm{~Hz}, 1 \mathrm{H}, \mathrm{Bim}-4-H\right), 7.71$ (bs, 1H, Bim-7-H), 7.70 (s, 1H, BBR-11-H), 7.41 (t, $J=7.6 \mathrm{~Hz}, 1 \mathrm{H}, \mathrm{Bim}-6-H), 7.37$ (t, $J=7.5 \mathrm{~Hz}, 1 \mathrm{H}$, Bim-5-H), 7.12 (s, 1H, BBR-1-H), 6.85 (s, 1H, BBR-4-H), $5.97\left(\mathrm{~s}, 2 \mathrm{H}, \mathrm{OCH}_{2} \mathrm{O}\right), 4.67$ (t, $\left.J=5.8 \mathrm{~Hz}, 2 \mathrm{H}, \mathrm{BBR}-6-2 H\right), 4.12\left(\mathrm{~d}, J=6.7 \mathrm{~Hz}, 2 \mathrm{H}, \mathrm{CH}_{2}\right), 3.94(\mathrm{~s}, 3 \mathrm{H}$, $\left.\mathrm{OCH}_{3}\right), 3.18-3.12(\mathrm{~m}, 2 \mathrm{H}, \mathrm{BBR}-5-2 H), 0.71(\mathrm{~d}, J=14.7 \mathrm{~Hz}, 1 \mathrm{H}$, cyclopropane-CH), $0.36(\mathrm{~d}, J=7.9 \mathrm{~Hz}, 2 \mathrm{H}$, cyclopropane- $\left.\mathrm{CH}_{2}\right), 0.06\left(\mathrm{~d}, J=4.7 \mathrm{~Hz}, 2 \mathrm{H}\right.$, cyclopropane- $\left.\mathrm{CH}_{2}\right) \mathrm{ppm} ;{ }^{13} \mathrm{C}$ NMR $\left(150 \mathrm{MHz}, \mathrm{CD}_{3} \mathrm{OD}-d_{4}\right) \delta 149.79,148.26$, 146.37, 144.91, 134.46, 133.43, 130.05, 128.24, 121.62, 121.18, 120.76, 116.42, 113.58, 109.08, 106.11, 102.57, 100.18, 53.92, 52.41, 47.04, 25.61, 9.05, $1.42 \mathrm{ppm}$; HRMS (ESI): calculated for $\mathrm{C}_{30} \mathrm{H}_{26} \mathrm{ClN}_{3} \mathrm{O}_{4}[\mathrm{M}-\mathrm{Cl}]^{+}, 491.19185$, found, 491.1914. 
12-(1-(Cyclohexylmethyl)-1H-benzoimidazol-2-yl)-9-hydroxy-10-methoxy-5,6-dihydro-[1,3]dioxolo[4,5-g]isoquin olino[3,2-a] isoquinolin-7-ium chloride (5b). Cyclohexyl derivative $5 \mathbf{b}$ was prepared by cyclization reaction of intermediate $2(250 \mathrm{mg}, 0.65 \mathrm{mmol}), \mathbf{1 2 b}(266 \mathrm{mg}, 1.30 \mathrm{mmol})$ and sodium pyrosulfite $(247 \mathrm{mg}, 1.30 \mathrm{mmol})$ according to the same procedure described for 3a. A pure yellow solid was obtained (90 mg, 25.9\%). Mp: $238-241{ }^{\circ} \mathrm{C}$; ${ }^{1} \mathrm{H}$ NMR $(600$ $\left.\mathrm{MHz}, \mathrm{CD}_{3} \mathrm{OD}-d_{4}\right) \delta 9.54$ (s, 1H, BBR-8-H), 7.88 (s, 1H, BBR-13-H), 7.77 (bs, 1H, Bim-4-H), 7.76 (s, 1H, BBR-11-H), 7.66 (d, $J=7.8 \mathrm{~Hz}, 1 \mathrm{H}, \mathrm{Bim}-7-H), 7.41$ (t, $J=7.6 \mathrm{~Hz}, 1 \mathrm{H}$, Bim-6- $H$ ), 7.37 (t, $J=7.1 \mathrm{~Hz}, 1 \mathrm{H}$, Bim-5-H), 7.09 (s, 1H, BBR-1-H), 6.85 (s, 1H, BBR-4-H), 5.97 (s, 2H, OCH $\left.H_{2} \mathrm{O}\right), 4.71$ (s, 2H, BBR-6-2H), 4.11 (d, J= $7.1 \mathrm{~Hz}, 2 \mathrm{H}, \mathrm{CH}_{2}$ ), 3.97 (s, 3H, OCH , $_{3}$, 3.16 (bs, 2H, BBR-5-2H), 1.73 (bs, 1H, cyclohexane-CH), 1.47 (bs, 3H, cyclohexane-( $\left.\left.\mathrm{CH}_{2}\right)_{2}\right), 1.35$ (d, $J=12.2 \mathrm{~Hz}, 2 \mathrm{H}$, cyclohexane- $\left.\mathrm{CH}_{2}\right), 0.97$ (bs, $3 \mathrm{H}$, cyclohexane- $\left.\left(\mathrm{CH}_{2}\right)_{2}\right), 0.70\left(\mathrm{~d}, \mathrm{~J}=10.3 \mathrm{~Hz}, 2 \mathrm{H}\right.$, cyclohexane- $\left.\mathrm{CH}_{2}\right) \mathrm{ppm} ;{ }^{13} \mathrm{C}$ NMR $(150$ $\left.\mathrm{MHz}, \mathrm{CD}_{3} \mathrm{OD}-d_{4}\right) \delta 151.49,150.24,148.23,146.76,136.67,130.19,123.98,123.11,122.74,120.89,118.25,115.45,111.17$, 107.98, 104.32, 102.07, 55.93, 54.43, 50.53, 37.58, 30.30, 27.32, 25.68, 25.14.HRMS (ESI): calculated for $\mathrm{C}_{33} \mathrm{H}_{32} \mathrm{ClN}_{3} \mathrm{O}_{4}[\mathrm{M}$ $-\mathrm{Cl}]^{+}, 531.1387$, found, 531.1388.

12-(1-Allyl-1H-benzoimidazol-2-yl)-9-hydroxy-10-methoxy-5,6-dihydro-[1,3]dioxolo[4,5-g]isoquinolino[3,2-a]isoq uinolin-7-ium chloride (5c). Allyl derivative 5c was prepared by cyclization reaction of intermediate 2 ( $250 \mathrm{mg}, 0.65 \mathrm{mmol}$ ), $\mathbf{1 2 c}(193 \mathrm{mg}, 1.30 \mathrm{mmol})$ and sodium pyrosulfite $(247 \mathrm{mg}, 1.30 \mathrm{mmol})$ according to the same procedure described for 3a. A pure yellow solid was obtained (192 mg, 57.4\%). Mp: $220-222{ }^{\circ} \mathrm{C} ;{ }^{1} \mathrm{H}$ NMR $\left(600 \mathrm{MHz}, \mathrm{CD}_{3} \mathrm{OD}-d_{4}\right) \delta 9.94(\mathrm{~s}, 1 \mathrm{H}$, BBR-8-H), 8.26 (s, 1H, BBR-13-H), 8.24 (s, 1H, BBR-11-H), 7.89 - 7.81 (m, 2H, Bim-4-H, Bim-7-H), 7.62 - 7.58 (m, 2H, Bim-5-H, Bim-6- $H$ ), 7.42 (s, 1H, BBR-1- $H$ ), 6.85 (s, 1H, BBR-4- $H$ ), $6.03-5.97$ (m, 1H, $\left.\mathrm{CH}=\mathrm{CH}_{2}\right), 5.94\left(\mathrm{~s}, 2 \mathrm{H}, \mathrm{OCH}_{2} \mathrm{O}\right)$, $5.22\left(\mathrm{~d}, J=10.6 \mathrm{~Hz}, 1 \mathrm{H}, \mathrm{CH}=\mathrm{CH}_{2}\right), 5.10\left(\mathrm{~d}, J=17.2 \mathrm{~Hz}, 1 \mathrm{H}, \mathrm{CH}=\mathrm{CH}_{2}\right), 4.95\left(\mathrm{~d}, J=4.1 \mathrm{~Hz}, 2 \mathrm{H}, \mathrm{CH}_{2}\right), 4.86-4.84(\mathrm{~m}, 2 \mathrm{H}$, BBR-6-2H), 4.01 (s, 3H, OCH $), 3.19-3.15$ (m, 2H, BBR-5-2H) ppm; ${ }^{13} \mathrm{C}$ NMR (150 MHz, $\left.\mathrm{CD}_{3} \mathrm{OD}-d_{4}\right) \delta 151.02,149.70$, $148.41,147.58,146.76,145.16,139.25,134.37,133.62$, 131.82, 131.28, 131.05, 127.25, 126.05, 125.91, 120.21, 118.11, 117.98, 116.66, 115.66, 112.90, 110.34, 108.00, 105.59, 102.30, 56.82, 55.85, 48.50, 26.82 ppm; HRMS (ESI): calculated for $\mathrm{C}_{29} \mathrm{H}_{24} \mathrm{ClN}_{3} \mathrm{O}_{4}[\mathrm{M}-\mathrm{Cl}]^{+}$, 478.1758; found, 478.1761.

9-Hydroxy-10-methoxy-12-(1-(prop-2-yn-1-yl)-1H-benzoimidazol-2-yl)-5,6-dihydro-[1,3]dioxolo[4,5-g]isoquinolin $\mathbf{0}$ [3,2-a] isoquinolin-7-ium chloride (5d). Propargyl derivative 5d was prepared by cyclization reaction of intermediate 2 $(250 \mathrm{mg}, 0.65 \mathrm{mmol}), \mathbf{1 2 d}(190 \mathrm{mg}, 1.30 \mathrm{mmol})$ and sodium pyrosulfite $(247 \mathrm{mg}, 1.30 \mathrm{mmol})$ according to the same procedure described for 3a. A pure yellow solid was obtained (215 mg, 65.0\%). Mp: $190-192{ }^{\circ} \mathrm{C}$; ${ }^{1} \mathrm{H} \mathrm{NMR}(600 \mathrm{MHz}$, $\left.\mathrm{CD}_{3} \mathrm{OD}-d_{4}\right) \delta 10.09$ (s, 1H, BBR-8- $H$ ), 8.49 (s, 1H, BBR-13-H), 8.47 (s, 1H, BBR-11- $H$ ), 8.14 (d, $\left.J=7.2 \mathrm{~Hz}, 1 \mathrm{H}, \mathrm{Bim}-4-H\right)$, $8.02(\mathrm{~d}, J=7.1 \mathrm{~Hz}, 1 \mathrm{H}, \mathrm{Bim}-7-H), 7.82-7.77 \mathrm{~m}, 2 \mathrm{H}, \mathrm{Bim}-5-H$, Bim-6-H), 7.61 (s, 1H, BBR-1-H), 6.98 (s, 1H, BBR-4-H), 6.07 (s, 2H, OCH$\left.H_{2} \mathrm{O}\right), 5.29$ (d, $\left.J=2.2 \mathrm{~Hz}, 2 \mathrm{H}, \mathrm{CH}_{2}\right), 4.99$ (t, $\left.J=6.2 \mathrm{~Hz}, 2 \mathrm{H}, \mathrm{BBR}-6-2 H\right), 4.20$ (s, 3H, OCH$)_{3}, 3.32-3.29(\mathrm{~m}$, 2H, BBR-5-2H), 3.19 (bs, 1H, C $\equiv \mathrm{CH}$ ) ppm; ${ }^{3} \mathrm{C}$ NMR (150 MHz, $\left.\mathrm{CD}_{3} \mathrm{OD}-d_{4}\right) \delta 151.02,149.70,148.41,147.58,146.76$, $145.16,139.25,134.37,133.62,131.82,131.28,131.05,127.25,126.05,125.91,120.21,118.11,117.98,116.66,115.66$, $112.90,110.34,108.00,105.59,102.30,56.82,55.85,48.50,26.82$ ppm; HRMS (ESI): calculated for $\mathrm{C}_{29} \mathrm{H}_{22} \mathrm{CIN}_{3} \mathrm{O}_{4}[\mathrm{M}-$ $\mathrm{Cl}]^{+}, 476.1605$; found, 476.1599 .

9-Hydroxy-12-(1-(2-hydroxyethyl)-1H-benzoimidazol-2-yl)-10-methoxy-5,6-dihydro-[1,3]dioxolo[4,5-g]isoquinoli no[3,2-a] isoquinolin-7-ium chloride (6a). Hydroxyl derivative 6a was prepared by cyclization reaction of intermediate 2 (250 mg, $0.65 \mathrm{mmol}), 13 \mathrm{a}(198 \mathrm{mg}, 1.30 \mathrm{mmol})$ and sodium pyrosulfite $(247 \mathrm{mg}, 1.30 \mathrm{mmol})$ according to the same procedure described for 3a. A pure yellow solid was obtained (130 mg, 38.6\%). Mp: $211-213{ }^{\circ} \mathrm{C}$; ${ }^{1} \mathrm{H} \mathrm{NMR}(600 \mathrm{MHz}$, 
$\left.\mathrm{CD}_{3} \mathrm{OD}-d_{4}\right) \delta 10.07$ (s, 1H, BBR-8-H), 8.66 (s, 1H, BBR-13- $H$ ), 8.30 (s, 1H, BBR-11- $H$ ), 8.14 (d, $J=9.1 \mathrm{~Hz}, 1 \mathrm{H}$, Bim-4- $H$ ), $8.00(\mathrm{~d}, J=9.0 \mathrm{~Hz}, 1 \mathrm{H}, \mathrm{Bim}-7-H), 7.80-7.79$ (m, 2H, Bim-5-H, Bim-6-H), 7.56 (s, 1H, BBR-1-H), 6.95 (s, 1H, BBR-4- $H$ ), $6.03\left(\mathrm{~s}, 2 \mathrm{H}, \mathrm{OCH}_{2} \mathrm{O}\right), 4.99-4.93(\mathrm{~m}, 2 \mathrm{H}, \mathrm{BBR}-6-2 \mathrm{H}), 4.62\left(\mathrm{bs}, 2 \mathrm{H}, \mathrm{CH}_{2} \mathrm{CH}_{2} \mathrm{OH}\right), 4.15\left(\mathrm{~s}, 3 \mathrm{H}, \mathrm{OCH}_{3}\right), 4.00-3.96(\mathrm{~m}, 2 \mathrm{H}$, $\mathrm{CH}_{2} \mathrm{CH}_{2} \mathrm{OH}$ ), 3.28 - 3.25 (m, 2H, BBR-5-2H) ppm; ${ }^{13} \mathrm{C}$ NMR (150 MHz, $\left.\mathrm{CD}_{3} \mathrm{OD}-d_{4}\right) \delta 151.11,149.64,148.41,147.41$, 146.76, 145.16, 139.41, 134.02, 133.07, 131.82, 131.03, 127.78, 126.43, 126.22, 120.12, 117.95, 116.71, 115.60, 112.63, 109.92, 107.97, 105.72, 102.30, 76.41, 56.82, 55.88, 35.46, 26.79 ppm; HRMS (ESI): calculated for $\mathrm{C}_{28} \mathrm{H}_{24} \mathrm{ClN}_{3} \mathrm{O}_{5}[\mathrm{M}-\mathrm{Cl}]^{+}$, 481.1710; found, 481.1709 .

12-(1-(2-(Dimethylamino)ethyl)-1H-benzoimidazol-2-yl)-9-hydroxy-10-methoxy-5,6-dihydro-[1,3]dioxolo[4,5-g]is oquinolino [3,2-a]isoquinolin-7-ium chloride (6b). Compound $6 \mathbf{b}$ was prepared by cyclization reaction of intermediate 2 (250 mg, $0.65 \mathrm{mmol}), \mathbf{1 3 b}(233 \mathrm{mg}, 1.30 \mathrm{mmol})$ and sodium pyrosulfite $(247 \mathrm{mg}, 1.30 \mathrm{mmol})$ according to the same procedure described for 3a. A pure yellow solid was obtained (67 mg, 20.2\%). Mp: $217-219{ }^{\circ} \mathrm{C} ;{ }^{1} \mathrm{H}$ NMR $(600 \mathrm{MHz}$, $\left.\mathrm{CD}_{3} \mathrm{OD}-d_{4}\right) \delta 9.41(\mathrm{~s}, 1 \mathrm{H}, \mathrm{BBR}-8-H), 7.95(\mathrm{~s}, 1 \mathrm{H}, \mathrm{BBR}-13-H), 7.77$ (d, $\left.J=7.7 \mathrm{~Hz}, 1 \mathrm{H}, \mathrm{Bim}-4-H\right), 7.70$ (s, 1H, BBR-11- $H$ ), 7.66 (d, $J=7.8$ Hz, 1H, Bim-7-H), $7.41-7.35$ (m, 2H, Bim-5-H, Bim-6-H), 7.15 (s, 1H, BBR-1-H), 6.85 (s, 1H, BBR-4- $H$ ),

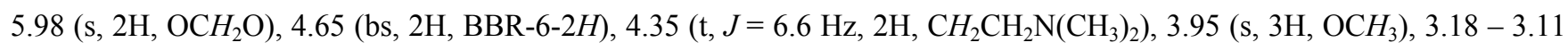
(m, 2H, BBR-5-2H), 2.69 (t, $\left.J=6.5 \mathrm{~Hz}, 2 \mathrm{H}, \mathrm{CH}_{2} \mathrm{CH}_{2} \mathrm{~N}\left(\mathrm{CH}_{3}\right)_{2}\right), 2.27\left(\mathrm{~s}, 3 \mathrm{H}, \mathrm{CH}_{2} \mathrm{CH}_{2} \mathrm{~N}\left(\mathrm{CH}_{3}\right)_{2}\right), 1.29\left(\mathrm{~s}, 3 \mathrm{H}, \mathrm{CH}_{2} \mathrm{CH}_{2} \mathrm{~N}\left(\mathrm{CH}_{3}\right)_{2}\right)$ ppm; ${ }^{13} \mathrm{C}$ NMR (100 MHz, $\left.\mathrm{CD}_{3} \mathrm{OD}-d_{4}\right) \delta 151.07,149.90,148.36,147.02,146.67,145.32,139.96,132.88,131.86,131.24$, $127.81,127.02,126.75,120.26,118.05,116.07,114.76,113.19,107.94,105.94,102.29,63.40,56.95,55.92,53.41,51.69$, 42.98, 26.73, $23.51 \mathrm{ppm}$; HRMS (ESI): calculated for $\mathrm{C}_{32} \mathrm{H}_{33} \mathrm{ClN}_{4} \mathrm{O}_{4}[\mathrm{M}-\mathrm{Cl}]^{+}$, 537.2496; found, 537.2496.

9-hydroxy-10-methoxy-12-(1-(2-morpholinoethyl)-1H-benzoimidazol-2-yl)-5,6-dihydro-[1,3]dioxolo[4,5-g]isoquin olino[3,2-a] isoquinolin-7-ium chloride (6c). Compound $\mathbf{6 c}$ was prepared by cyclization reaction of intermediate 2 (250 $\mathrm{mg}$, $0.65 \mathrm{mmol}), \mathbf{1 3 b}(288 \mathrm{mg}, 1.30 \mathrm{mmol})$ and sodium pyrosulfite $(247 \mathrm{mg}, 1.30 \mathrm{mmol})$ according to the same procedure described for 3a. A pure yellow solid was obtained (95 mg, 26.5\%). Mp: $215-217{ }^{\circ} \mathrm{C} ;{ }^{1} \mathrm{H}$ NMR (400 MHz, $\left.\mathrm{CD}_{3} \mathrm{OD}-d_{4}\right) \delta$ 10.06 (s, 1H, BBR-8-H), 8.55 (s, 1H, BBR-13-H)), 8.28 (s, 1H, BBR-11-H), 8.22 (d, $J=7.4$ Hz, 1H, Bim-4-H), $8.01-7.97$ (m, 1H, Bim-7-H), 7.83 - 7.74 (m, 2H, Bim-5-H, Bim-6-H), 7.60 (s, 1H, BBR-1-H), 6.94 (s, 1H, BBR-4-H), 6.03 (s, 2H, $\left.\mathrm{OCH}_{2} \mathrm{O}\right), 4.98-4.94(\mathrm{~m}, 2 \mathrm{H}, \mathrm{BBR}-6-2 \mathrm{H}), 4.64-4.54\left(\mathrm{~m}, 2 \mathrm{H}, \mathrm{CH}_{2} \mathrm{CH}_{2}\right), 4.19\left(\mathrm{~s}, 3 \mathrm{H}, \mathrm{OCH}_{3}\right), 3.91(\mathrm{~d}, \mathrm{~J}=11.9 \mathrm{~Hz}, 2 \mathrm{H}$, morpholine-3- $\mathrm{CH}_{2}$ ), 3.74 (t, $J=12.2 \mathrm{~Hz}, 2 \mathrm{H}$, morpholine-5- $\mathrm{CH}_{2}$ ), 3.26 (bs, 2H, morpholine-2- $\left.\mathrm{CH}_{2}\right), 3.20-3.13(\mathrm{~m}, 2 \mathrm{H}$, , BBR-5-2H), 3.02 (t, $J=10.7 \mathrm{~Hz}, 2 \mathrm{H}, \mathrm{CH}_{2} \mathrm{CH}_{2}$ ), 2.29 (bs, 2H, morpholine-6- $\mathrm{CH}_{2}$ ) ppm; ${ }^{13} \mathrm{C}$ NMR $\left(100 \mathrm{MHz}, \mathrm{CD}_{3} \mathrm{OD}-d_{4}\right) \delta$ 151.07, 149.90, 148.36, 147.02, 146.67, 145.32, 139.96, 132.88, 131.86, 131.24, 127.81, 127.02, 126.75, 120.26, 118.05, 116.07, 114.76, 113.19, 107.94, 105.94, 102.29, 63.40, 56.95, 55.92, 53.41, 51.69, 42.98, 26.73, 23.51 ppm; HRMS (ESI): calculated for $\mathrm{C}_{32} \mathrm{H}_{31} \mathrm{ClN}_{4} \mathrm{O}_{5}[\mathrm{M}-\mathrm{Cl}]^{+}, 551.2289$, found, 551.2287.

12-(1-(2-Fluorobenzyl)-1H-benzoimidazol-2-yl)-9-hydroxy-10-methoxy-5,6-dihydro-[1,3]dioxolo[4,5-g]isoquinolin o[3,2-a] isoquinolin-7-ium chloride (7a). Compound 7a was prepared by cyclization reaction of intermediate 2 (250 $\mathrm{mg}$, $0.65 \mathrm{mmol}), 14 \mathrm{a}(281 \mathrm{mg}, 1.30 \mathrm{mmol})$ and sodium pyrosulfite $(247 \mathrm{mg}, 1.30 \mathrm{mmol})$ according to the same procedure described for 3a. A pure yellow solid was obtained (192 mg, 50.8\%). Mp: $211-213{ }^{\circ} \mathrm{C} ;{ }^{1} \mathrm{H}$ NMR $\left(600 \mathrm{MHz}, \mathrm{CD}_{3} \mathrm{OD}-d_{4}\right) \delta$ 10.05 (s, 1H, BBR-8-H), 8.41 (s, 1H, BBR-13-H), 8.12 (d, $J=7.5 \mathrm{~Hz}, 1 \mathrm{H}$, Bim-4- $H), 8.06(\mathrm{~d}, J=6.9 \mathrm{~Hz}, 1 \mathrm{H}$, Bim-7- $H), 8.01$ (s, 1H, BBR-11-H), $7.84-7.79$ (m, 2H, Bim-5-H, Bim-6-H), 7.50 (s, 1H, BBR-1-H), $7.23-7.19$ (m, 1H, Ph-4-H), 7.16 (t, $J$ $=7.3 \mathrm{~Hz}, 1 \mathrm{H}, \mathrm{Ph}-3-H), 7.00$ (t, $J=7.5 \mathrm{~Hz}, 1 \mathrm{H}, \mathrm{Ph}-6-H), 6.97$ (s, 1H, BBR-4-H), $6.95-6.90(\mathrm{~m}, 1 \mathrm{H}, \mathrm{Ph}-5-H), 6.08(\mathrm{~s}, 2 \mathrm{H}$, $\mathrm{OCH}_{2} \mathrm{O}$ ), 5.79 (s, $2 \mathrm{H}, \mathrm{CH}_{2}$ ), 4.96 (bs, 2H, BBR-6-2H, CD $\mathrm{CD}_{3} \mathrm{H}_{2} \mathrm{O}$ ), 4.07 (s, 3H, OCH $\left.H_{3}\right), 3.28(\mathrm{t}, J=5.9 \mathrm{~Hz}, 2 \mathrm{H}, \mathrm{BBR}-5-2 H$ ) 
ppm; ${ }^{13} \mathrm{C}$ NMR $\left(150 \mathrm{MHz}, \mathrm{CD}_{3} \mathrm{OD}-d_{4}\right) \delta 161.29,159.65,151.18,149.88,148.39,146.90,145.14,139.56,133.18,131.69$, $131.19,130.86,130.06,127.93,127.31,127.00,124.59,120.88,119.96,117.59,115.84,115.44,115.30,114.63,113.45$, 108.59, 107.96, 105.88, 102.32, 56.81, 55.97, 41.16, 26.80 ppm. HRMS (ESI): calculated for $\mathrm{C}_{33} \mathrm{H}_{25} \mathrm{ClFN}_{3} \mathrm{O}_{4}[\mathrm{M}-\mathrm{Cl}]^{+}$, 546.1824 , found, 546.1823 .

12-(1-(2,4-Difluorobenzyl)-1H-benzoimidazol-2-yl)-9-hydroxy-10-methoxy-5,6-dihydro-[1,3]dioxolo[4,5-g]isoquin olino[3,2-a] isoquinolin-7-ium chloride (7b). Compound $7 \mathbf{b}$ was prepared by cyclization reaction of intermediate $2(250 \mathrm{mg}$, $0.65 \mathrm{mmol}), 14 \mathrm{~b}(305 \mathrm{mg}, 1.30 \mathrm{mmol})$ and sodium pyrosulfite $(247 \mathrm{mg}, 1.30 \mathrm{mmol})$ according to the same procedure described for 3a. A pure yellow solid was obtained (317 mg, 81.5\%). Mp: $190-192{ }^{\circ} \mathrm{C} ;{ }^{1} \mathrm{H}$ NMR $\left(600 \mathrm{MHz}, \mathrm{CD}_{3} \mathrm{OD}-d_{4}\right) \delta$ 9.97 (s, 1H, BBR -8-H), 8.22 (s, 1H, BBR-13-H), 7.94 (bs, 2H, BBR-11-H, Bim-4-H), 7.87 - 7.84 (m, 1H, Bim-7-H), 7.61 7.57 (m, 2H, Bim-5-H, Bim-6-H), 7.26 (s, 1H, BBR-1-H), 7.07 (dd, $J=14.7,8.3$ Hz, 1H, Ph-3-H), 6.95 (s, 1H, BBR-4- H), $6.83(\mathrm{t}, J=7.4 \mathrm{~Hz}, 1 \mathrm{H}, \mathrm{Ph}-5-H), 6.79-6.72$ (m, 2H, Ph-6- $H$, BBR-4- $H$ ), 6.06 (s, 2H, OCH $\mathrm{H}_{2}$ ), 5.59 (s, 2H, $\left.\mathrm{CH}_{2}\right), 4.93(\mathrm{ds}$, 2H, BBR-6-2H), 4.04 (s, 3H, OCH $\left.H_{3}\right), 3.25$ (t, $\left.J=6.1 \mathrm{~Hz}, 2 \mathrm{H}, \mathrm{BBR}-5-2 H\right) \mathrm{ppm} ;{ }^{13} \mathrm{C}$ NMR $\left(150 \mathrm{MHz}, \mathrm{CD}_{3} \mathrm{OD}-d_{4}\right) \delta 150.99$, 148.90, 148.38, 146.46, 145.23, 138.64, 138.46, 134.78, 131.74, 130.84, 130.68, 126.82, 124.91, 124.47, 122.91, 119.98, $118.95,117.59,116.42,113.88,111.69,111.46,111.32,108.01,105.01,103.72,103.55,103.38,103.13,102.30,56.56$, 55.72, 42.39, 26.85 ppm; HRMS (ESI): calculated for $\mathrm{C}_{33} \mathrm{H}_{24} \mathrm{ClF}_{2} \mathrm{~N}_{3} \mathrm{O}_{4}[\mathrm{M}-\mathrm{Cl}]^{+}, 564.1729$, found, 546.1733.

12-(1-(2-Chlorobenzyl)-1H-benzoimidazol-2-yl)-9-hydroxy-10-methoxy-5,6-dihydro-[1,3]dioxolo[4,5-g]isoquinoli no[3,2-a] isoquinolin-7-ium chloride (7c). Compound 7c was prepared by cyclization reaction of intermediate 2 ( $250 \mathrm{mg}$, $0.65 \mathrm{mmol}), 14 \mathrm{c}(303 \mathrm{mg}, 1.30 \mathrm{mmol})$ and sodium pyrosulfite $(247 \mathrm{mg}, 1.30 \mathrm{mmol})$ according to the same procedure described for 3c. Pure product was obtained as yellow solid (257 mg, 67.5\%). Mp: $215-217{ }^{\circ} \mathrm{C}$; ${ }^{1} \mathrm{H}$ NMR $(600 \mathrm{MHz}$, DMSO- $\left.d_{6}\right) \delta 10.08(\mathrm{~s}, 1 \mathrm{H}, \mathrm{BBR}-8-H), 8.28$ (s, 2H, BBR-13-H, BBR-11- $H$ ), 7.96 (d, $\left.J=7.0 \mathrm{~Hz}, 1 \mathrm{H}, \mathrm{Bim}-4-H\right), 7.83(\mathrm{~d}, J=$ 7.0 Hz, 1H, Bim-7-H), 7.61 (s, 1H, BBR-1-H), 7.55 (bs, 2H, Bim-5-H, Bim-6-H), 7.22 (d, $J=8.4$ Hz, 2H, Ph-3-H, Ph-4- $H$ ), 7.10 (d, $J=8.3 \mathrm{~Hz}, 2 \mathrm{H}, \mathrm{Ph}-6-H, \mathrm{Ph}-5-H), 7.06$ (s, 1H, BBR-4-H), 6.13 (s, 2H, OCH $\mathrm{O}$ ), 5.57 (s, 2H, CH $), 4.92$ (bs, 2H, BBR-6-2H), 3.93 (s, 3H, OCH ), $3.25-3.14$ (m, 2H, BBR-5-2H) ppm; ${ }^{13} \mathrm{C}$ NMR (150 MHz, DMSO- $d_{6}$ ) $\delta 150.36,148.93$, $147.91,147.27,145.35,138.31,135.02,134.85,132.79,131.67,131.43,129.40,128.92,128.20,125.19,120.68,118.22$, 117.38, 113.01, 108.81, 106.55, 102.51, 57.48, 55.43, 48.12, 26.95 ppm; HRMS (ESI): calculated for $\mathrm{C}_{33} \mathrm{H}_{25} \mathrm{Cl}_{2} \mathrm{~N}_{3} \mathrm{O}_{4}[\mathrm{M}-$ $\mathrm{Cl}]^{+}, 561.1528$, found, 561.1538 .

12-(1-(2,4-Dichlorobenzyl)-1H-benzoimidazol-2-yl)-9-hydroxy-10-methoxy-5,6-dihydro-[1,3]dioxolo[4,5-g]isoquin olino[3,2-a] isoquinolin-7-ium chloride (7d). Compound 7d was prepared by cyclization reaction of intermediate 2 (250 $\mathrm{mg}$, $0.65 \mathrm{mmol}), \mathbf{1 4 d}(347 \mathrm{mg}, 1.30 \mathrm{mmol})$ and sodium pyrosulfite $(247 \mathrm{mg}, 1.30 \mathrm{mmol})$ according to the same procedure described for 3a. A pure yellow solid was obtained (171 mg, 41.5\%). Mp: $190-192{ }^{\circ} \mathrm{C} ;{ }^{1} \mathrm{H}$ NMR $\left(600 \mathrm{MHz}, \mathrm{CD}_{3} \mathrm{OD}-d_{4}\right) \delta$ 10.04 (s, 1H, BBR-8-H), 8.40 (s, 1H, BBR-13-H), 8.12 (d, $J=8.7$ Hz, 1H, Bim-4-H), 8.09 (d, $J=8.6$ Hz, 1H, Bim-7-H), 7.90 (s, 1H, BBR-11-H), $7.88-7.82$ (m, 2H, Bim-5-H, Bim-6-H), 7.46 (s, 1H, BBR-1-H), 7.27 (s, 1H, Ph-3-H), 7.17 (d, $J=$ $8.4 \mathrm{~Hz}, 1 \mathrm{H}, \mathrm{Ph}-5-H), 7.13$ (d, $J=10.0 \mathrm{~Hz}, 1 \mathrm{H}, \mathrm{Ph}-6-H), 6.96$ (s, 1H, BBR-4- $H$ ), 6.10 (s, 2H, OCH $\mathrm{O}$ ), 5.78 (s, 2H, $\mathrm{CH}_{2}$ ), 4.936 (s, 2H, BBR-6-2H, CD $\mathrm{CD}_{3} \mathrm{H}_{2} \mathrm{O}$ ), 4.09 (s, 3H, OCH $\left.H_{3}\right), 3.29$ (t, $\left.J=6.1 \mathrm{~Hz}, 2 \mathrm{H}, \mathrm{BBR}-5-2 H\right) \mathrm{ppm} ;{ }^{13} \mathrm{C} \mathrm{NMR}(150 \mathrm{MHz}$, $\left.\mathrm{CD}_{3} \mathrm{OD}-d_{4}\right) \delta 151.32,150.01,148.40,147.12,146.92,145.18,139.41,135.00,133.72,133.51,131.51,131.20,131.01$, 130.22 , 129.18, 127.96, 127.58, 127.45, 127.24, 119.64, 117.53, 115.63, 114.78, 113.36, 108.56, 108.07, 105.75, 102.41, 56.81, 55.96, 47.04, 26.80 ppm. HRMS (ESI): calculated for $\mathrm{C}_{33} \mathrm{H}_{24} \mathrm{Cl}_{3} \mathrm{~N}_{3} \mathrm{O}_{4}[\mathrm{M}-\mathrm{Cl}]^{+}$, 596.1138, found, 596.1118.

12-(1-(3,4-Dichlorobenzyl)-1H-benzoimidazol-2-yl)-9-hydroxy-10-methoxy-5,6-dihydro-[1,3]dioxolo[4,5-g]isoquin S17 
olino [3,2-a]isoquinolin-7-ium chloride (7e). Compound 7e was prepared by cyclization reaction of intermediate 2 (250 $\mathrm{mg}$, $0.65 \mathrm{mmol}), 14 \mathrm{e}(347 \mathrm{mg}, 1.30 \mathrm{mmol})$ and sodium pyrosulfite $(247 \mathrm{mg}, 1.30 \mathrm{mmol})$ according to the same procedure described for 3a. A pure yellow solid was obtained (170 mg, 41.2\%). Mp: $201-203{ }^{\circ} \mathrm{C}$; ${ }^{1} \mathrm{H}$ NMR $\left(600 \mathrm{MHz}, \mathrm{CD}_{3} \mathrm{OD}-d_{4}\right) \delta$ 9.95 (s, 1H, BBR-8-H), 8.15 (s, 1H, BBR-13-H), 7.94 (d, $J=7.7$ Hz, 1H, Bim-4-H), 7.86 (d, $J=7.8$ Hz, 1H, Bim-7-H), 7.73 (s, 1H, BBR-11-H), $7.63-7.54$ (m, 2H, Bim-5- H, Bim-6-H), 7.24 (d, $J=8.3$ Hz, 1H, Ph-5-H), 7.10 (s, 1H, BBR-1-H), 6.98 (s, 1H, Ph-2-H), 6.94 (bs, 1H, Ph-6-H), 6.92 (s, 1H, BBR-4-H), 6.06 (s, 2H, OCH $H_{2} \mathrm{O}$ ), 5.47 (s, 2H, CH CH $_{2}, 4.92(\mathrm{t}, J=6.1 \mathrm{~Hz}$, 2H, BBR-6-2H), $4.03\left(\mathrm{~s}, 3 \mathrm{H}, \mathrm{OCH}_{3}\right), 3.27-3.23(\mathrm{~m}, 2 \mathrm{H}, \mathrm{BBR}-5-2 H) \mathrm{ppm} ;{ }^{13} \mathrm{C}$ NMR $\left(150 \mathrm{MHz}, \mathrm{CD}_{3} \mathrm{OD}-d_{4}\right) \delta 151.00$, 149.22 , 148.33, 146.33, 145.21, 140.07, 138.15, 136.86, 135.21, 131.12, 131.50, 130.65, 129.00, 126.71, 124.76, 124.10, 119.82, 118.25, 117.64, 116.41, 111.16, 108.04, 104.89, 102.30, 56.42, 55.65, 46.96, 26.87 ppm. HRMS (ESI): calculated for $\mathrm{C}_{33} \mathrm{H}_{24} \mathrm{Cl}_{3} \mathrm{~N}_{3} \mathrm{O}_{4}[\mathrm{M}-\mathrm{Cl}]^{+}$, 596.1138, found, 596.1118 .

9-Hydroxy-10-methoxy-12-(1-(2-oxo-2-(pyrrolidin-1-yl)ethyl)-1H-benzoimidazol-2-yl)-5,6-dihydro-[1,3]dioxolo[4, 5-g] isoquinolino [3,2-a]isoquinolin-7-ium chloride (8a). Compound 8a was prepared by cyclization reaction of intermediate $2(250 \mathrm{mg}, 0.65 \mathrm{mmol}), 15 \mathrm{a}(285 \mathrm{mg}, 1.30 \mathrm{mmol})$ and sodium pyrosulfite $(247 \mathrm{mg}, 1.30 \mathrm{mmol})$ according to the same procedure described for 3a. A pure yellow solid was obtained (294 mg, 77.2\%). Mp: $238-241{ }^{\circ} \mathrm{C}$; ${ }^{1} \mathrm{H} \mathrm{NMR}(600 \mathrm{MHz}$, $\left.\mathrm{CD}_{3} \mathrm{OD}-d_{4}\right) \delta 9.52(\mathrm{~s}, 1 \mathrm{H}, \mathrm{BBR}-8-H), 8.12(\mathrm{~s}, 1 \mathrm{H}, \mathrm{BBR}-13-H), 7.79-7.68(\mathrm{~m}, 2 \mathrm{H}, \mathrm{Bim}-4-H$, Bim-7-H), $7.49(\mathrm{~s}, 1 \mathrm{H}$, BBR-11-H), 7.39 - 7.35 (m, 2H, Bim-5-H, Bim-6-H), 7.29 (s, 1H, BBR-1-H), 6.79 (s, 1H, BBR-4-H), 5.96 (s, 2H, OCH $H_{2} \mathrm{O}$ ), $4.94\left(\mathrm{~s}, 2 \mathrm{H}, \mathrm{CH}_{2}\right), 4.87$ (bs, 2H, BBR-6-2H, CD $\left.\mathrm{OD}-\mathrm{H}_{2} \mathrm{O}\right), 4.68$ (bs, $2 \mathrm{H}$, pyrrole- $\left.\mathrm{CH}_{2}\right), 3.88\left(\mathrm{~s}, 3 \mathrm{H}, \mathrm{OCH}_{3}\right), 3.43(\mathrm{bs}, 2 \mathrm{H}$, pyrrole- $\mathrm{CH}_{2}$ ), 3.07 (bs, 2H, BBR-5-2H), $1.93\left(\mathrm{~d}, J=6.0 \mathrm{~Hz}, 2 \mathrm{H}\right.$, pyrrole- $\left.\mathrm{CH}_{2}\right), 1.85-1.77\left(\mathrm{~m}, 2 \mathrm{H}\right.$, pyrrole-C $\left.\mathrm{H}_{2}\right) \mathrm{ppm} ;{ }^{13} \mathrm{C}$ NMR $\left(150 \mathrm{MHz}, \mathrm{CD}_{3} \mathrm{OD}-d_{4}\right) \delta 165.52(\mathrm{C}=\mathrm{O}), 151.30,150.26,148.14,146.85,146.12,141.33,136.97,135.74,131.86$, $130.14,121.12$, 123.48, 123.04, 120.70, 118.85, 118.14, 116.64, 110.66, 107.80, 105.15, 102.06, 55.80, 54.77, 46.29, 46.04, 45.61, 27.08, 25.56, 23.57 ppm; HRMS (ESI): calculated for $\mathrm{C}_{32} \mathrm{H}_{29} \mathrm{ClN}_{4} \mathrm{O}_{5}[\mathrm{M}-\mathrm{Cl}]^{+}$, 549.2132, found, 549.2126.

9-hydroxy-10-methoxy-12-(1-(2-morpholino-2-oxoethyl)-1H-benzoimidazol-2-yl)-5,6-dihydro-[1,3]dioxolo[4,5-g]i soquinolino[3,2-a]isoquinolin-7-ium chloride. Compound $\mathbf{8 b}$ was prepared by cyclization reaction of intermediate $\mathbf{2}$ (250 $\mathrm{mg}, 0.65 \mathrm{mmol}), \mathbf{1 5 b}(306 \mathrm{mg}, 1.30 \mathrm{mmol})$ and sodium pyrosulfite $(247 \mathrm{mg}, 1.30 \mathrm{mmol})$ according to the same procedure described for 3a. A pure yellow solid was obtained (342 mg, 87.5\%). Mp: $232-234{ }^{\circ} \mathrm{C} ; \quad{ }^{1} \mathrm{H}$ NMR (400 MHz, DMSO- $\left.d_{6}\right) \delta$ $9.63(\mathrm{~s}, 1 \mathrm{H}, \mathrm{BBR}-8-H), 8.12$ (s, 1H, BBR-13-H), 7.77 (d, $J=9.0 \mathrm{~Hz}, 1 \mathrm{H}, \mathrm{Bim}-4-H), 7.67$ (s, 1H, BBR-11-H), $7.55(\mathrm{~d}, J=$ $9.0 \mathrm{~Hz}, 1 \mathrm{H}), 7.37$ - 7.29 (m, 2H, Bim-5-H, Bim-6-H), 7.27 (s, 1H, BBR-1-H), 7.00 (s, 1H, BBR-4-H), 6.07 (s, 2H, OCH $H_{2} \mathrm{O}$ ), 5.15 (s, 2H, $\mathrm{CH}_{2}$ ), $4.80-4.69$ (m, 2H, BBR-6-2H), 3.86 (s, 3H, OCH $\left.H_{3}\right), 3.48$ (d, $J=10.7 \mathrm{~Hz}, 4 \mathrm{H}$, morpholine-4H), 3.39 (d, $J$ $=7.1 \mathrm{~Hz}, 4 \mathrm{H}$, morpholine-4H), $3.14-3.06(\mathrm{~m}, 2 \mathrm{H}, \mathrm{BBR}-5-2 H) \mathrm{ppm} ;{ }^{13} \mathrm{C}$ NMR $\left(100 \mathrm{MHz}, \mathrm{DMSO}-d_{6}\right) \delta 166.09,162.78$, 151.92 , 149.75, 147.84, 147.15, 146.82, 142.47, 136.58, 131.96, 130.84, 121.16, 123.01, 122.72, 121.25, 119.17, 119.03, $116.51,111.71,108.80,105.27,102.35,66.49,66.41,56.61,46.35,45.25,42.45,40.62,40.41,40.21,40.00,39.79,39.58$, 39.37, 36.25, 31.24, 27.34 ppm; HRMS (ESI): calculated for $\mathrm{C}_{32} \mathrm{H}_{29} \mathrm{ClN}_{4} \mathrm{O}_{6}[\mathrm{M}-\mathrm{Cl}]^{+}$, 565.2082, found, 565.2072.

12-(1-(2-(Diethylamino)-2-oxoethyl)-1H-benzoimidazol-2-yl)-9-hydroxy-10-methoxy-5,6-dihydro-[1,3]dioxolo[4,5g] isoquinolino[3,2-a]isoquinolin-7-ium chloride (9a). Compound 9a was prepared by cyclization reaction of intermediate $2(250 \mathrm{mg}, 0.65 \mathrm{mmol}), 16 \mathrm{a}(190 \mathrm{mg}, 1.30 \mathrm{mmol})$ and sodium pyrosulfite $(247 \mathrm{mg}, 1.30 \mathrm{mmol})$ according to the same procedure described for 3a. A pure yellow solid was obtained $(257 \mathrm{mg}, 67.5 \%)$. Mp: $>250{ }^{\circ} \mathrm{C} ;{ }^{1} \mathrm{H} \mathrm{NMR}(600 \mathrm{MHz}$, $\left.\mathrm{CD}_{3} \mathrm{OD}-d_{4}\right) \delta 10.01(\mathrm{~s}, 1 \mathrm{H}, \mathrm{BBR}-8-H), 8.34$ (s, 1H, BBR-13-H), 8.29 (s, 1H, BBR-11-H), 7.96 (d, $\left.J=8.9 \mathrm{~Hz}, 1 \mathrm{H}, \mathrm{Bim}-4-H\right)$, 7.80 (d, $J=8.9$ Hz, 1H, Bim-7-H), $7.73-7.68$ (m, 2H, Bim-5-H, Bim-6-H), 7.57 (s, 1H, BBR-1-H), 6.90 (s, 1H, BBR-4-H), 
$6.02\left(\mathrm{~s}, 2 \mathrm{H}, \mathrm{OCH}_{2} \mathrm{O}\right), 5.45$ (s, 2H, CH$\left.H_{2}\right), 4.92\left(\mathrm{~s}, 2 \mathrm{H}, \mathrm{BBR}-6-2 \mathrm{H}, \mathrm{CD}_{3} \mathrm{OD}-\mathrm{H}_{2} \mathrm{O}\right), 4.11\left(\mathrm{~s}, 3 \mathrm{H}, \mathrm{OCH}_{3}\right), 3.44-3.37(\mathrm{~m}, 2 \mathrm{H}$, $\left.\mathrm{CON}\left(\mathrm{CH}_{2} \mathrm{CH}_{3}\right)_{2}\right), 3.22(\mathrm{t}, J=6.9 \mathrm{~Hz}, 2 \mathrm{H}, \mathrm{BBR}-5-2 \mathrm{H}), 1.32\left(\mathrm{t}, J=7.3 \mathrm{~Hz}, 2 \mathrm{H}, \mathrm{CON}\left(\mathrm{CH}_{2} \mathrm{CH}_{3}\right)_{2}\right), 1.15-1.10(\mathrm{~m}, 3 \mathrm{H}$, $\left.\mathrm{CON}\left(\mathrm{CH}_{2} \mathrm{CH}_{3}\right)_{2}\right), 0.98\left(\mathrm{dd}, J=6.1,3.7 \mathrm{~Hz}, 3 \mathrm{H}, \mathrm{CON}\left(\mathrm{CH}_{2} \mathrm{CH}_{3}\right)_{2}\right) \mathrm{ppm} ;{ }^{13} \mathrm{C}$ NMR $\left(150 \mathrm{MHz}, \mathrm{CD}_{3} \mathrm{OD}-d_{4}\right) \delta 164.53(\mathrm{C}=\mathrm{O})$, $151.06,149.68,148.41,148.11,146.72,145.13,139.25,133.83,132.66,131.93,131.03,127.57,126.58,126.47,120.12$, 117.83, 116.72, 115.05, 112.70, 109.35, 107.93, 105.98, 102.28, 56.81, 55.85, 41.36, 40.70, 26.76, 13.01, 11.68, 7.88 ppm; HRMS (ESI): calculated for $\mathrm{C}_{32} \mathrm{H}_{31} \mathrm{ClN}_{4} \mathrm{O}_{5}[\mathrm{M}-\mathrm{Cl}]^{+}, 551.2289$, found, 551.2282.

12-(1-(2-(Diisopropylamino)-2-oxoethyl)-1H-benzoimidazol-2-yl)-9-hydroxy-10-methoxy-5,6-dihydro-[1,3]dioxolo [4,5-g] isoquinolino[3,2-a]isoquinolin-7-ium chloride (9b). Compound 9b was prepared by cyclization reaction of intermediate $2(250 \mathrm{mg}, 0.65 \mathrm{mmol}), \mathbf{1 6 b}(324 \mathrm{mg}, 1.30 \mathrm{mmol})$ and sodium pyrosulfite $(247 \mathrm{mg}, 1.30 \mathrm{mmol})$ according to the same procedure described for 3a. A pure yellow solid was obtained $(246 \mathrm{mg}, 61.5 \%)$. Mp: $>250{ }^{\circ} \mathrm{C} ;{ }^{1} \mathrm{H} \mathrm{NMR}(400 \mathrm{MHz}$, $\left.\mathrm{CD}_{3} \mathrm{OD}-d_{4}\right) \delta 10.06(\mathrm{~s}, 1 \mathrm{H}, \mathrm{BBR}-8-H), 8.45$ (s, 1H, BBR-13-H), 8.30 (s, 1H, BBR-11- $H$ ), 8.01 (d, $\left.J=9.2 \mathrm{~Hz}, 1 \mathrm{H}, \mathrm{Bim}-4-H\right)$, 7.87 (d, $J=9.4$ Hz, 1H, Bim-7-H), $7.82-7.76$ (m, 2H, Bim-5-H, Bim-6-H), 7.62 (s, 1H, BBR-1-H), 6.93 (s, 1H, BBR-4- $H$ ), $6.03\left(\mathrm{~s}, 2 \mathrm{H}, \mathrm{OCH}_{2} \mathrm{O}\right), 5.50\left(\mathrm{~s}, 2 \mathrm{H}, \mathrm{CH}_{2}\right), 4.95\left(\mathrm{bs}, 2 \mathrm{H}, \mathrm{BBR}-6-2 \mathrm{H}, \mathrm{CD}_{3} \mathrm{OD}-\mathrm{H}_{2} \mathrm{O}\right), 4.14\left(\mathrm{~s}, 3 \mathrm{H}, \mathrm{OCH}_{3}\right), 4.05-3.97(\mathrm{~m}, 1 \mathrm{H}$, $\left.\mathrm{CON}\left(\mathrm{CH}\left(\mathrm{CH}_{3}\right)_{2}\right)_{2}\right), 3.56-3.47\left(\mathrm{~m}, 1 \mathrm{H}, \mathrm{CON}\left(\mathrm{CH}\left(\mathrm{CH}_{3}\right)_{2}\right)_{2}\right), 3.25$ (bs, 2H, BBR-5-2H), 1.09 (d, $J=79.6 \mathrm{~Hz}, 12 \mathrm{H}$, $\left.\mathrm{CON}\left(\mathrm{CH}\left(\mathrm{CH}_{3}\right)_{2}\right)_{2}\right) \mathrm{ppm} ;{ }^{13} \mathrm{C} \mathrm{NMR}\left(100 \mathrm{MHz}, \mathrm{CD}_{3} \mathrm{OD}-d_{4}\right) \delta 163.21,151.17,149.92,148.47,147.77,146.86,145.10,139.47$, 133.43, 132.02, 131.06, 130.94, 127.84, 127.29, 127.01, 120.08, 117.77, 116.68, 114.45, 112.97, 108.29, 107.90, 106.12, 102.30, 56.88, 55.89, 26.76, 19.46, 19.16 ppm. HRMS (ESI): calculated for $\mathrm{C}_{34} \mathrm{H}_{35} \mathrm{ClN}_{4} \mathrm{O}_{5}[\mathrm{M}-\mathrm{Cl}]^{+}, 579.2602$, found, 579.2599 .

12-(1-(2-(Tert-butoxy)-2-oxoethyl)-1H-benzoimidazol-2-yl)-9-hydroxy-10-methoxy-5,6-dihydro-[1,3]dioxolo[4,5-g]i soquinolino [3,2-a]isoquinolin-7-ium chloride (10). Compound 10 was prepared by cyclization reaction of intermediate 2 (250 mg, $0.65 \mathrm{mmol}), 17(289 \mathrm{mg}, 1.30 \mathrm{mmol})$ and sodium pyrosulfite $(247 \mathrm{mg}, 1.30 \mathrm{mmol})$ according to the same procedure described for 3a. A pure yellow solid was obtained (332 mg, 86.8\%). Mp: $220-222{ }^{\circ} \mathrm{C}$; ${ }^{1} \mathrm{H}$ NMR $(600 \mathrm{MHz}$, $\left.\mathrm{CD}_{3} \mathrm{OD}-d_{4}\right) \delta 10.07(\mathrm{~s}, 1 \mathrm{H}, \mathrm{BBR}-8-H), 8.41(\mathrm{~s}, 1 \mathrm{H}, \mathrm{BBR}-13-H), 8.23(\mathrm{~s}, 1 \mathrm{H}, \mathrm{BBR}-11-H), 7.99(\mathrm{~d}, J=24.0 \mathrm{~Hz}, 1 \mathrm{H}$, Bim-4-H), 7.91 (d, $J=1.7$ Hz, 1H, Bim-7-H), $7.82-7.75$ (m, 2H, Bim-5-H, Bim-6- H), 7.54 (s, 1H, BBR-1-H), 6.94 (s, 1H, BBR-4-H), 5.28 (s, 2H, CH$\left.H_{2}\right), 4.95$ (bs, 2H, BBR-6-2H), 4.14 (s, 3H, OCH $), 3.26$ (bs, 2H, BBR-5-2H), $1.35\left(\mathrm{~s}, 9 \mathrm{H}, \mathrm{C}\left(\mathrm{CH}_{3}\right)_{3}\right)$ ppm; ${ }^{13} \mathrm{C}$ NMR $\left(150 \mathrm{MHz}, \mathrm{CD}_{3} \mathrm{OD}-d_{4}\right) \delta 166.09\left(\mathrm{CO}_{2}\right), 151.22,150.02,148.47,147.80,147.00,145.20,139.56,133.21$, 131.95, 131.14, 127.91, 127.20, 126.98, 120.02, 117.81, 116.26, 114.93, 112.77, 112.60 - 112.49 , 108.47, 107.94, 105.88, 102.32, 84.51, 56.81, 55.89, 48.46, 46.64, 26.69 ppm. HRMS (ESI): calculated for $\mathrm{C}_{32} \mathrm{H}_{30} \mathrm{ClN}_{3} \mathrm{O}_{6}[\mathrm{M}-\mathrm{Cl}]^{+}, 552.2129$, found, 552.2119 .

Synthesis of monosubstituted o-phenylenediamines (11-17). Monosubstituted $o$-phenylenediamines 11-17 were synthesized following the procedures described in the literature. ${ }^{20}$

\subsection{Antibacterial activity assay}

The microorganism strains (MRSA N315, S. aureus, S. aureus ATCC 29213, P. aeruginosa, A. baumannii, K. pneumonia, E. coli) were cultured in Muller-Hinton broth and Mueller-Hinton agar. The pre-cultured bacterial cells were transferred to $20 \mathrm{~mL}$ Brain-heart infusion broth in $150 \mathrm{~mL}$ flasks, and the cells were cultivated to exponential phase at $37^{\circ} \mathrm{C}$ at $180 \mathrm{rpm}$. They are used as indicator strains for subsequent tests for the inhibitory activity of new compounds and reference 
drugs (berberine and norfloxacin).

The MIC values of intermediate 2, berebrine-derived benzimidazoles 3-10 and positive controls (berberine and norfloxacin) were determined by using the broth microdilution method for microdilution plates following the guidelines from Clinical and Laboratory Standard Institute (CLSI). The MIC was defined as the lowest concentration at which no growth is observed. Microorganism was cultured for $4-6 \mathrm{~h}$ to give $10^{8} \mathrm{CFU} / \mathrm{mL}$ of bacteria. The bacterial cultures were then diluted to afford about $10^{6} \mathrm{CFU} / \mathrm{mL}$ in Muller-Hinton broth media which were then used for determining antibacterial efficacy. Stock solutions of the final compounds and clinical drugs were prepared with sterile Milli-Q water and Muller-Hinton broth media to different concentrations of $256,128,64,32,16,8,4,2,1,0.5,0.25 \mu \mathrm{g} / \mathrm{mL}$. These dilutions $(100 \mu \mathrm{L})$ were added to the wells of 96 well plate followed by the addition of $100 \mu \mathrm{L}$ of bacterial suspension $\left(10^{6} \mathrm{CFU} / \mathrm{mL}\right)$. The plates were then incubated at $37^{\circ} \mathrm{C}$ for $16-20 \mathrm{~h}$. After the incubation, read MIC values.

\subsection{Biofilm disruption evaluation}

The bacteria $S$. aureus ATCC 29213 ( $4-6$ h grown, mid-log phase) were diluted to $\sim 10^{5} \mathrm{CFU} / \mathrm{mL}$ into suitable media. The 96-well plates containing these suspensions $(100 \mu \mathrm{L})$ were incubated under stationary conditions for about $24 \mathrm{~h}$. After incubation, the bacteria suspensions were centrifuged at $3500 \mathrm{rpm}$ for $5 \mathrm{~min}$, the medium was removed and the wells were washed with $1 \times$ PBS once. Compound $7 \mathbf{d}(100 \mu \mathrm{L}$ at 2, 4, 8, 16, 32, 64, and $128 \mathrm{mg} / \mathrm{mL})$ was then added to the wells containing preformed bacterial biofilms and allowed to incubate for $24 \mathrm{~h}$ at $37{ }^{\circ} \mathrm{C}$. A control was made where the above medium $(100 \mu \mathrm{L})$ was added. After $24 \mathrm{~h}$, medium was discarded and the planktonic cells were removed by washing with $1 \times$ PBS. Cell suspension was then assessed by plating the 10-fold serial dilutions of the suspension on suitable agar plates. After $24 \mathrm{~h}$ of incubation, bacterial colonies were counted and cell viability was expressed as $\log 10$ (CFU/well) along with the control. For visualizing the disruption of biofilm by the small molecules, Crystal Violet (CV) staining was done as described previously except that the cells were grown in 24-well plates. The 24 -well plates containing $1.5 \mathrm{~mL} / \mathrm{well}$ of these suspensions were incubated at $37{ }^{\circ} \mathrm{C}$ for about $72 \mathrm{~h}$. Wells were stained with $300 \mathrm{~mL}$ of $1.0 \%$ crystal violet dye, rinsed twice with $2 \mathrm{~mL}$ deionized water and thoroughly dried. For quantification, $0.5 \mathrm{~mL}$ of $95 \%$ ethanol was added to each well. Plates were incubated for $1 \mathrm{~h}$ at room temperature with shaking. Then take photos for these wells.

\subsection{Bactericidal activity evaluation}

An overnight culture of S. aureus ATCC 29213 was diluted 1 : 10,000 in Muller-Hinton broth medium and incubated at $37{ }^{\circ} \mathrm{C}$ with aeration at $225 \mathrm{rpm}$ for $2 \mathrm{~h}$ (early exponential) or $5 \mathrm{~h}$ (late exponential). Bacteria were then challenged with compound 7d at $6 \times \mathrm{MIC}$ and $8 \times \mathrm{MIC}$ in culture tubes at $37^{\circ} \mathrm{C}$ and $225 \mathrm{rpm}$. At different intervals, bacteria solution $(100 \mu \mathrm{L})$ were removed to 96 -well plate, centrifuged at $4000 \mathrm{rpm}$ for $3 \mathrm{~min}$ and re-suspended in of sterile phosphate buffered saline (PBS, $100 \mu \mathrm{L}$ ). Ten-fold serially diluted suspensions were plated on Muller-Hinton agar plates and incubated at $37^{\circ} \mathrm{C}$ overnight. Colonies were counted and CFU per mL was calculated.

\subsection{Cytotoxicity evaluation}

MTT assay was conducted to evaluate the cytotoxicity of active compound 7d against human embryonic kidney (Hek) 
293 T and human fibroblast (HFC) normal cells. The cells $\left(1 \times 10^{4}\right)$ were inoculated in 96-well plate containing Dulbecco's modified Eagle's medium (DMEM) supplemented with 10\% fetal bovine serum and incubated overnight in a humidified chamber at $37{ }^{\circ} \mathrm{C}$ and $5 \% \mathrm{CO}_{2}$. Different concentrations of compound $7 \mathbf{d}$ ranging from 0.01 to $0.05 \mathrm{mM}$ were added and incubated further for $24 \mathrm{~h}$ at $37{ }^{\circ} \mathrm{C}$. MTT $(5 \mu \mathrm{g} / \mathrm{mL})$ dye was added and incubated for $4 \mathrm{~h}$. DMSO $(100 \mu \mathrm{L})$ was added to dissolve the formazan crystals and the absorbance at $570 \mathrm{~nm}$ was measured.

Fresh blood $(10 \mathrm{~mL})$ was centrifuged at $4000 \mathrm{r} / \mathrm{min}$ for $10 \mathrm{~min}$, and discarded the supernatant. The red blood cells (RBCs) were laved 3 times with physiological saline until the supernatant did not show red. The obtained RBCs were made into $2.0 \%$ suspension with physiological saline and then treated with $\mathbf{7 d}(0.5,1,2,4,8,16,32,64,128,256$ and $512 \mu \mathrm{g} / \mathrm{mL})$, then cultivated in a constant temperature water bath at $37^{\circ} \mathrm{C}$ for $60 \mathrm{~min}$. The absorbed values of the supernatant were measured at $540 \mathrm{~nm}$ with a microplate reader. The physiological saline was used as the negative group, and the sterile distilled water was used as the positive group. Each group was set with 3 parallel groups.

\subsection{Drug combination}

The drug combination studies between the most active compound $\mathbf{7 d}$ and standard drugs norfloxacin were investigated by a 2 -fold dilution checkerboard assay method with concentration values from 1/64 to 4-fold the MIC value of each molecule. The drug combination effect is usually expressed using the fractional inhibitory concentration (FIC) index. The FIC value may be calculated as FIC $=$ MIC of molecule A in mixture/MIC of molecule A alone + MIC of molecule B in mixture/MIC of molecule $\mathrm{B}$ alone. Using this method, FIC $\leq 0.5$ represents synergism, FIC $>0.5$ and $\leq 1.0$ represents additivism, FIC $>1$ and $\leq 2$ represents an indifferent effect, and FIC $>2$ represents antagonism.

\subsection{Propensity to develop bacterial resistance}

The representative compound 7d was selected to investigate the developing rate of bacterial resistance. We exposed a standard strain of resistant S. aureus ATCC 29213 toward increasing concentrations of compound 7d from sub-MIC $(0.5 \times$ MIC, MIC is the minimal inhibitory concentration) for sustained passages and determined the new MIC values of compound 7d for each passage of S. aureus ATCC 29213. The initial MIC values of compound 4d, norfloxacin, combination use were determined against S. aureus ATCC 29213 as mentioned above in antibacterial assay. For the next MIC experiment, the bacterial dilution was prepared by using the bacteria from sub-MIC concentration of the compound $(0.5 \times \mathrm{MIC})$. After a $12 \mathrm{~h}$ incubation period, again bacterial dilution was prepared by using the bacterial suspension from sub-MIC concentration of the compound $(0.5 \times$ MIC) and assayed for the next MIC experiment. The process was repeated for 15 passages. The MIC values for compound 7d, norfloxacin and combination use against each passage of $S$. aureus ATCC 29213 were determined.

\subsection{Membrane depolarization assay}

S. aureus TCC 29213 cells in mid log phase $\left(\mathrm{OD}_{600}=0.4-0.5\right)$ were washed with a buffer solution (5 mM HEPES buffer, $5 \mathrm{mM}$ glucose, $\mathrm{pH}$ 7.2) and re-dispersed in the same buffer to an $\mathrm{OD}_{600}$ of 0.1 . The re-dispersed cells were then incubated with of 3,3'-dipropylthiadicarbocyanine iodide (diSC35) dye $(0.4 \mu \mathrm{M}, 50 \mu \mathrm{L})$ for $1 \mathrm{~h}$ at $37^{\circ} \mathrm{C}$ in a 96 -well plate, following which $\mathrm{KCl}(100 \mathrm{mM})$ was added to the suspensions. After incubation with dye, S. aureus ATCC 29213cells were 
treated with compound $\mathbf{7 d}$ at the respective MIC concentrations, and the fluorescence of the treated cells was monitored periodically over a period of $1 \mathrm{~h}$ in a F-7000 spectrofluorometer set to an excitation wavelength of $622 \mathrm{~nm}$ and emission wavelength of $670 \mathrm{~nm}$. Increase in fluorescence with time indicates membrane depolarization.

\subsection{Inner membrane permeabilization assay}

The 4-6 h grown bacteria (mid-log phase) were harvested (3500 rpm, $5 \mathrm{~min}$ ), washed and resuspended with $1 \times$ PBS. Then bacterial suspension $\left(\sim 10^{8} \mathrm{CFU} / \mathrm{mL}, 150 \mu \mathrm{L}\right)$ was transferred into the wells of a black $96-$ well plate. Then PI dye (10 $\mathrm{mM}, 50 \mu \mathrm{L}$ ) was added to the wells containing bacterial suspension and pre-incubated for about $30 \mathrm{~min}$ for $S$. aureus ATCC 29213. After the incubation, fluorescence was monitored for next $2 \mathrm{~h}$ at every $5 \mathrm{~min}$ interval at an excitation wavelength of $350 \mathrm{~nm}$ (slit width: $10 \mathrm{~nm}$ ) and emission wavelength of $420 \mathrm{~nm}$ (slit width: $5 \mathrm{~nm}$ ). Then, the bacterial suspensions were transferred to another black well-plate containing $10 \mu \mathrm{L}$ compound $\mathbf{7 d}$ in different concentrations and fluorescence intensity was monitored immediately for another $2 \mathrm{~h}$ at every $5 \mathrm{~h}$ interval, A control experiment was performed by treating the pre-incubated bacterial suspension and dye solution only with sterile Milli-Q water $(50 \mu \mathrm{L})$.

\subsection{Supramolecular interactions between active molecule 7d and Calf Thymus DNA}

UV spectra were recorded at room temperature on a TU-2450 spectrophotometer (Puxi Analytic Instrument Ltd. of Beijing, China) equipped with $1.0 \mathrm{~cm}$ quartz cells. The stock solution of compound 7d was prepared in DMSO. Tris, $\mathrm{NaCl}$, and $\mathrm{HCl}$ were analytical purity. Sample masses were weighed on a microbalance with a resolution of $0.1 \mathrm{mg}$. All other chemicals and solvents were commercially available, and used without further purification. Calf thymus DNA was used without further purification, and its stock solution was prepared by dissolving an appropriate amount of DNA in doubly distilled water. The solution was allowed to stand overnight and store at $4{ }^{\circ} \mathrm{C}$ in the dark for about a week. The concentration of DNA in stock solution was determined by UV absorption at $260 \mathrm{~nm}$ using a molar absorption coefficient $\xi_{260}=6600 \mathrm{~L}$ $\mathrm{mol}^{-1} \mathrm{~cm}^{-1}$ (expressed as molarity of phosphate groups) by Bouguer-Lambert-Beer law. The purity of DNA was checked by monitoring the ratio of the absorbance at $260 \mathrm{~nm}$ to that at $280 \mathrm{~nm}$. The solution gave a ratio of $>1.8$ at $\mathrm{A}_{260} / \mathrm{A}_{280}$, which indicated that DNA was sufficiently free from protein.

Fluorescence quenching experiments were further performed to explore the target mode of compound 7d toward DNA. As the concentration of compound $\mathbf{7 d}$ increased, the DNA-AO complex fluorescence intensity was significantly quenched, however, there was no blue or red shift occurred. Meanwhile, the fluorescence quenching data could be computed using the well-known Stern-Volmer equation (1):

$$
\frac{E_{0}}{F}=1+K_{q} \tau_{0}[\mathrm{Q}]=1+K_{s v}[\mathrm{Q}]
$$

$F_{0}$ and $F$ were denoted as DNA-AO complex fluorescence intensity with and without compound 7d, respectively; [Q] was the addition of compound $\mathbf{7 d} ; K_{\mathrm{sv}}$ was the Stern-Volmer quenching constant that implies the difficulty of large volume quencher to approach DNA chromophore; $K_{\mathrm{q}}$ denotes the quenching rate constant of DNA-AO complex; $\tau_{0}$ is the average life span of DNA-AO system in the absence of compound $7 \mathbf{d}$ ranges from $10^{-9}$ to $10^{-7} \mathrm{~s}$. The $K_{\mathrm{sv}}$ value was calculated according 
to the linear regression of $\mathrm{F}_{0} / \mathrm{F}$ and $[\mathrm{Q}]$ (Figure S5C). The calculated values of $K_{\mathrm{sv}}$ and $K_{\mathrm{q}}$ were $1.40 \times 10^{4} \mathrm{~L} \cdot \mathrm{mol}^{-1}$ and 1.40

$\times 10^{13} \mathrm{~L} \cdot \mathrm{mol}^{-1} \cdot \mathrm{S}^{-1}$, which was larger than the maximum diffusion collision quenching constants of various quenchers to fluorescent molecules $2.0 \times 10^{10} \mathrm{~L} \cdot \mathrm{mol}^{-1} \cdot \mathrm{S}^{-1}$, indicating compound $7 \mathbf{d}$ could quench DNA-AO via static quenching mechanism.

\subsection{Determination of intracellular ROS}

The bacterial cells were grown in Muller-Hinton broth at $37{ }^{\circ} \mathrm{C}$ to exponential phase and then diluted the final concentration to $10^{6} \mathrm{CFU} \mathrm{mL} \mathrm{mL}^{-1}$. The Muller-Hinton broth containing bacterial both suspension and compound 7d with the final concentrations of $0.1 \mathrm{mM}$ was added to each flask to co-incubate for $2 \mathrm{~h}$. The bacteria cells were then harvested by centrifugation $\left(6000 \mathrm{~g}, 4^{\circ} \mathrm{C}\right)$ for 5 mins and resuspended with an equal volume of PBS $(\mathrm{pH}=7.2,0.1 \mathrm{M})$. To detect the overall ROS levels, 2',7'-dichlorodihydrofluorescein diacetate (DCFH-DA, $10 \mu \mathrm{L}$ ) with the final concentrations of $10 \mu \mathrm{M}$ was added to the above suspension. After co-incubation for $30 \mathrm{~min}$, the bacteria cells were washed three times to remove the extra fluorescence probe. Fluorescence intensity was detected at an excitation wavelength of $484 \mathrm{~nm}$ and an emission wavelength of $525 \mathrm{~nm}$.

\subsection{Intracellular glutathione oxidation activity}

The activity of intracellular GSH was determined using standard Ellman's assay. Then $10^{6} \mathrm{CFU} / \mathrm{mL}$ of $S$. aureus ATCC 29213 cells were treated with increasing concentrations of compound $7 \mathbf{d}$ for $6 \mathrm{~h}$ at $37^{\circ} \mathrm{C}$ and $200 \mathrm{rpm}$. Following treatment, both control and treated cells were centrifuged at $5000 \mathrm{rpm}$ for $5 \mathrm{~min}$, washed with PBS, and lysed. The lysed cells were further centrifuged, and the clear supernatant was collected. The supernatant was mixed with $50 \mathrm{mM}$ Tris- $\mathrm{HCl}$ and $100 \mathrm{mM}$ 5,5-dithiobis (2-nitrobenzoic acid) (DTNB) and incubated for $30 \mathrm{~min}$ in dark at $37^{\circ} \mathrm{C}$. The absorbance of the resulting solution was measured at $412 \mathrm{~nm}$ using a UV-visible spectrometer. The percentage loss of glutathione was calculated as

$$
\left(1-\frac{O D 412 \text { nm of treated }}{O D 412 \text { nm of control }}\right) \times 100
$$

\section{NMR and HRMS spectra of some representative compounds}

3.1 Spectra of compound $\mathbf{4 a}$

${ }^{1} \mathrm{H}$ NMR spectrum 


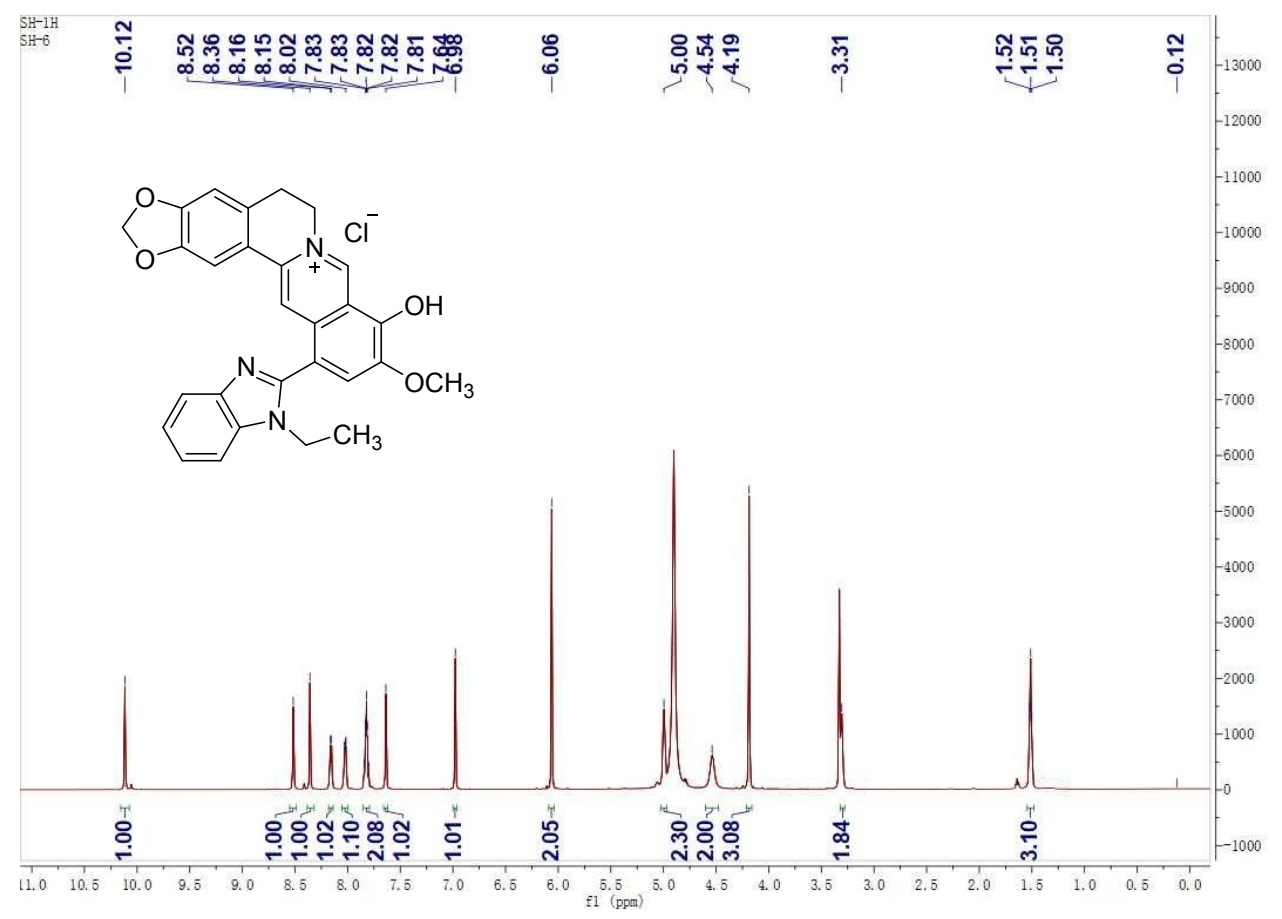

${ }^{13} \mathrm{C}$ NMR spectrum

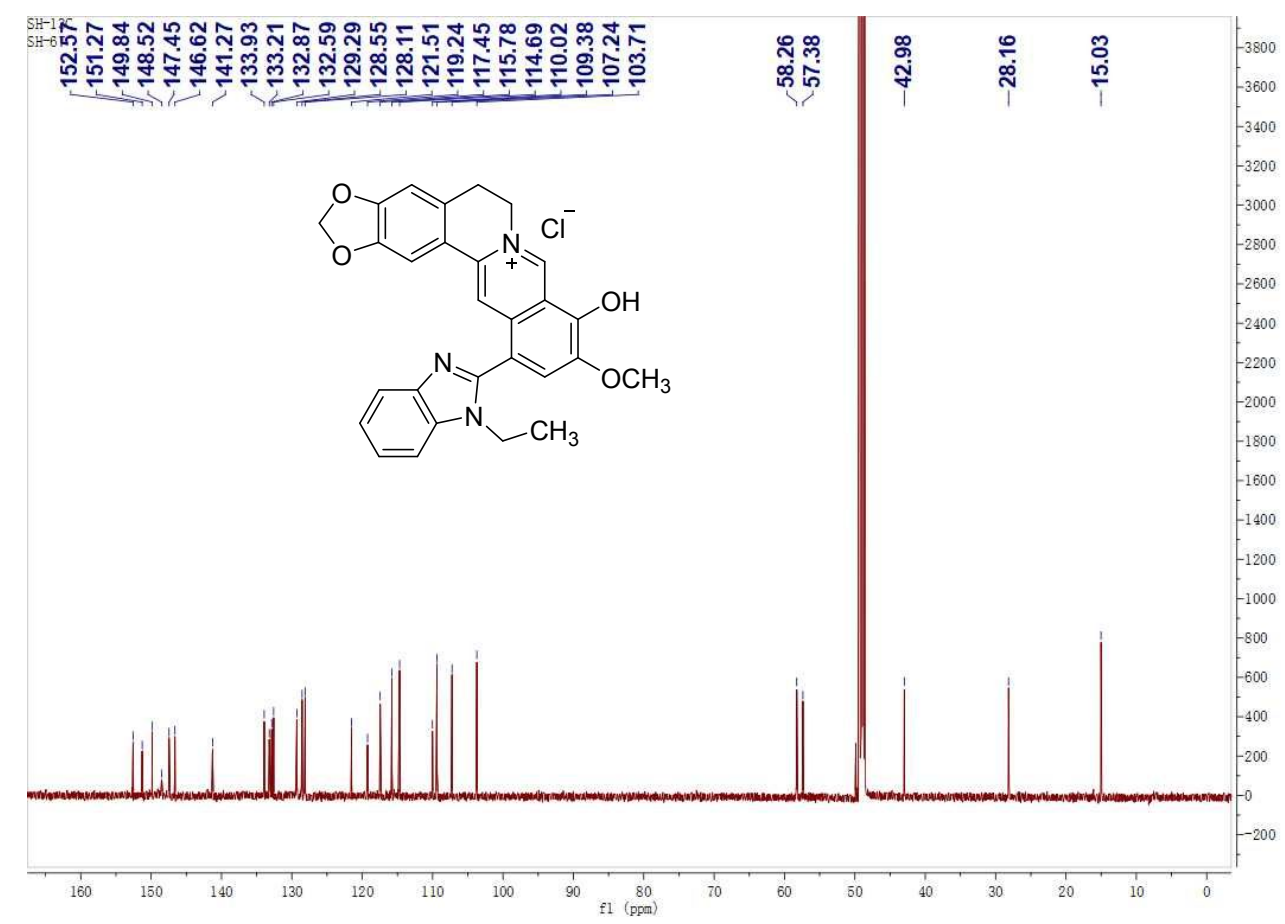

HRMS spectrum

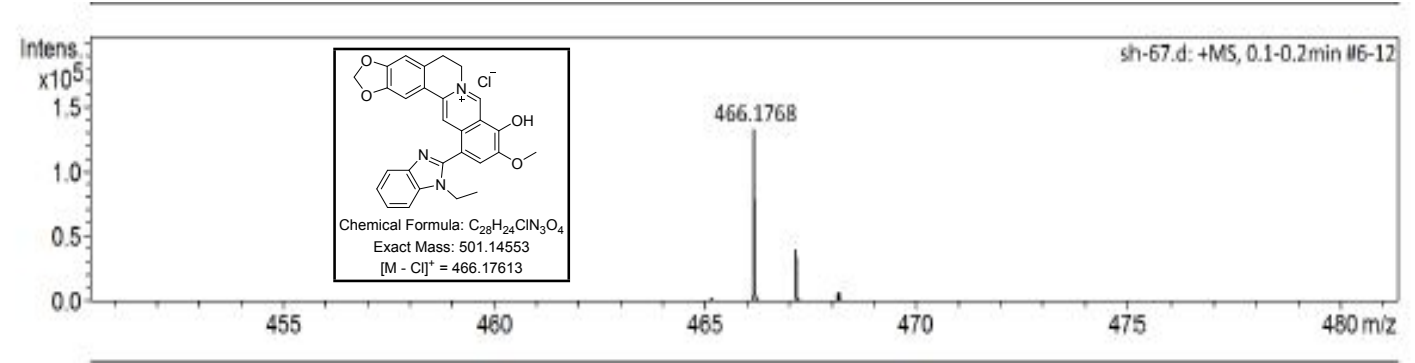


3.2 Spectra of compound 5a

${ }^{1} \mathrm{H}$ NMR spectrum

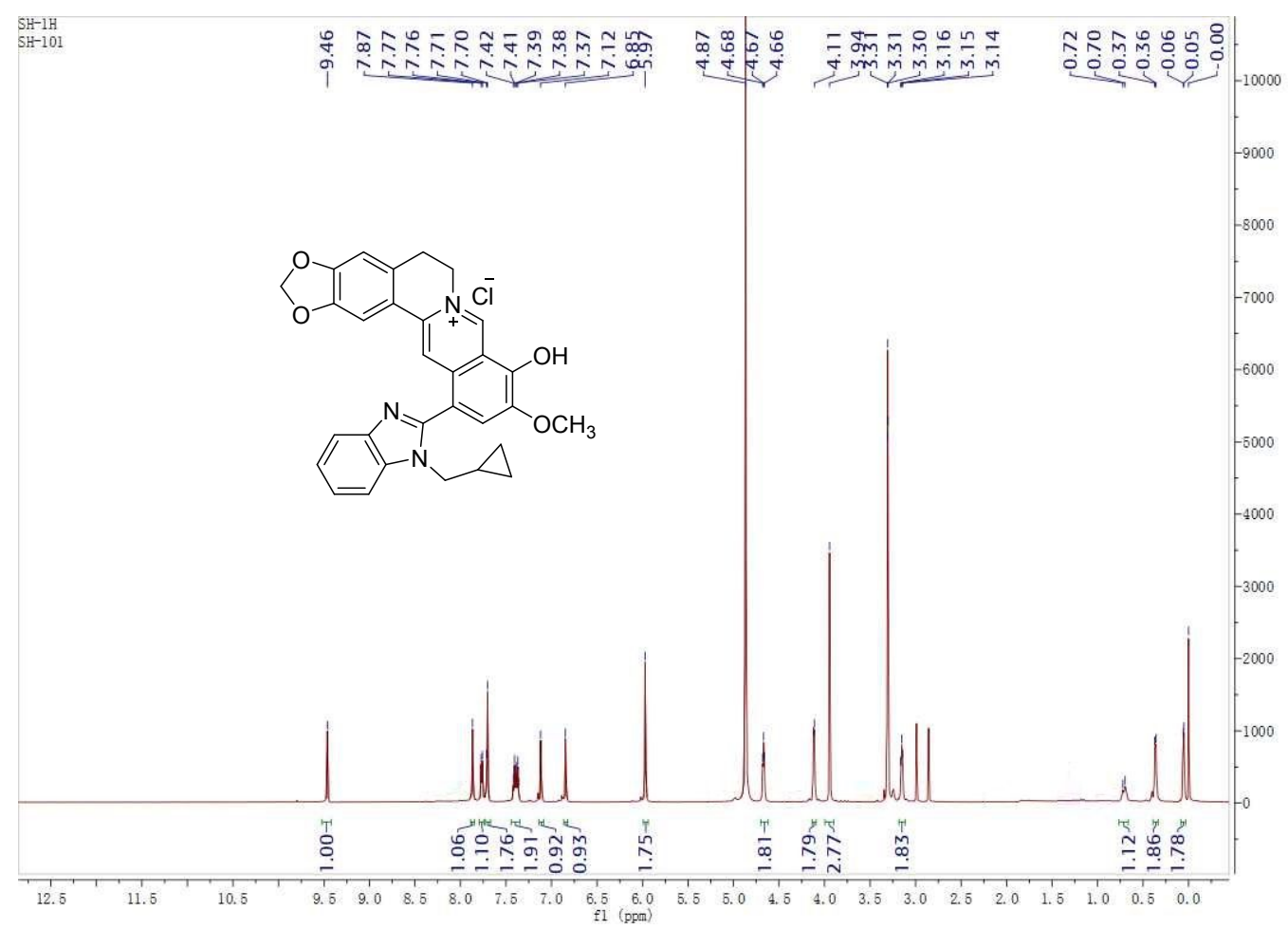

${ }^{13} \mathrm{C}$ NMR spectrum

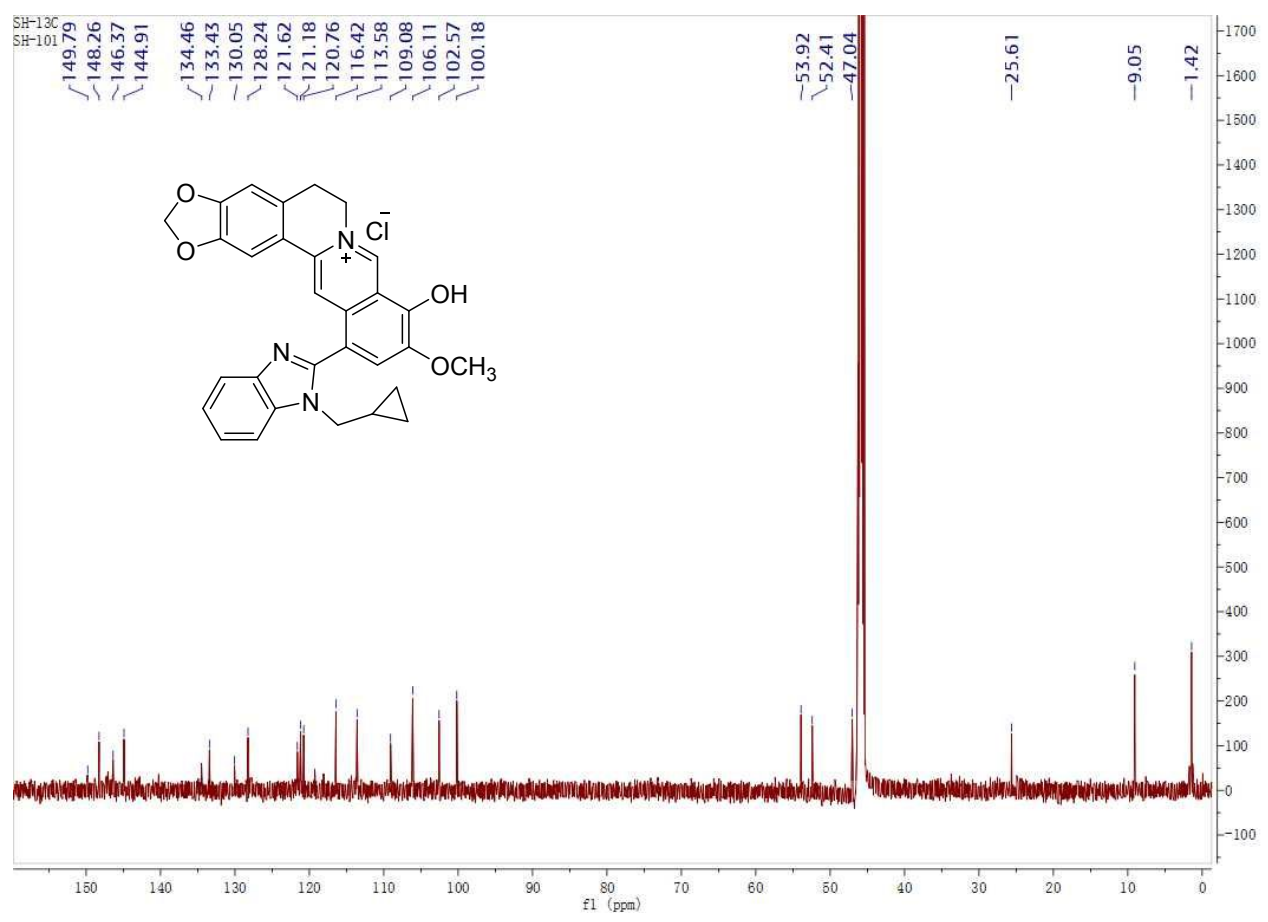

HRMS spectrum 


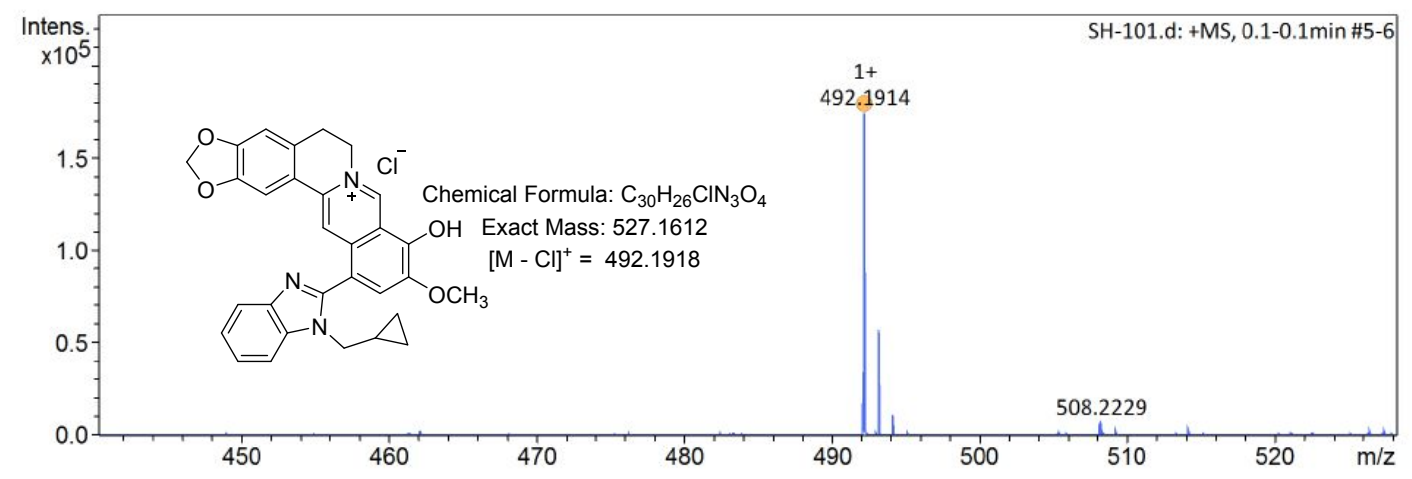

3.3 Spectra of compound $\mathbf{5 b}$

${ }^{1} \mathrm{H}$ NMR spectrum

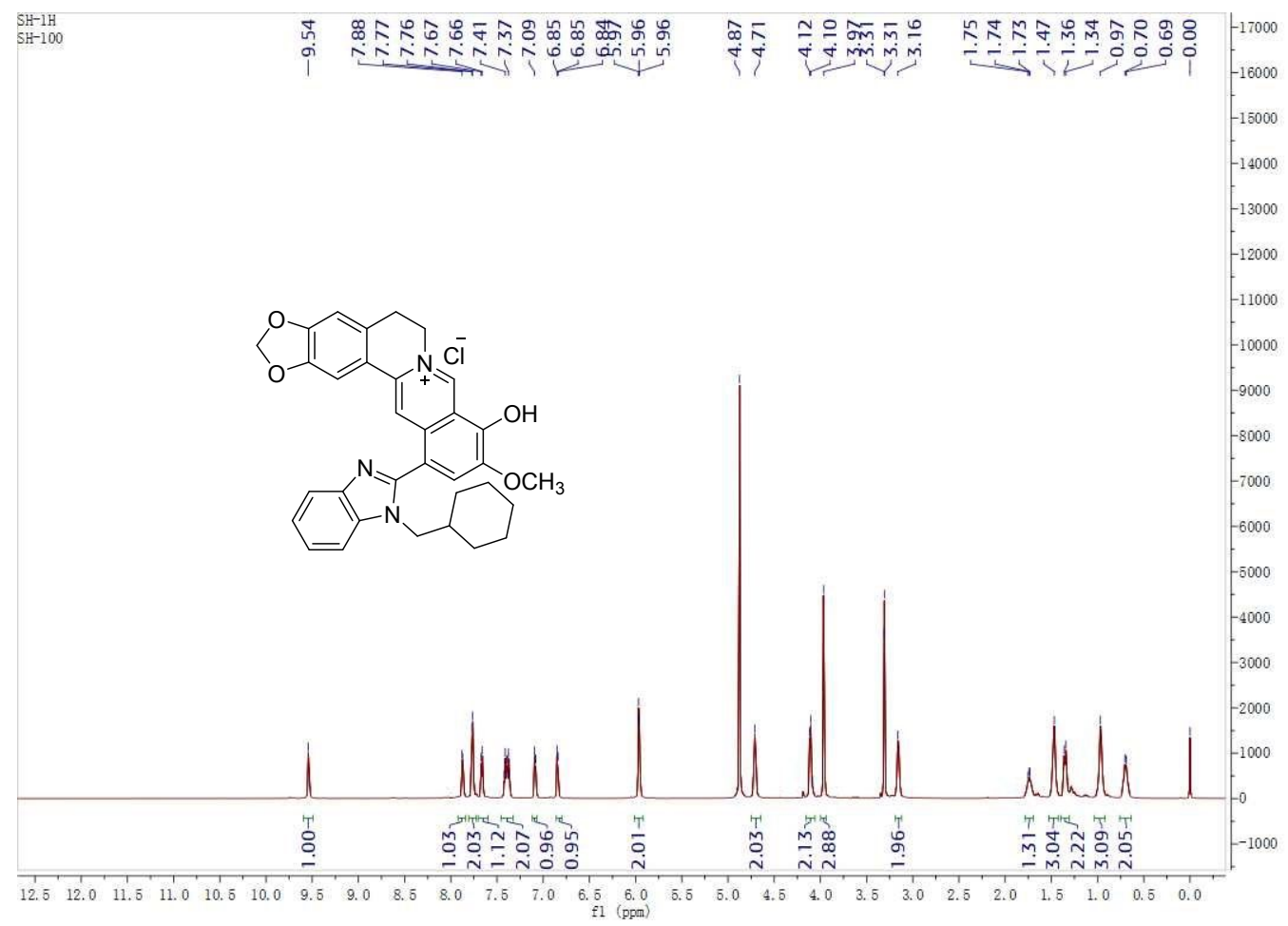

${ }^{13} \mathrm{C}$ NMR spectrum 


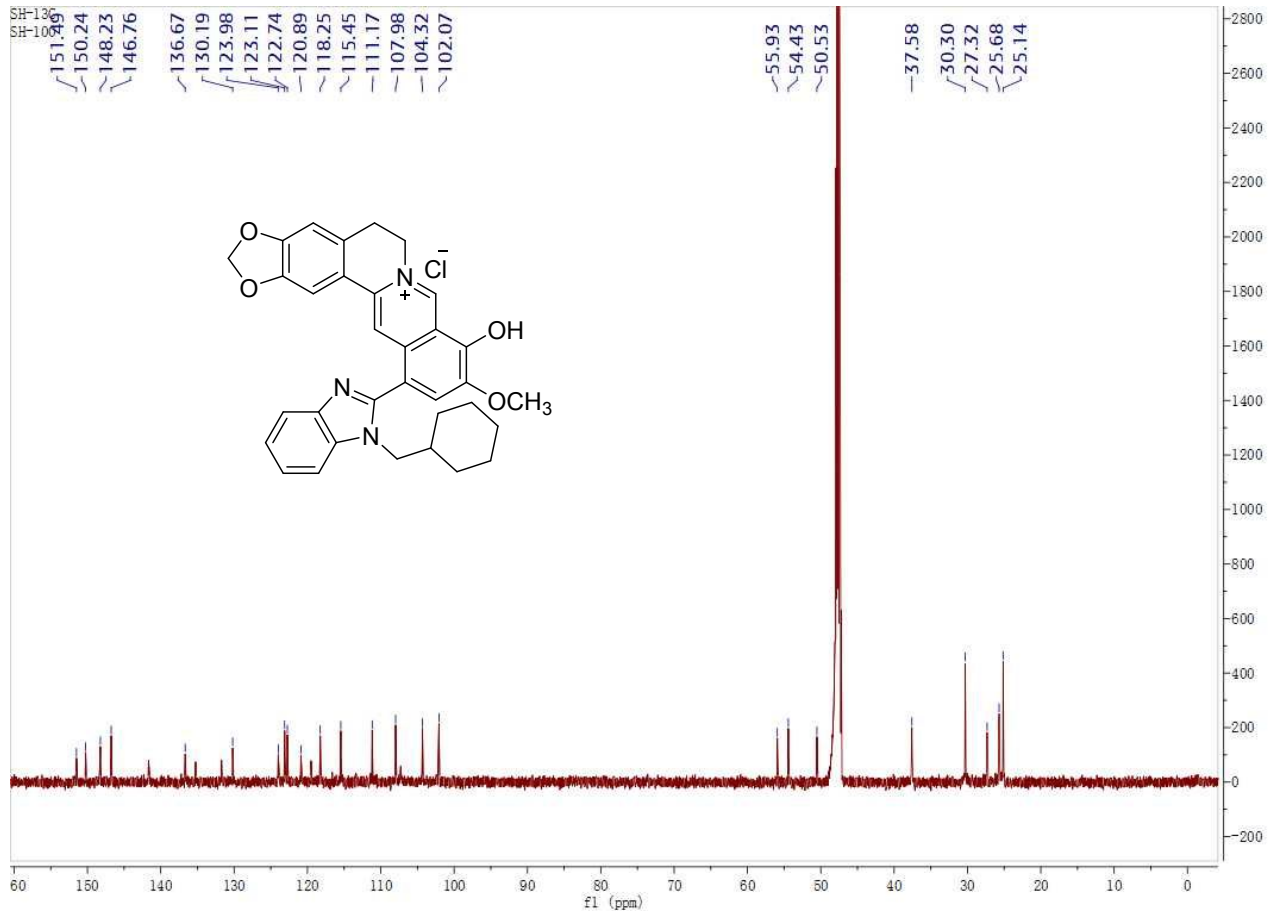

HRMS spectrum

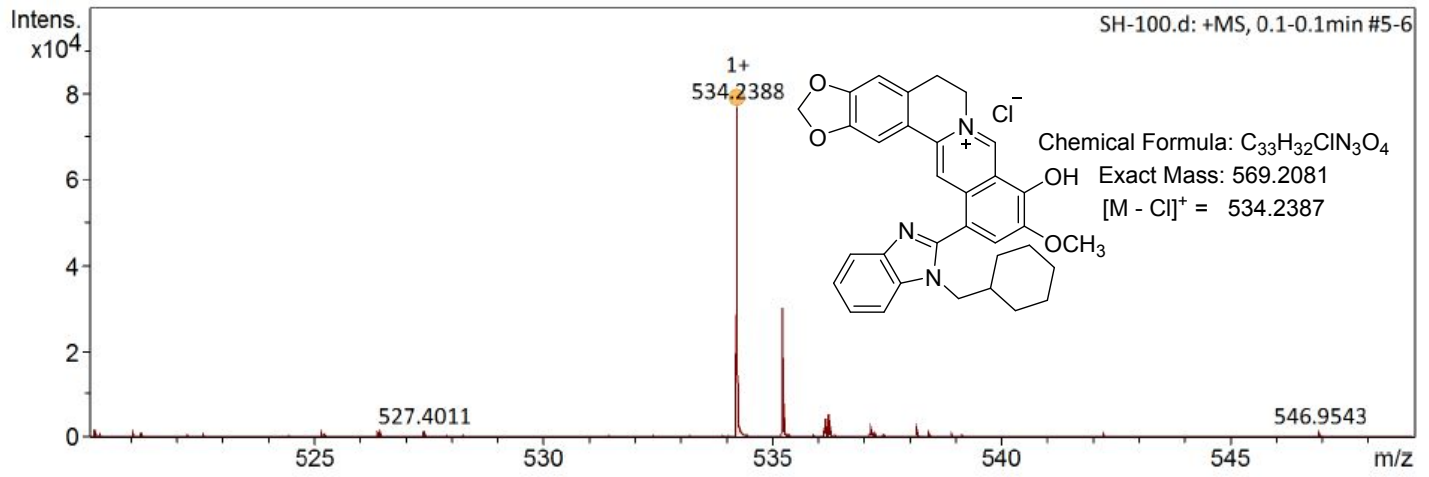

3.4 Spectra of compound $\mathbf{5 c}$

${ }^{1} \mathrm{H}$ NMR spectrum 


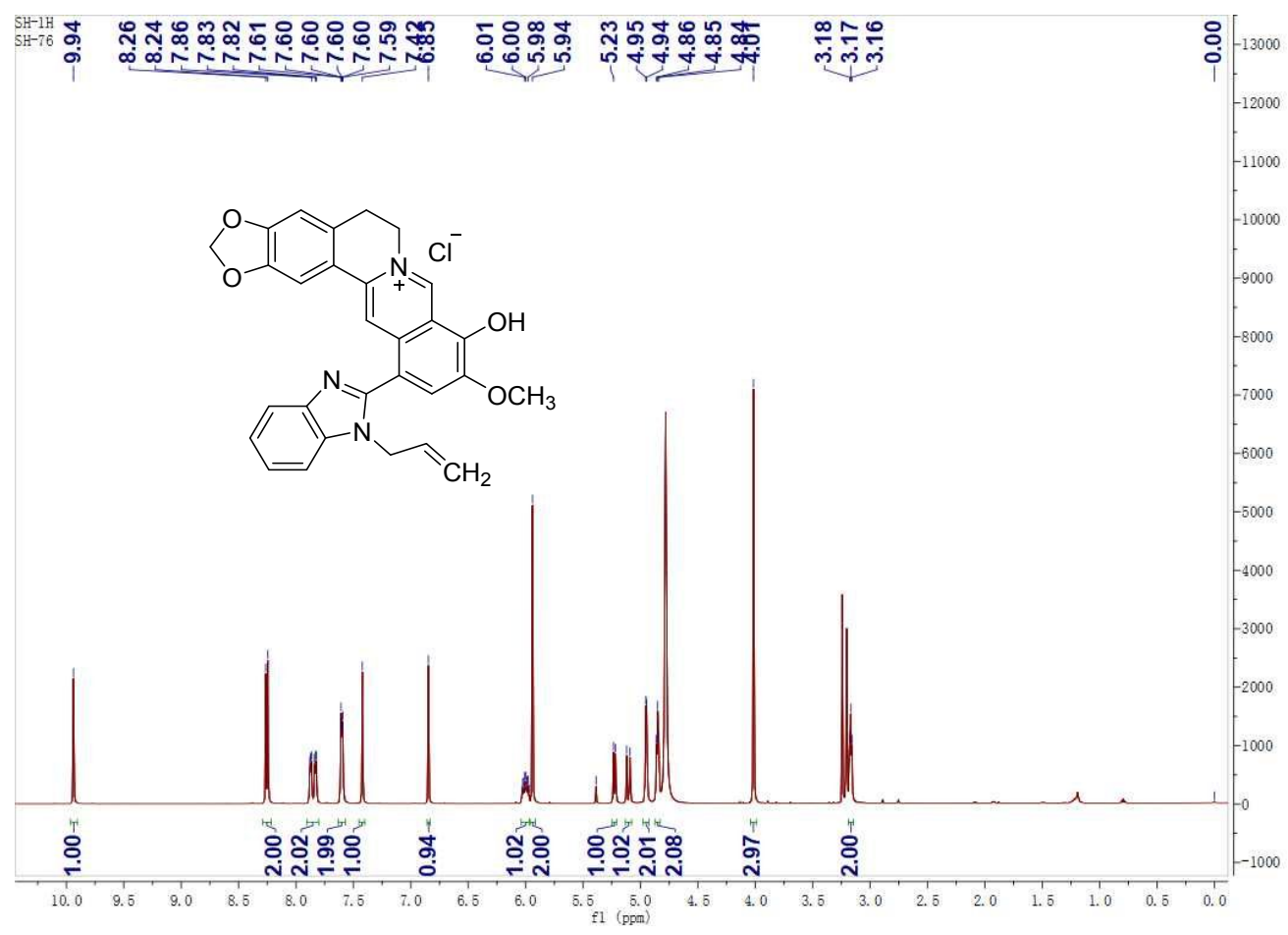

${ }^{13} \mathrm{C}$ NMR spectrum

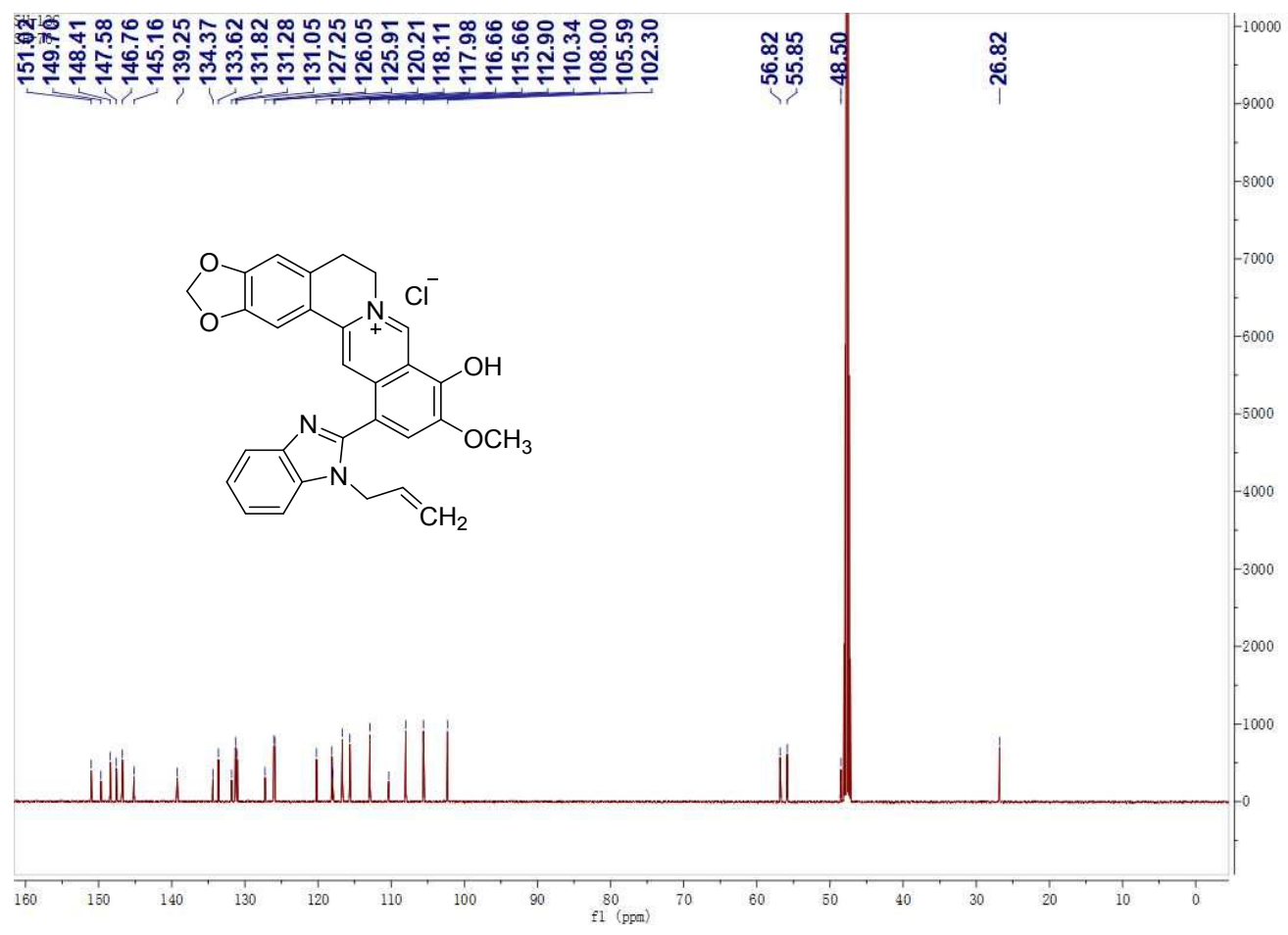

${ }^{1} \mathrm{H}-{ }^{-1} \mathrm{H}$ COSY spectrum 


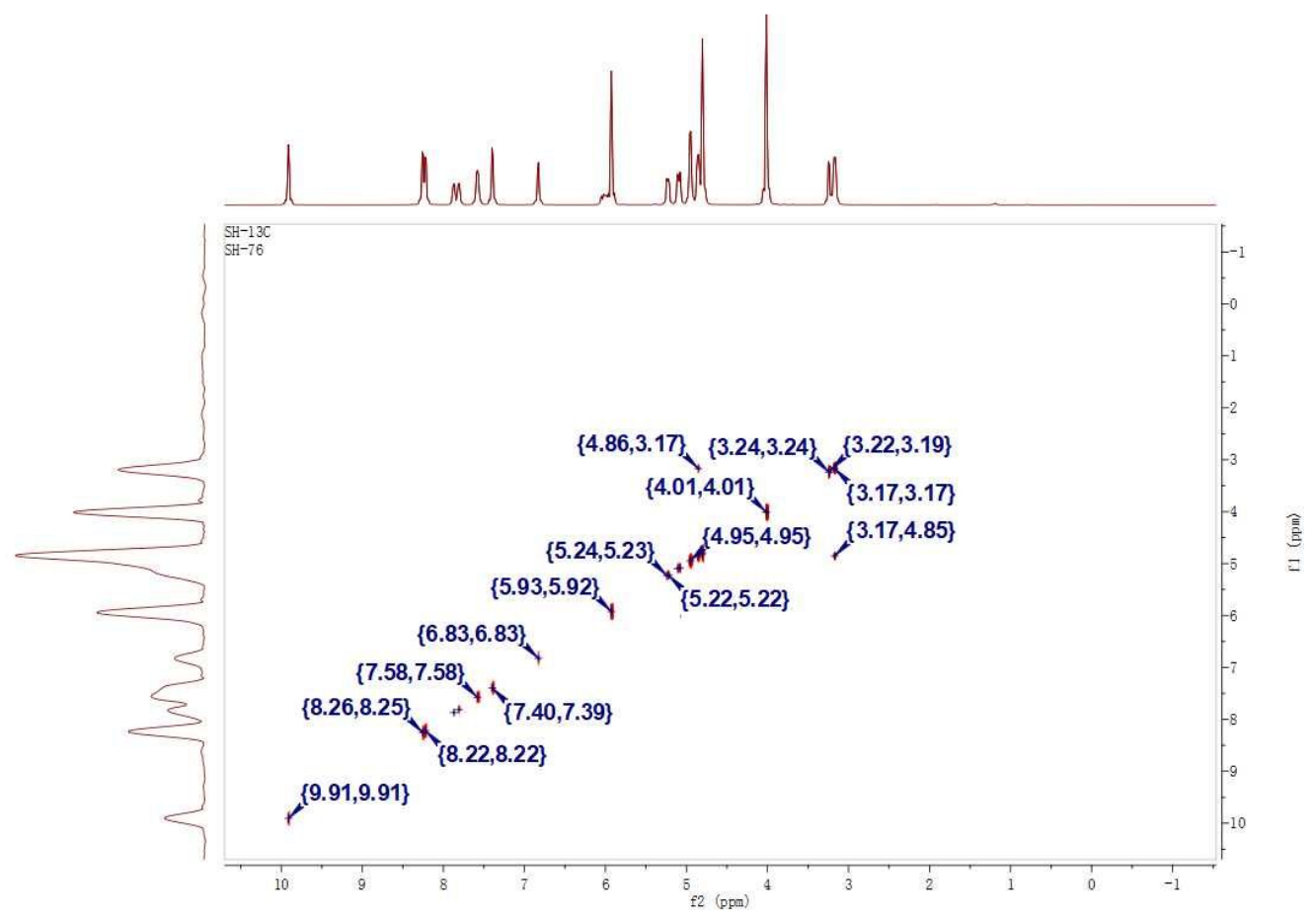

HRMS spectrum

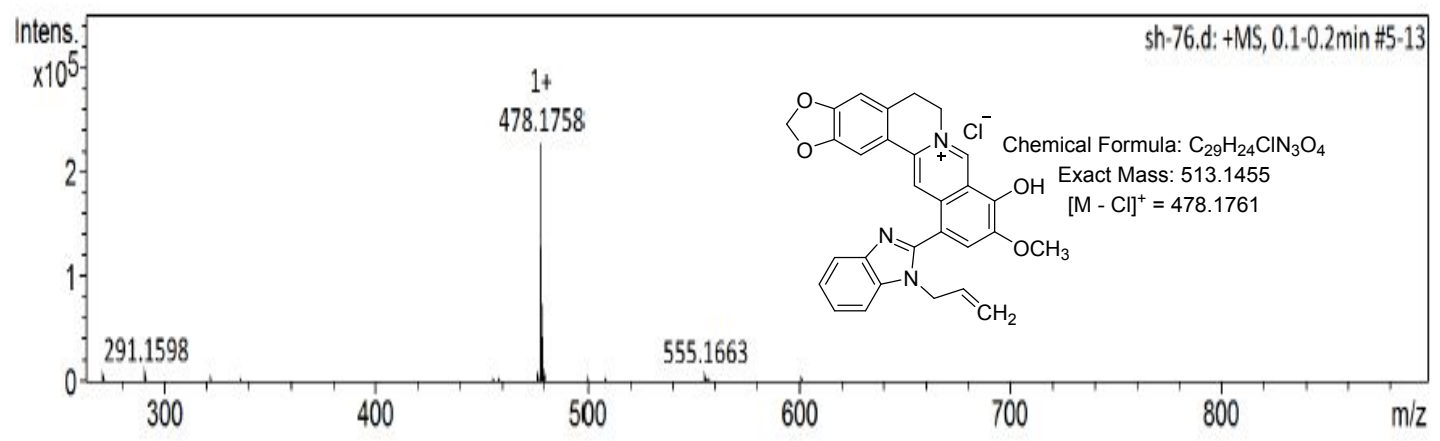

3.5 Spectra of compound $\mathbf{6 c}$

${ }^{1} \mathrm{H}$ NMR spectrum 


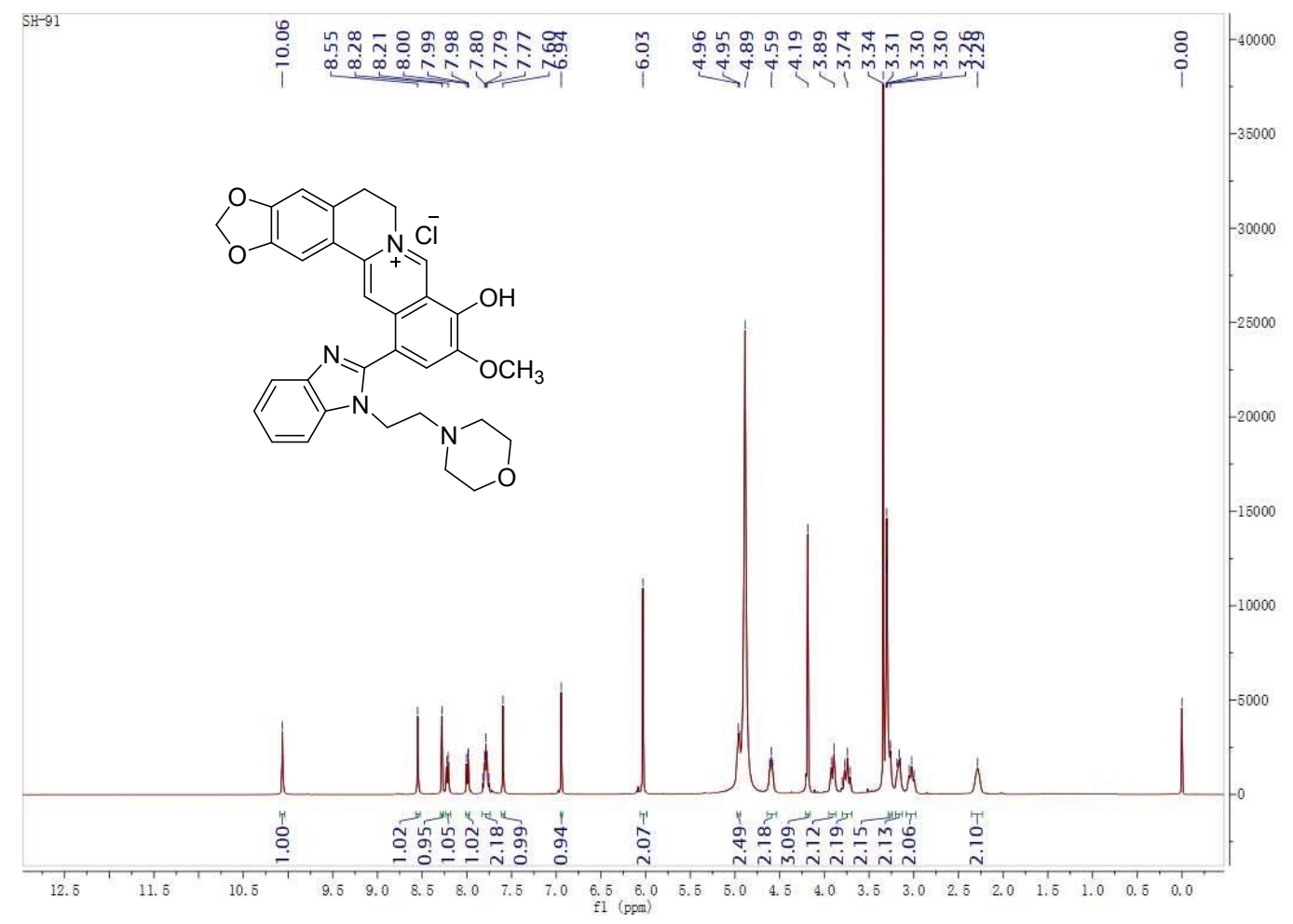

${ }^{13} \mathrm{C}$ NMR spectrum

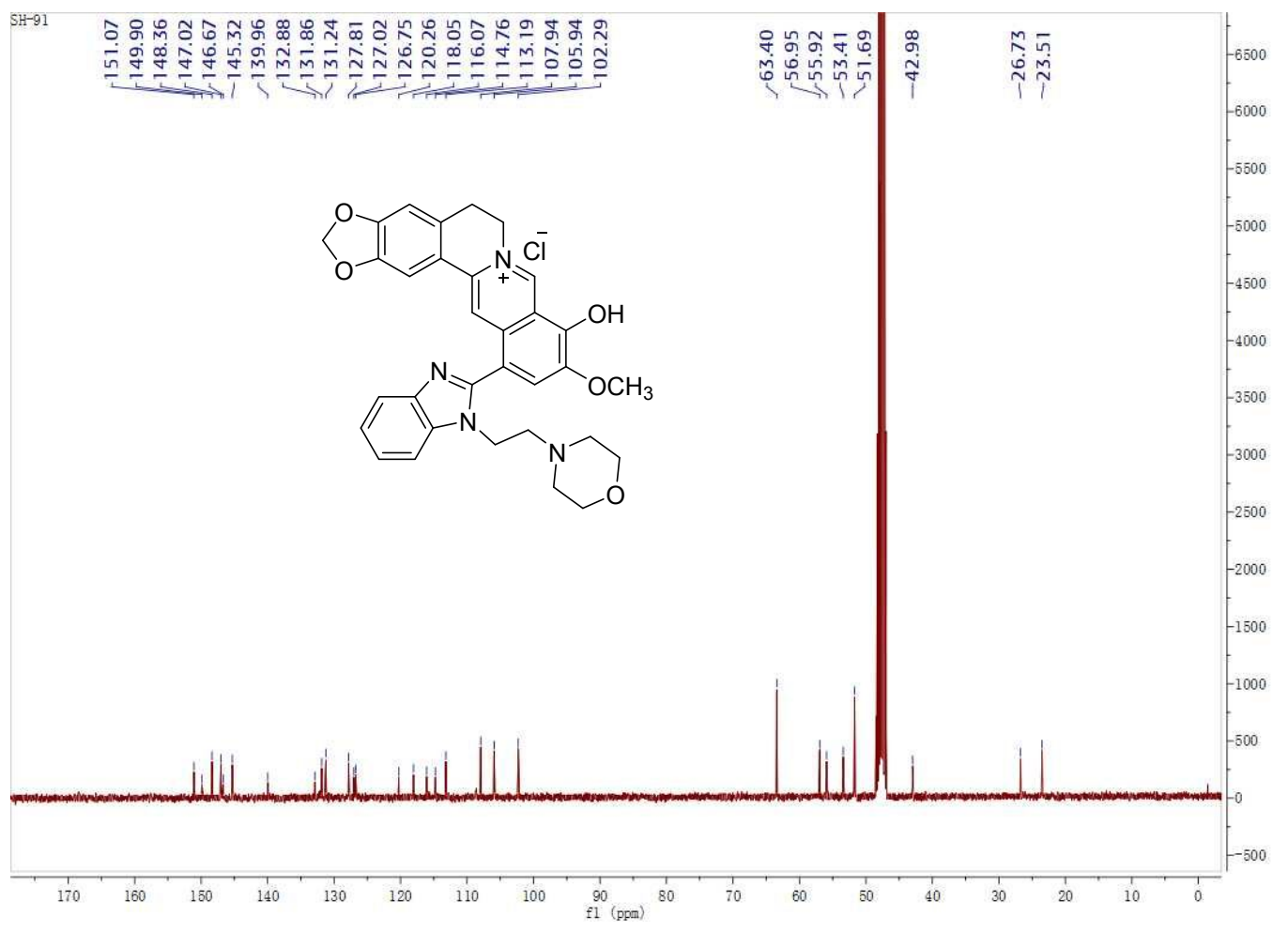

HRMS spectrum 


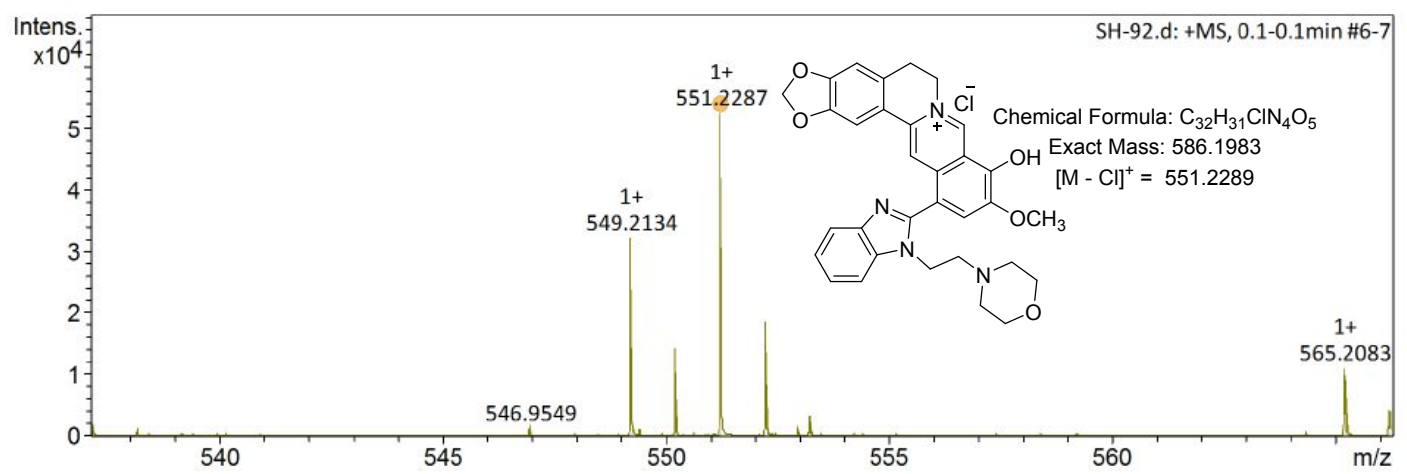

3.6 Spectra of compound 7e

${ }^{1} \mathrm{H}$ NMR spectrum

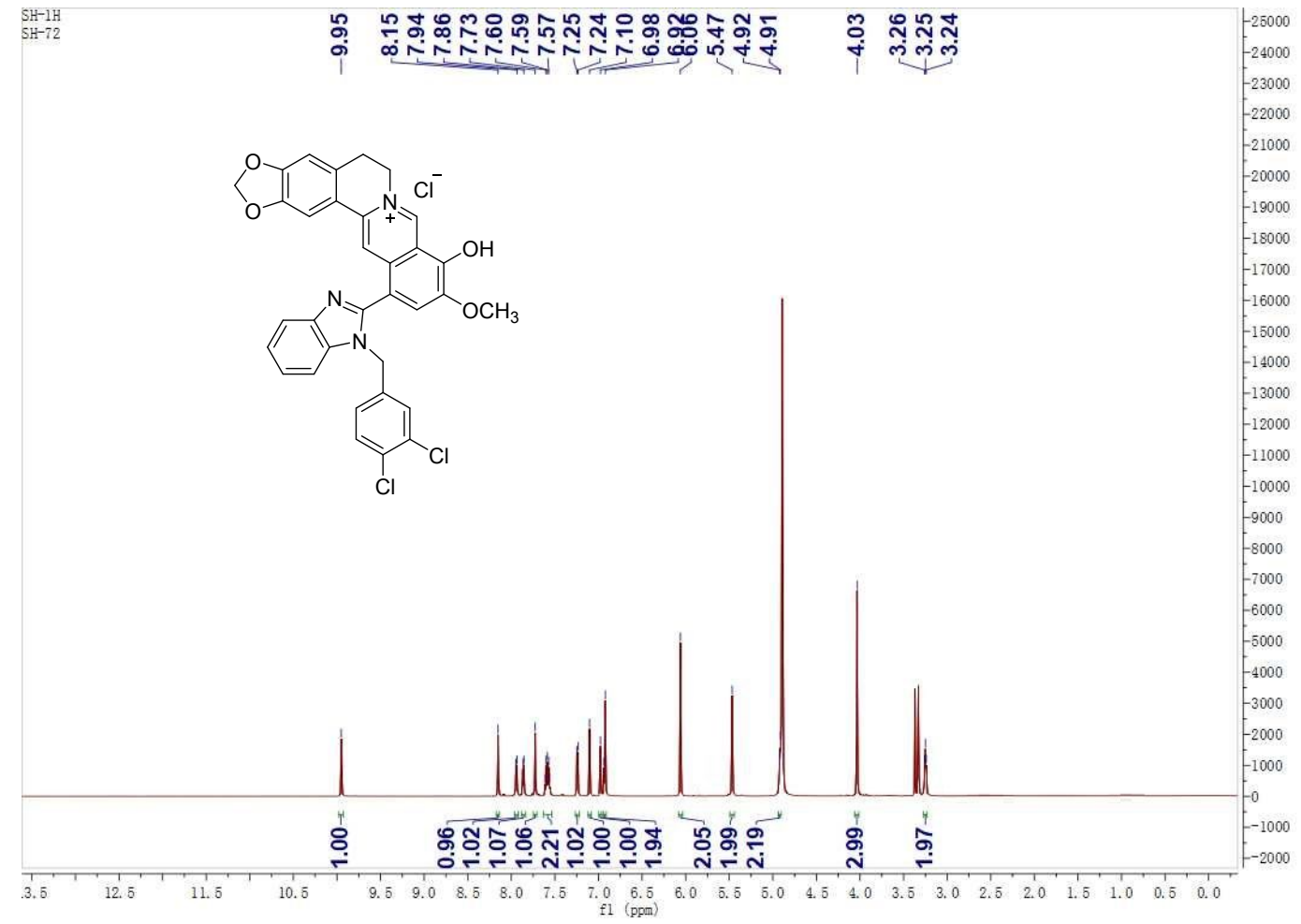

${ }^{13} \mathrm{C}$ NMR spectrum 


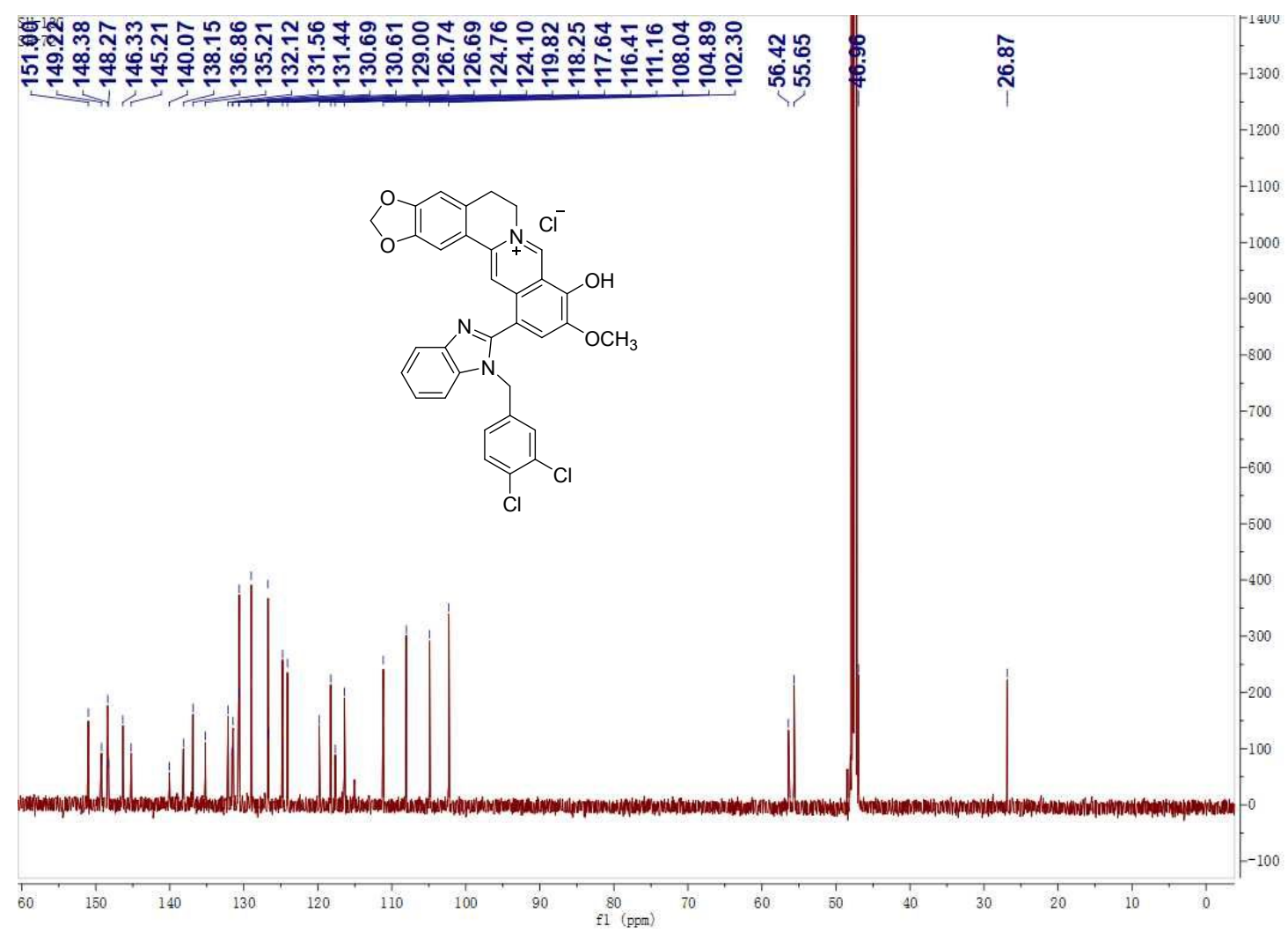

${ }^{1} \mathrm{H}-{ }^{-1} \mathrm{H}$ COSY spectrum

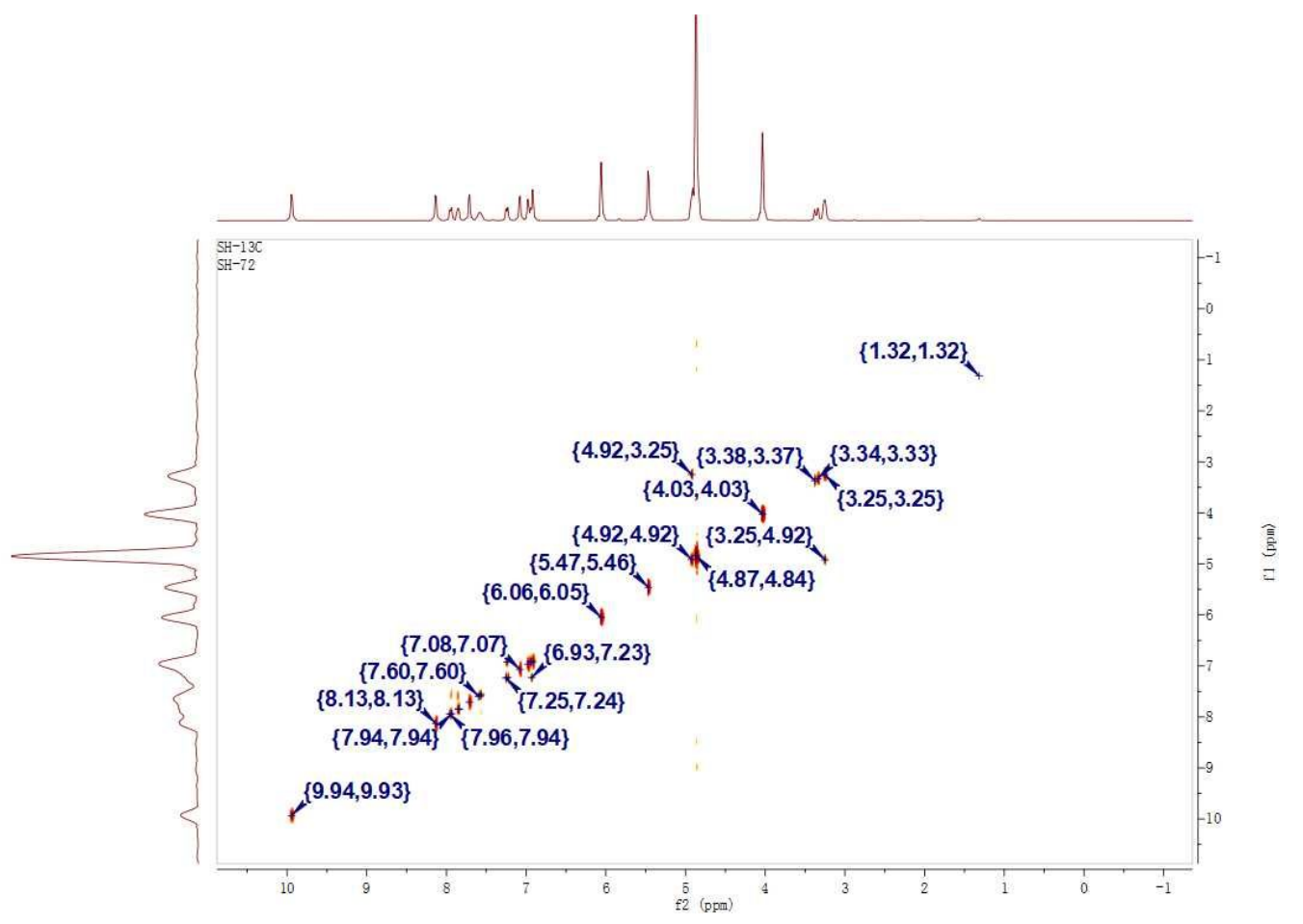

HRMS spectrum 


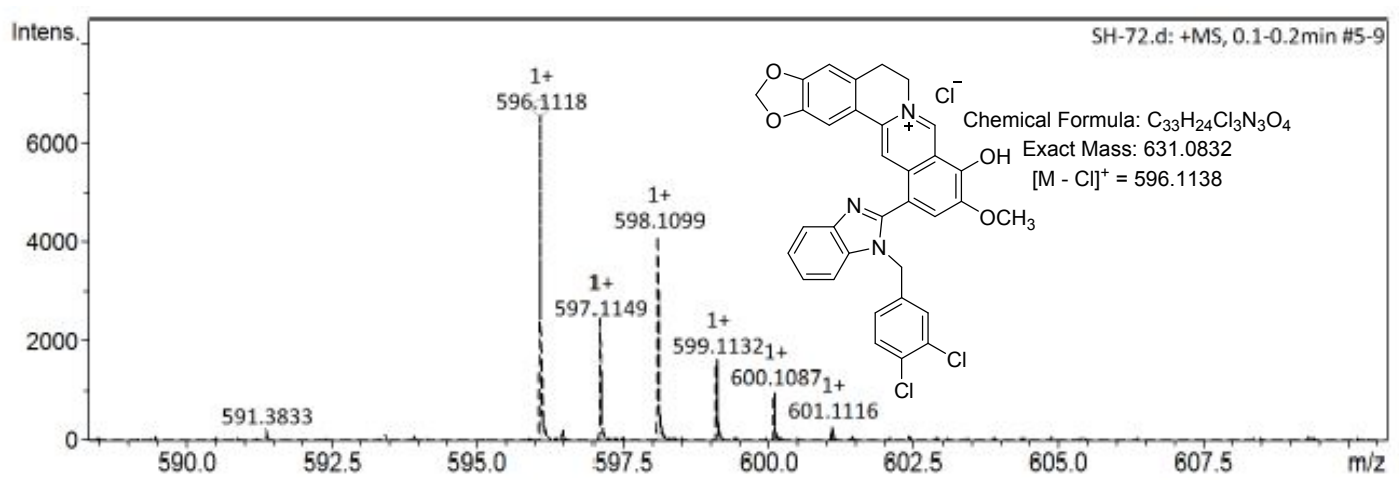

3.7 Spectra of compound 8a

${ }^{1} \mathrm{H}$ NMR spectrum

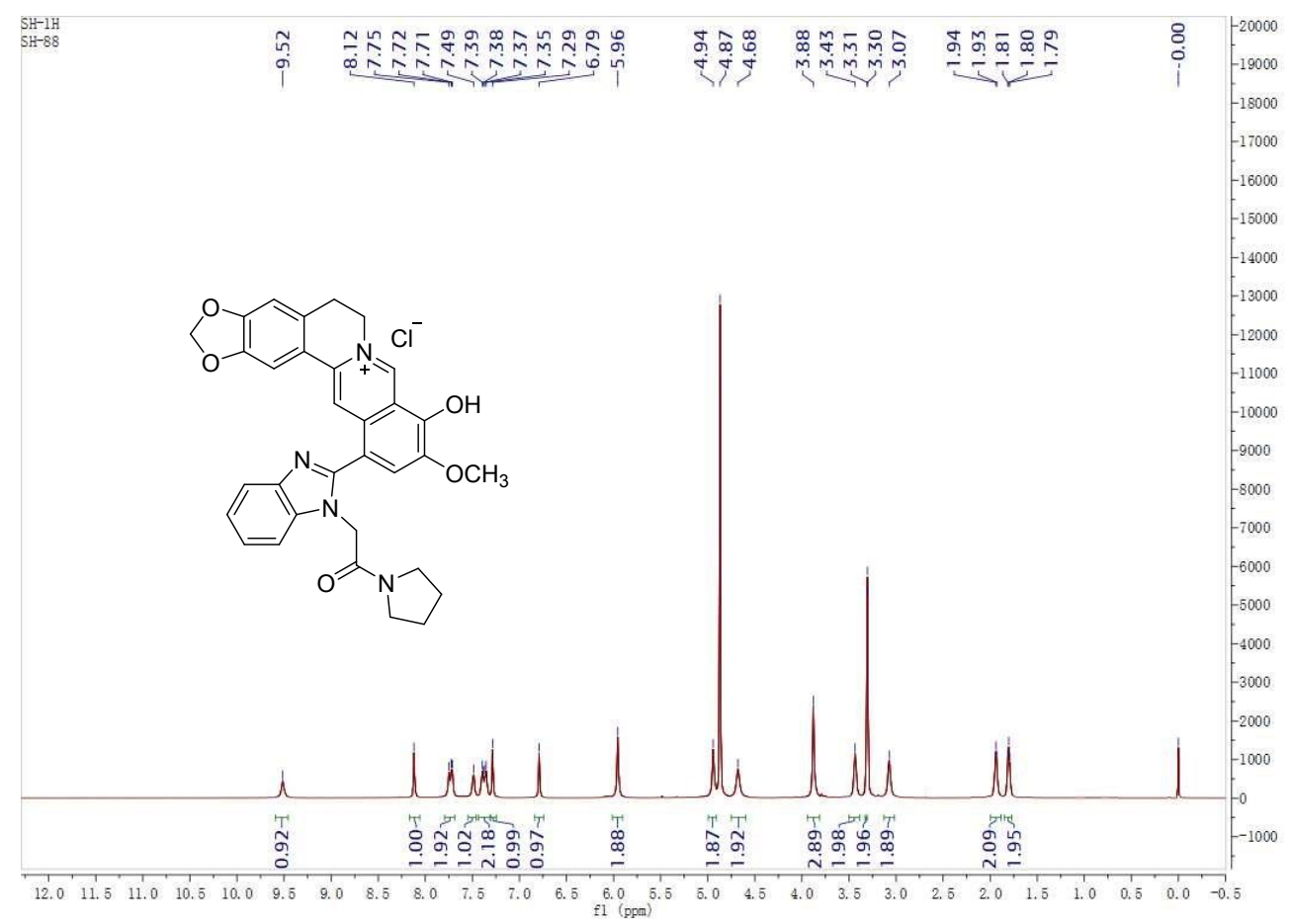

${ }^{13} \mathrm{C}$ NMR spectrum 


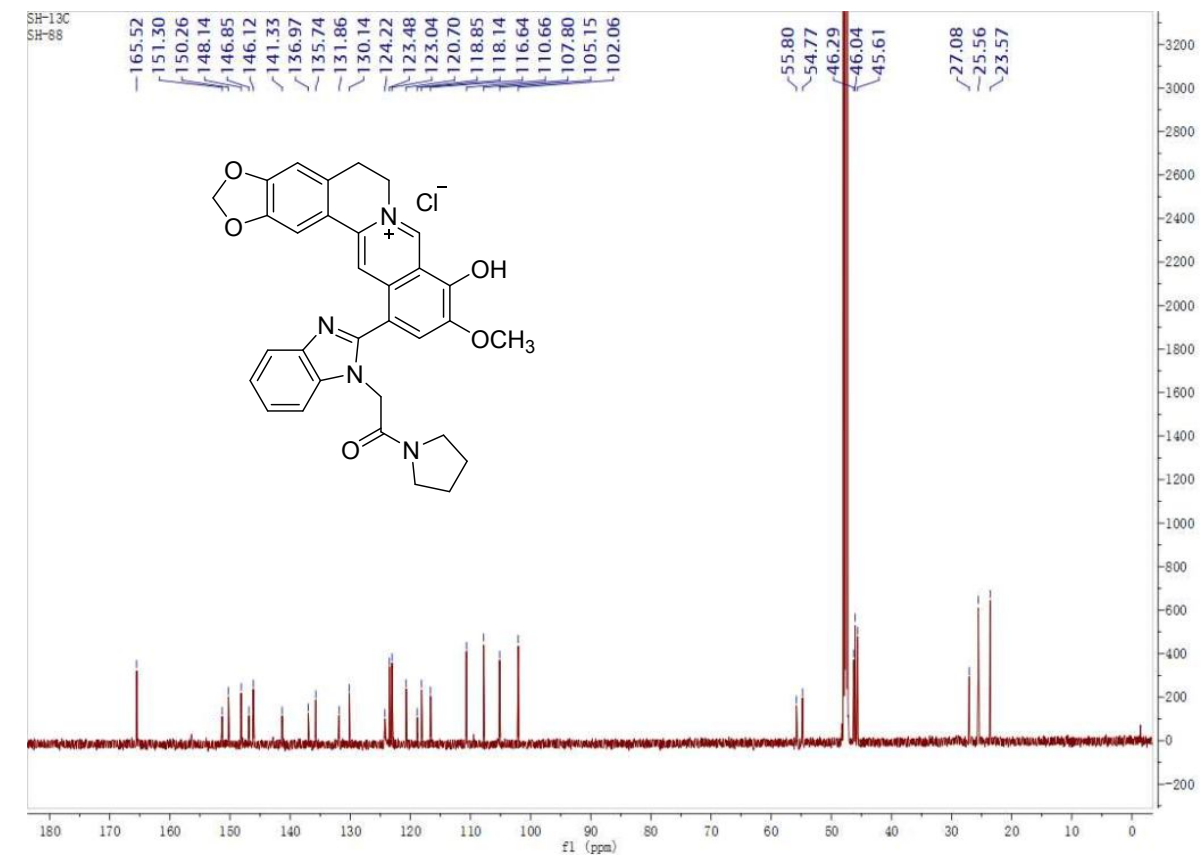

HRMS spectrum

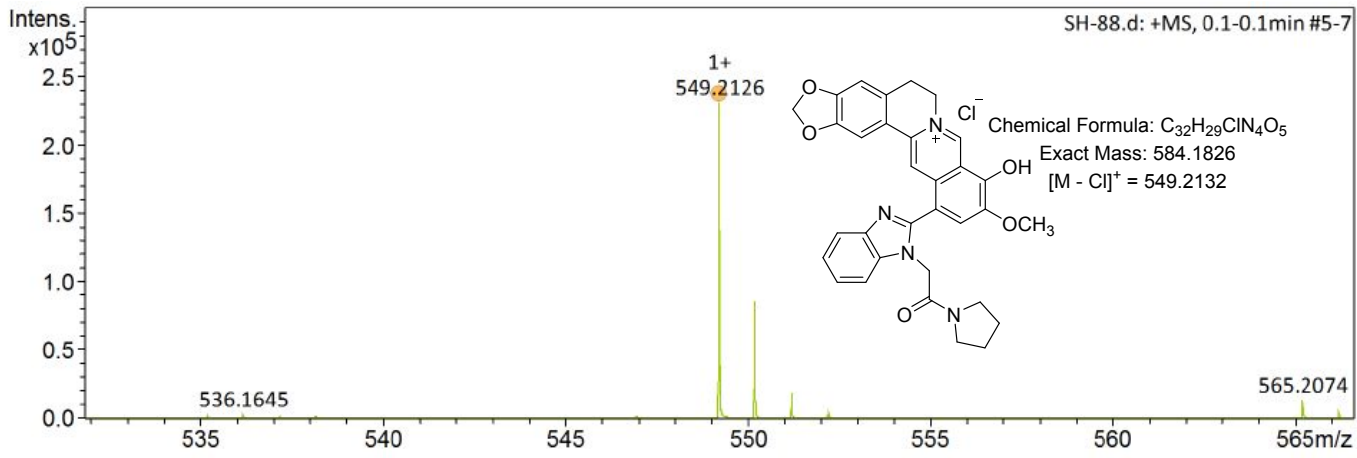

3.8 Spectra of compound 9a

${ }^{1} \mathrm{H}$ NMR spectrum 


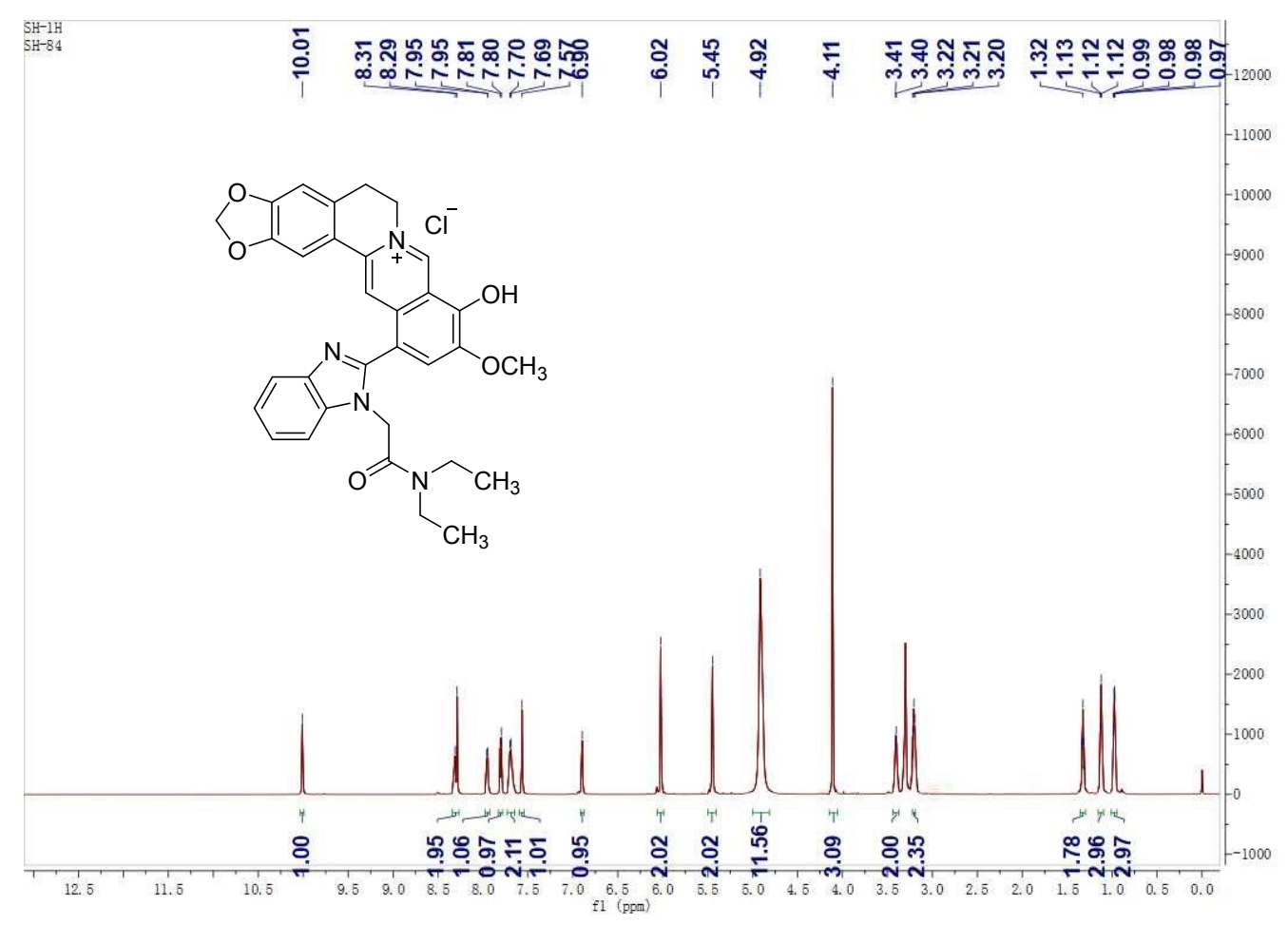

${ }^{13} \mathrm{C}$ NMR spectrum

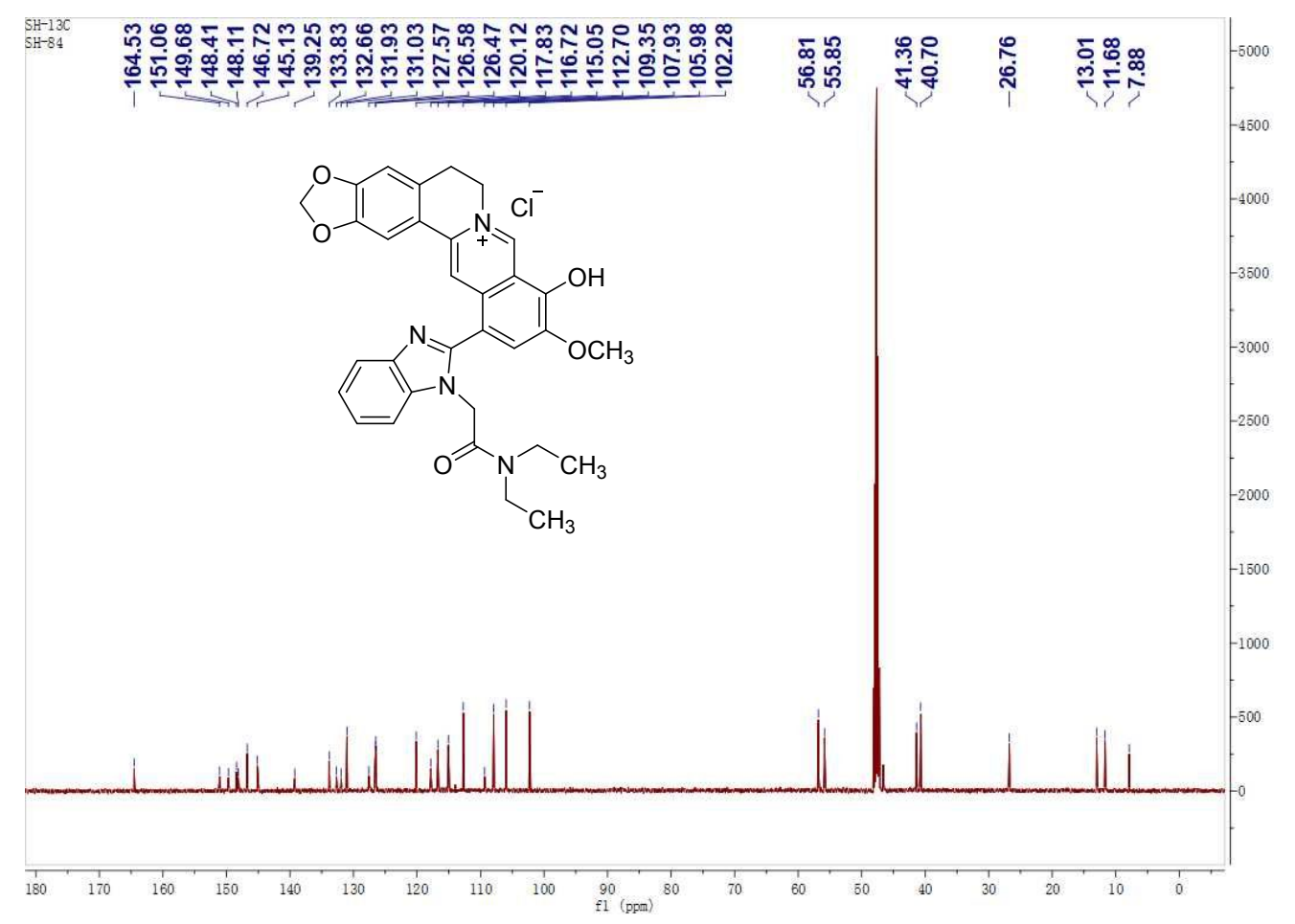

HRMS spectrum 


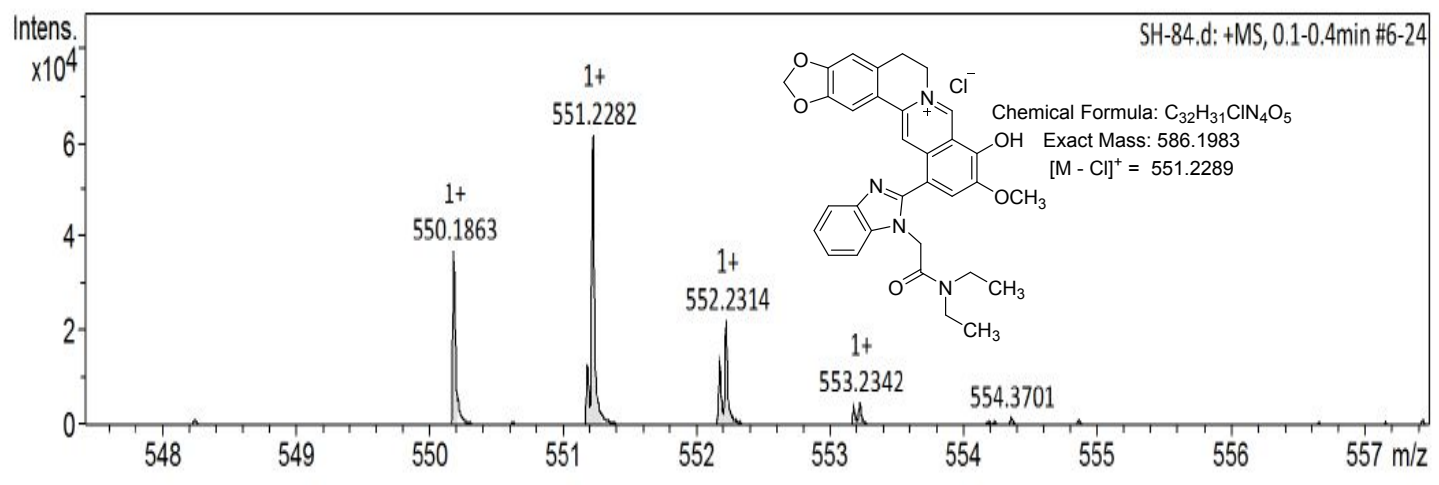

